NIOSH FIRE FIGHTER FATALITY INVESTIGATION AND PREVENJION PROCRAM

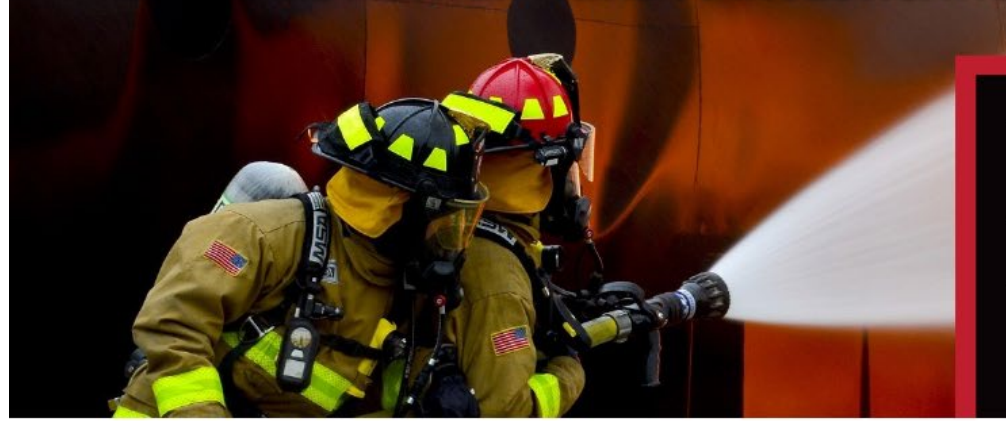
LINE OFDUTY

F2019-16 • January 3, 2022

1095 WILLOWDALE ROAD, MORGANTOWN, WV 26505 • 304.285.5916

\title{
Captain Killed and Six Firefighters Injured at a Propane Explosion in an Office Building-Maine
}

\section{Executive Summary}

On September 16, 2019, a 68-year-old captain was killed in a propane explosion and six firefighters were injured. At approximately 0808 hours, the fire and rescue department was dispatched to an office building for a possible propane leak. The building maintenance supervisor had called the fire station directly. The fire chief called county dispatch, so the call could be transmitted by radio to the fire and rescue department. County dispatch alerted Car 1, Engine 2, and Tower 3 at 0808 hours. The fire chief (Car 1) arrived on-scene and met with the building maintenance supervisor. The employees had moved to their designated evacuation area, which was the northwest corner of the parking lot. Firefighters from Engine

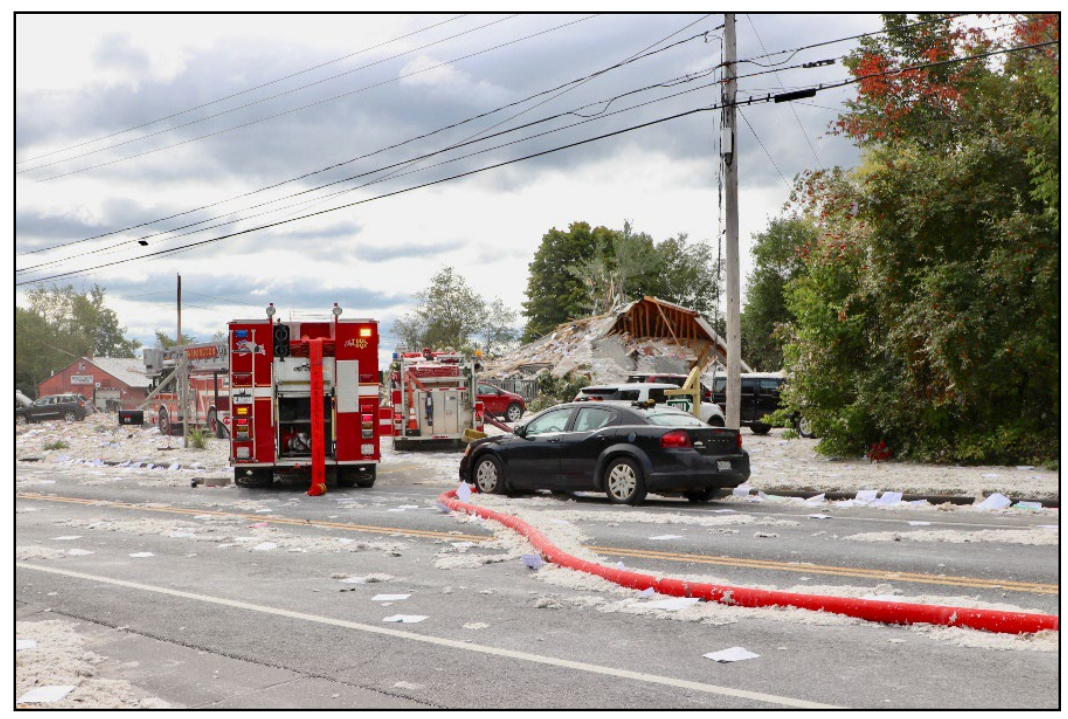

Destruction of the propane explosion. This photo shows Side Alpha/Side Delta of the building. The white debris is insulation and papers from the building. (Photo courtesy of the Fire and Rescue Department) 2 and Tower 3 arrived on-scene. The officer and firefighter from Tower 3 initiated air sampling with a portable multi-gas detector. Tower 3 members conducted air sampling around the propane tank. They found no indication of a propane leak, but the propane tank was empty with frost on the bottom half of the tank and the ground around the tank at approximately 0813 hours. Firefighters were ordered to the basement of the building by the fire chief. The fire chief and a captain who responded on Engine 2 were reportedly on the $1^{\text {st }}$ floor of the building. A firefighter assigned to Tower 3 went to the basement with a portable multi-gas detector. The captain from Tower 3 was already in the basement with the building maintenance supervisor and a firefighter from Engine 2. The firefighter from Tower 3 stated that the multi-gas detector started to read a lower explosive limit (LEL) as he went down the basement stairs. The LEL continued to increase until the multi-gas detector alarmed at $100 \%$ at the bottom of the steps. The firefighter from Tower 3 stated he was in the basement less than one minute. At 0817 hours, 


\section{Captain Killed and Six Firefighters Injured at a Propane Explosion in an Office Building-Maine}

an explosion occurred that leveled the building. The captain of Engine 2, who was reportedly on the $1^{\text {st }}$ floor, was killed as a result of injuries sustained in the explosion. Two firefighters were standing on Side Bravo in the parking lot when the explosion occurred. The force of the explosion threw them to the dirt road approximately 20 - 30 feet away. Six firefighters, including the fire chief, and the building maintenance supervisor were injured. Initially, all six injured firefighters were transported to a local hospital. One firefighter was treated and released. The other five firefighters were transported by air or ground to various hospitals throughout the state. The captain of Engine 2 was pronounced deceased by EMS personnel at approximately 0840 hours.

\section{Contributing Factors}

- Lack of locating and marking of underground utilities prior to digging or excavation

- Installation of vertical protective posts (Bollards) that severed the propane supply line

- Lack of pressure testing an empty tank by the propane company

- Odorant fade or scrubbing of ethyl mercaptan by soil and concrete

- Lack of scene size-up and risk assessment

- Lack of incident management

- Lack of understanding a multi-gas monitor's capability

- Improper gas sampling, monitoring, and detection

- Lack of hazardous materials training and recertification.

\section{Key Recommendations}

- Fire departments responding to a hazardous materials incident should ensure that a scene sizeup and initial risk assessment are performed. In addition, fire departments should establish isolation zones and ensure a continuous risk assessment is conducted throughout the incident

- Fire departments should ensure incident commanders initiate a defensive strategy and communicates the incident action plan (tactics) during initial operations of a hazardous materials incident. The strategy and incident action plan are revised based upon the tactical objectives taken to mitigate the hazard

- Fire departments should ensure firefighters are trained to understand the scrubbing or odorant fade of ethyl mercaptan from propane. This training includes the use of multi-gas detectors to determine if a potentially explosive atmosphere is present.

The National Institute for Occupational Safety and Health (NIOSH) initiated the Fire Fighter Fatality Investigation and Prevention Program to examine deaths of fire fighters in the line of duty so that fire departments, fire fighters, fire service organizations, safety experts and researchers could learn from these incidents. The primary goal of these investigations is for NIOSH to make recommendations to prevent similar occurrences. These NIOSH investigations are intended to reduce or prevent future fire fighter deaths and are completely separate from the rulemaking, enforcement, and inspection activities of any other federal or state agency. Under its program, NIOSH investigators interview persons with knowledge of the incident and review available records to develop a description of the conditions and circumstances leading to the deaths in order to provide a context for the agency's recommendations. The NIOSH summary of these conditions and circumstances in its report is not intended as a legal statement of facts. This summary, as well as the conclusions and recommendations made by NIOSH, should not be used for the purpose of litigation or the adjudication of any claim.

For further information, visit the program website at www.cdc.gov/niosh/fire or call toll free 1-800-CDC-INFO (1-800-232-4636). 
NIOSH FIRE FIGHTER FATALITY INVESTIGATION AND PREVENJION PRIOGRAM

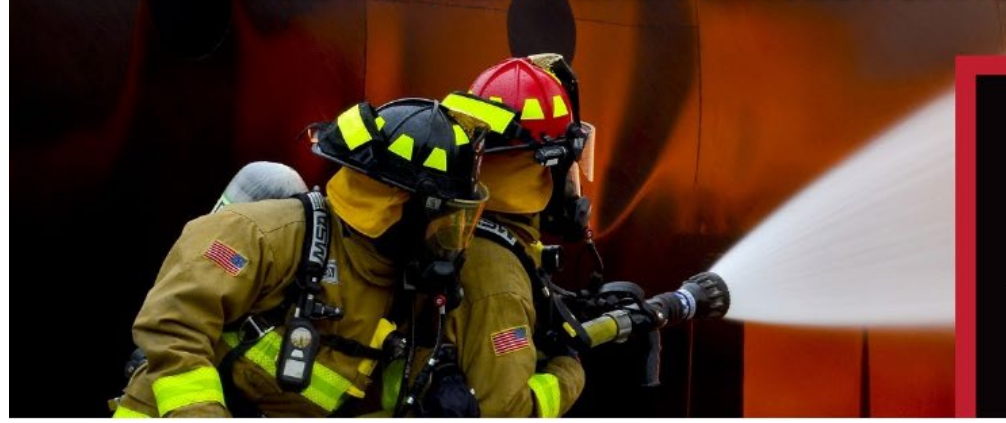

LINE OFDUTY

F2019-16 • November 18, 2020

1095 WILLOWDALE ROAD, MORGANTOWN, WV 26505 • 304.285.5916

\section{Introduction}

On September 16, 2019, a 68-year-old captain was killed, and six firefighters were injured in a propane explosion at an office building. On October 17, 2019, an investigator and two occupational health and safety specialists with the National Institute for Occupational Safety and Health (NIOSH) Fire Fighter Fatality Investigation and Prevention Program traveled to Maine to investigate the circumstances contributing to this incident. The NIOSH representatives met with fire and rescue department officials including the fire chief, the deputy chief of operations, and members of the department involved in this incident. NIOSH investigators also met with a representative for the town's code enforcement and planning office; officers from the town's police department; employees from the town's public works division; employees of the private ambulance service; representatives from the Maine Fuel Board, Maine Department of Labor, Bureau of Labor and Standards, Workplace Safety and Health Division; a representative from the federal Occupational Safety and Health Association (OSHA); representatives from the Maine Office of the State Fire Marshal, Investigation Division; representatives from the Maine Office of the State Medical Examiner; representatives from the Maine Fire Service Institute; and representatives from the county's 9-1-1 Communications Center. NIOSH investigators visited the incident site with representatives of the Maine Office of the State Fire Marshal. NIOSH investigators conducted interviews with the fire and rescue department officers and firefighters, plus members of mutual aid fire departments directly involved in this incident. The NIOSH investigators inspected and photographed the personal protective clothing of the deceased firefighter and injured firefighters. NIOSH investigators reviewed training records and standard operating procedures (SOPs) from the involved fire and rescue department. Photographs and building information were obtained from the Maine Office of the State Fire Marshal, Investigation Division.

\section{Fire and Rescue Department}

The fire and rescue department delivers fire protection and life safety services to an area encompassing 56 square miles and a population of 8,200. A college located in the town adds an additional population of approximately 1,800 students during the school year. The department operates out of two fire stations. The department's apparatus consists of two pumpers (Engine $1 \&$ Engine 2), one tower ladder (Tower 3), one squad truck (Squad 1), one rescue/air truck (Rescue 1), one communications vehicle (Com1), one Chief's vehicle (Car 1), a hazmat trailer, and a Gator which is used as a quick attack on wood/brush fires and in the winter as a rescue unit with tracks. There are $12-15$ active members of the fire and rescue department, which responds to approximately 400 alarms annually.

The rank structure for the fire and rescue department is:

- $\quad$ Fire Chief

- Deputy Chief 


\section{Captain Killed and Six Firefighters Injured at a Propane Explosion in an Office Building-Maine}

- Captain

- Lieutenant

- Firefighter

The fire and rescue department members are emergency medical technicians who respond to EMS incidents supporting the private hospital-based ambulance service.

The fire chief is a paid member of the department. The department has four full-time members that work Monday - Friday from 0700 - 1900 hours. Two members work daily for two days on and then have two days off. Also, the department has a per diem shift from 0800 - 1630 hours Monday through Friday. Note: On September 16, the full-time work schedule was changed due to the town's annual fair which started on this date and continued through September 23. The work scheduled was changed Monday - Friday from 0700 - 1900 hours to 1000 - 2200 hours. The per diem shift was changed from $0800-1630$ hours to $1000-1830$ hours

The fire and rescue department has written policies and SOPs, which are available to all department members.

\section{Training and Experience}

Fire service training in Maine is provided by the Maine Fire Service Institute (MFSI). The MFSI is a division within Southern Maine Community College. They had a full-time staff of 10 and an additional 100 instructors throughout the state of Maine at the time of the incident. MFSI produces a variety of programs in regions around the state of Maine to meet the demands of the local fire departments. Complementing the program delivery, MFSI also serves as the certification entity for all firefighter programs. MFSI accomplishes all this by fostering partnerships and collaborating with local departments, regional programs, the Fire Science Programs of Southern Maine Community College and Eastern Maine Community College and other state agencies, such as the Maine Office of the State Fire Marshal and the Maine Bureau of Labor and Standards.

MFSI offers National Fire Protection Association (NFPA) training including NFPA 1001, Standard for Fire Fighter Professional Qualifications, Fire Fighter I which is approximately 150 hours and Fire Fighter II which is approximately 150 hours. MFSI also offers a 75-hour course which is the minimum requirement mandated for any firefighter that performs interior structural firefighting by the Maine Department of Labor (See Section on Maine Bureau of Labor and Standards).

MFSI also offers the following Pro Board accredited certification training:

- $\quad$ NFPA 1001, Standard for Fire Fighter Professional Qualifications, Fire Fighter I and Fire Fighter II

- $\quad$ NFPA 1021, Standard for Fire Officer Professional Qualifications, Fire Officer I and Fire Officer II

- NFPA 1041, Standard for Fire and Emergency Services Instructor Professional Qualifications, Instructor I and Instructor II 


\section{Captain Killed and Six Firefighters Injured at a Propane Explosion in an Office Building-Maine}

- NFPA 1035, Standard on Fire and Life Safety Educator, Public Information Officer, Youth Firesetter Intervention Specialist and Youth Firesetter Program Manager Professional Qualifications, Fire Life Safety Educator I.

Note: The Pro Board is a non-profit corporation that was incorporated in 1990 as the "National Board on Fire Service Professional Qualifications." The organization is commonly known as the Pro Board.

Fire Inspector certifications are through the NFPA.

Hazardous materials training and certification is provided through the Maine Emergency Management Agency, State Emergency Response Commission (SERC). The SERC supports training of first responders and emergency managers across the state. Training is coordinated regionally through the 16-county local emergency planning committees. The SERC offers the following hazardous materials training, which complies with OSHA 29 CFR 1910.120, Hazardous Waste Operations and Emergency Response:

- First Responder Awareness Level

- Hazardous Materials Operations Level

- Hazardous Materials Technician Level [OSHA 1990]

The deputy chief of the fire and rescue department who served as incident commander of the incident had the following certifications: NFPA 1001, Standard for Fire Fighter Professional Qualifications, Fire Fighter I and Fire Fighter II. The deceased captain had the following certifications: NFPA 1001, Standard for Fire Fighter Professional Qualifications, Fire Fighter I and Fire Fighter II. The fire chief had the following certifications: NFPA 1001, Standard for Fire Fighter Professional Qualifications, Fire Fighter I and Fire Fighter II.

\section{Maine Bureau of Labor and Standards}

The Maine Department of Labor, Bureau of Labor and Standards mandates that all firefighters be certified to meet the Interior Structural Firefighter - Minimum Training Requirements. This 75-hour course consists of 18 topics.

- The History and Orientation of the Fire Service

- Firefighter Qualifications and Safety

- Fire Service Communications

- Incident Management System

- Fire Behavior

- Portable Fire Extinguishers

- Firefighter Tools and Equipment

- Response and Size-Up

- Forcible Entry

- Ladders

- Search and Rescue

- Ventilation

- Water Supply

- Fire Hose, Nozzles, Streams, and Foam 


\section{Captain Killed and Six Firefighters Injured at a Propane Explosion in an Office Building-Maine}

- Firefighter Survival

- Salvage and Overhaul

- Firefighter Rehabilitation

- Fire Suppression

The curriculum is based on training requirements from the Maine Department of Labor, Bureau of Labor and Standards and NFPA 1001, Standard for Fire Fighter Professional Qualifications.

Based upon Maine state statutes, the following apply to each fire department in the state:

- Maine MRSA (Maine Revised Statutes Annotated) Title 26

$\S 2102$. Firefighter Training and Education

- Maine MRSA Title 26

$\S 2103$. Standards for Equipment and Clothing

- Maine MRSA Title 26

$\S 2104$. Required Provision and Use of Protective Equipment

\section{Apparatus, Staffing, and Communications}

On September 16, 2019, at 0808 hours, the fire and rescue department was dispatched to a report of a possible propane leak at an office building. The following resources were dispatched at 0808 hours:

- Car 1 (Fire Chief) (PAR 1)

- $\quad$ Engine 2 (PAR 3)

- $\quad$ Tower 3 (PAR 3)

The 9-1-1 center and communication center (identified as county dispatch) is operated by the county. County dispatch was managed by an interim director at the time of this investigation and staffed with 11 dispatchers. County dispatch receives approximately 1100 calls annually. Dispatchers work tours of 0600 hours to 1800 hours and 1800 hours to 0600 hours. The minimum staffing is two dispatchers per shift. All dispatchers are assigned permanent day or night tours and work three days the first week and four days the second week.

The county 9-1-1 center and communication center dispatches for 17 fire departments, four municipal police departments, the county Sheriff's Office, and the private EMS agency. The county dispatch transmits on a VHF frequency. The county is divided into County Fire North and County Fire South dispatch frequencies. The state fire channel is used for a tactical channel for working incidents.

\section{Building Construction}

The structure involved in the incident served as a central office for an organization that provides residential and life skill support to individuals with intellectual and developmental disabilities since 2003. The original building was one story with a partial basement and was approximately $2500-3000$ square feet (See Photo 1). 


\section{Captain Killed and Six Firefighters Injured at a Propane Explosion in an Office Building-Maine}

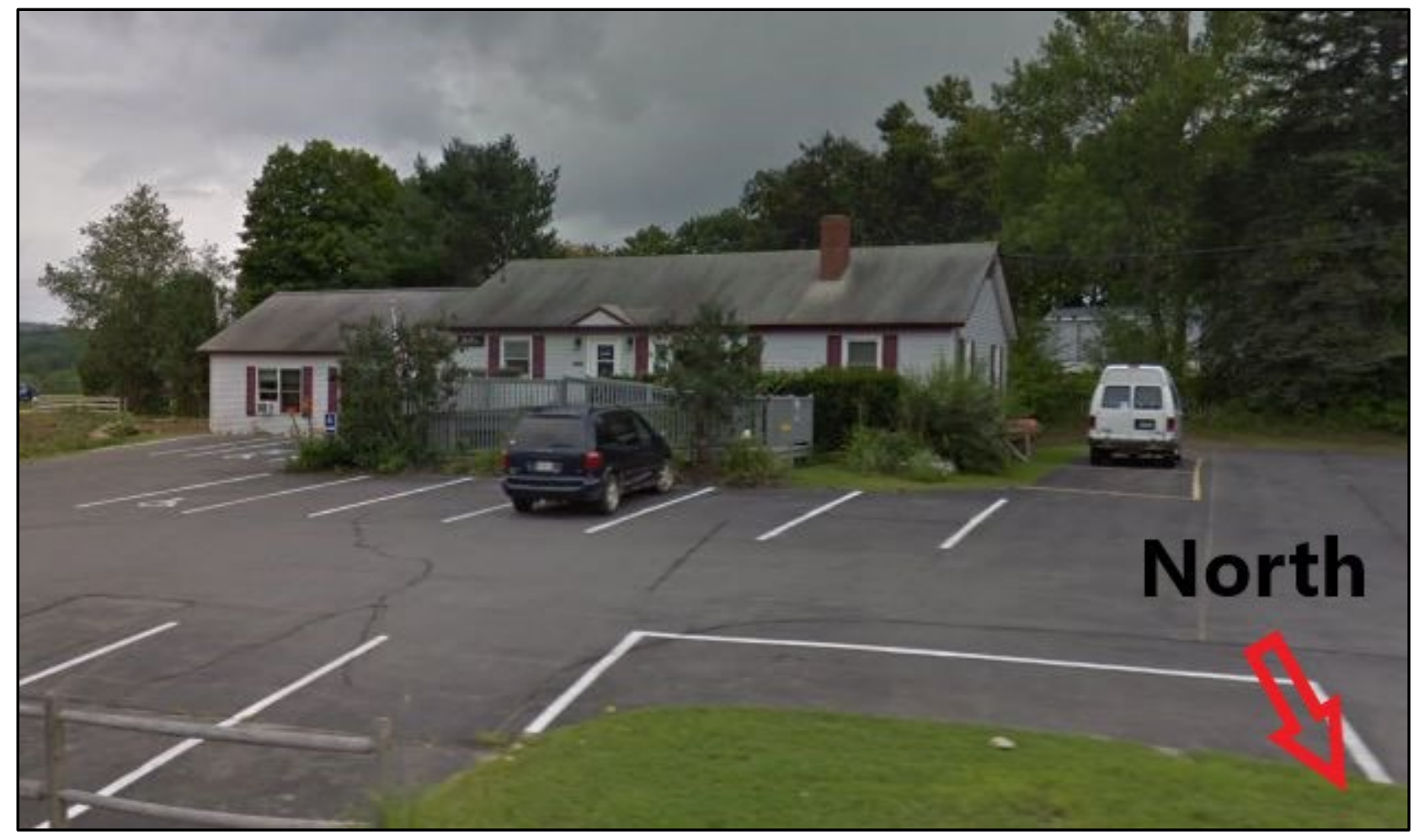

Photo 1. The original structure that was purchased in 2003 and before the renovation project in 2018.

\section{(Photo adapted from Google Earth)}

The organization identified the need for a larger facility due to training, meeting rooms, and administrative purposes. They purchased land to the east of the original structure for their expansion project. In the fall of 2018, the organization started construction of the expansion project (See Diagram 1) which included an addition and parking on all sides of the building.

The addition included a basement for utilities and storage; a $1^{\text {st }}$ floor with a large meeting room, offices, kitchen, and restrooms that adjoined the existing $1^{\text {st }}$ floor offices; and a $2^{\text {nd }}$ floor with offices and restrooms. The new basement did not connect with the existing basement in the original building. The basement had two rooms that were separated by a block wall (See Diagrams 2, 3 and 4).

During the renovation project, the existing propane tank (250 gallons), which was located on the Side Bravo/Side Alpha corner of the original building was removed. A new propane tank (500 gallons) was located on the southeast corner of the property approximately 100 feet from the Side Bravo/Side Charlie corner of the new addition. The propane tank was protected by a jersey barrier. 


\section{Captain Killed and Six Firefighters Injured at a Propane Explosion in an} Office Building-Maine

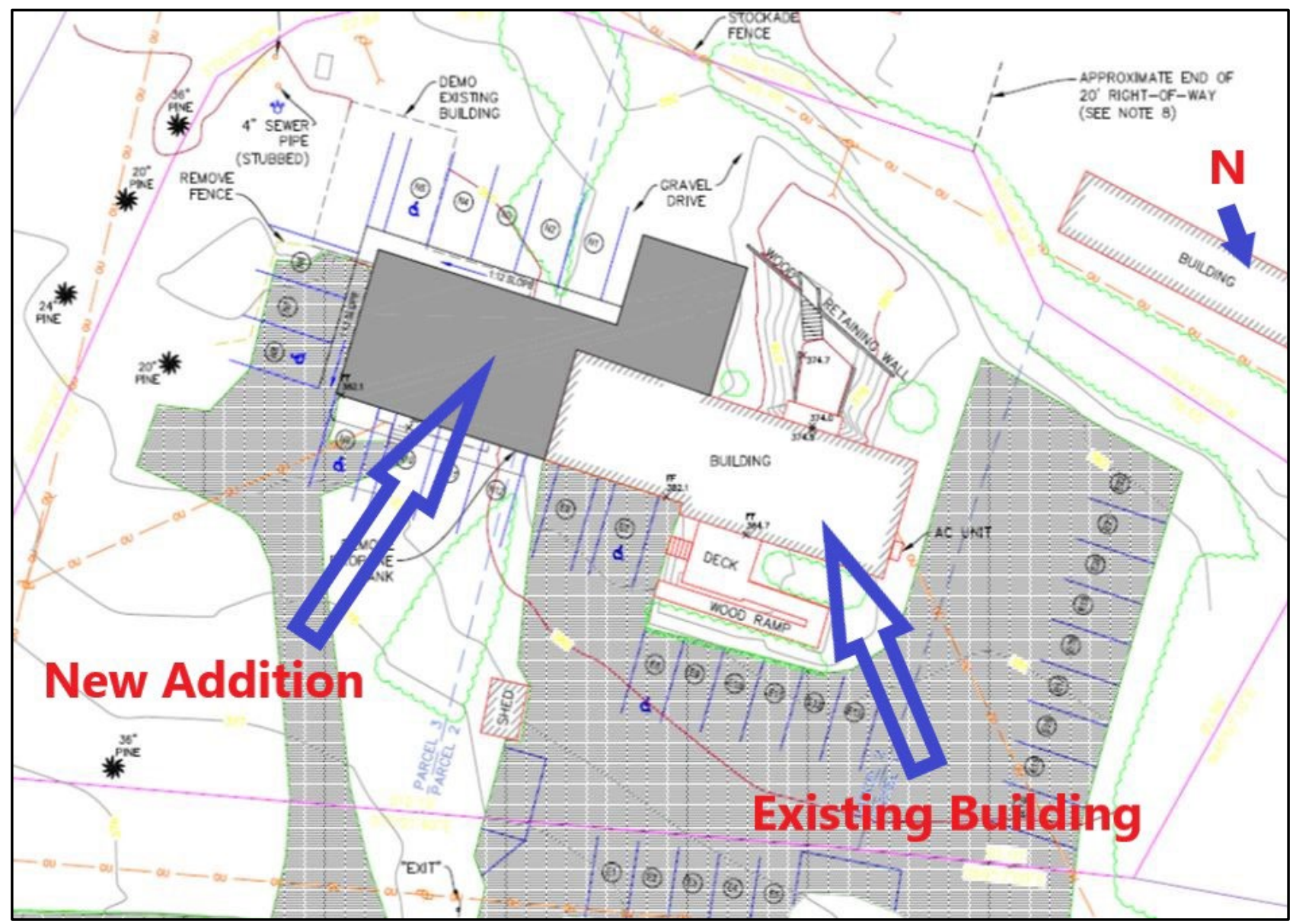

Diagram 1. Diagram shows the changes that were made to the structure during the renovation project.

(Diagram courtesy of the Maine Office of the State Fire Marshal) 
Captain Killed and Six Firefighters Injured at a Propane Explosion in an Office Building-Maine

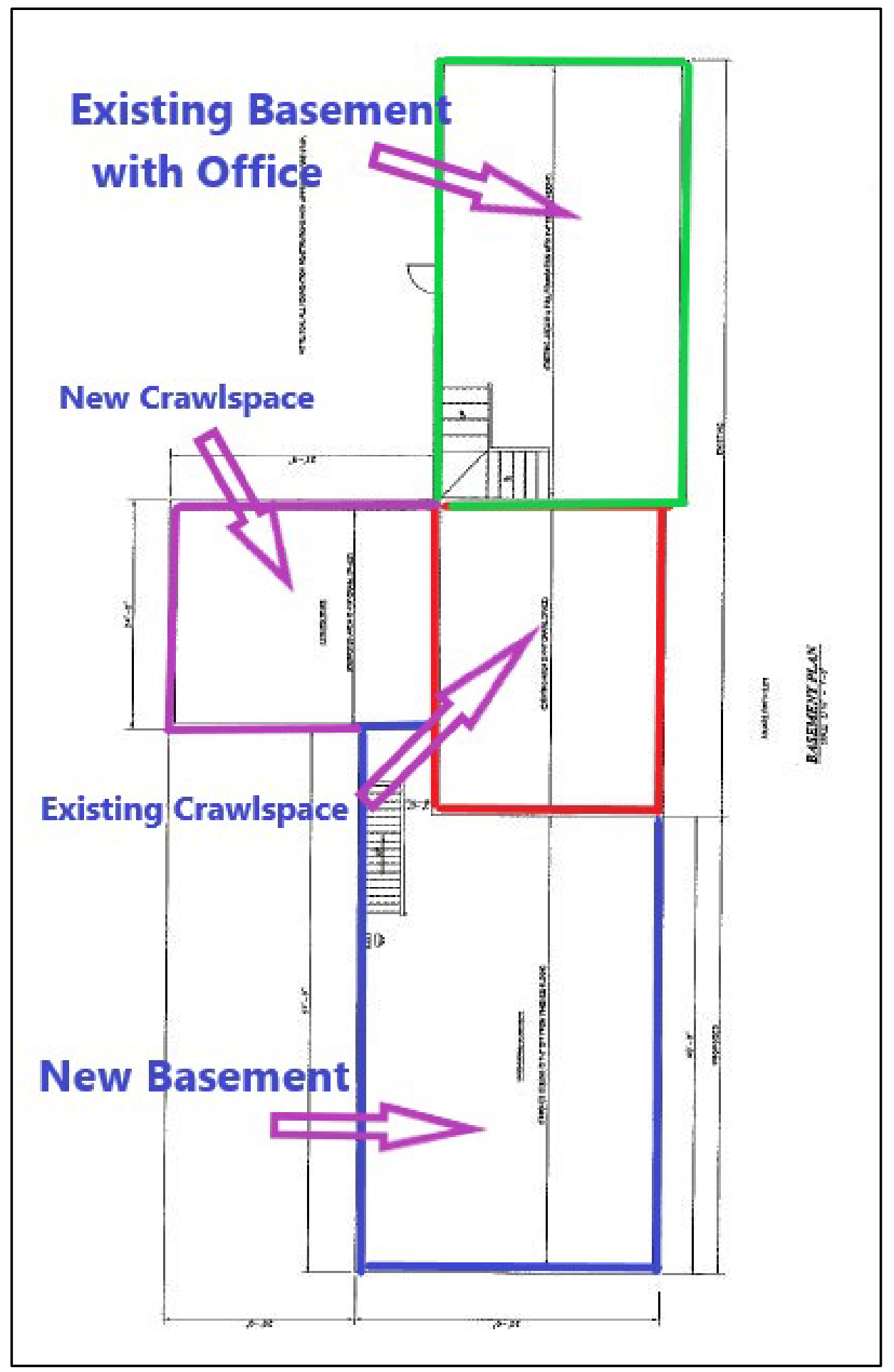

Diagram 2. Blue highlights the new basement as part of the renovation project.

The green highlight is the existing basement with offices.

(Diagram courtesy of the Maine Office of the State Fire Marshal) 
Captain Killed and Six Firefighters Injured at a Propane Explosion in an Office Building-Maine

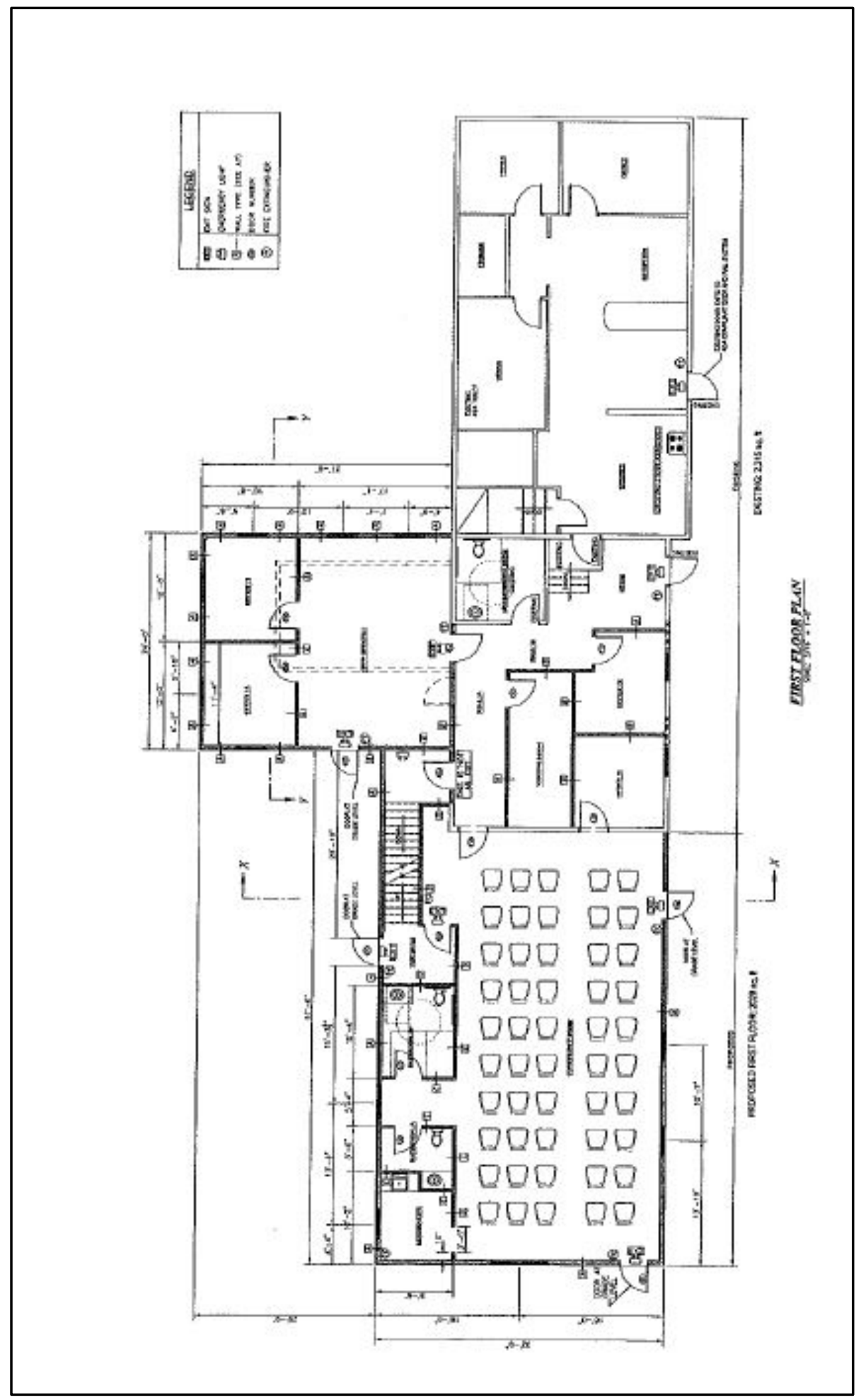

Diagram 3. The floor plan of the $1^{\text {st }}$ floor of the new and existing building. (Diagram courtesy of the Maine Office of the State Fire Marshal) 
Captain Killed and Six Firefighters Injured at a Propane Explosion in an Office Building-Maine

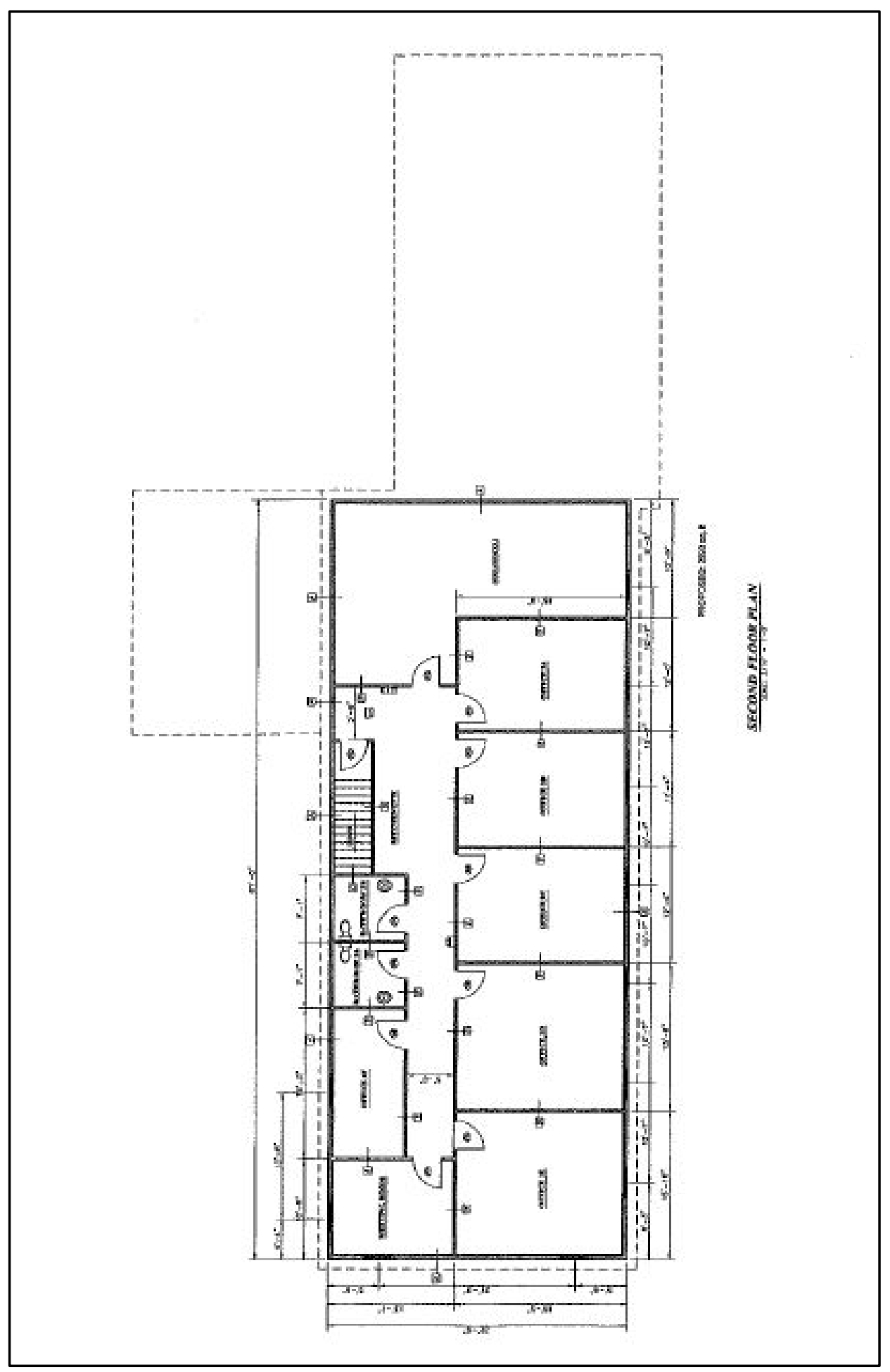

Diagram 4. The floor plan of the $2^{\text {nd }}$ floor of the new building, which consisted primarily of offices.

(Diagram courtesy of the Maine Office of the State Fire Marshal) 


\section{Captain Killed and Six Firefighters Injured at a Propane Explosion in an Office Building-Maine}

The construction was completed, and the building was operational on July 1, 2019. The two-story office building with a full basement building was approximately 32 feet wide by 81 feet long. The building consisted of approximately 8,300 square feet.

\section{Timeline of Construction and Renovation Project}

The construction events that were relevant to this incident were:

- October 29, 2018:

- June 20, 2019:

- June 28, July 1- 2, 2019:

- July 1, 2019:

- July 25, 2019:

- August 1, 2019:

- September 1, 2019:

- September 10, 2019:

- September 12, 2019:

- September 13, 2019:

- $\quad$ September 16, 2019:
Building contractor broke ground for construction of the new structure.

Propane tank was placed on the building office property, ditching was completed for the propane supply line, and propane service company delivered 125 gallons of propane.

Parking lot paved. The "service riser" or "anodeless riser" for the propane system was paved over by the paving company. Construction project completed. Employees started moving furniture and office equipment into the building. Propane company delivered 257.3 gallons of propane. Company continued the moving process into the new building Building opened for business. Note: The Third-Party Inspector never certified the completion of the construction project. Four bollards were drilled into the ground on Side Bravo in the vicinity of the propane supply line entering the building. One of the bollards severed the propane supply running from the tank to the building. The bollards were installed to protect the three air conditioning units on Side Bravo of the building (See Photo 2). Note: The company that installed the bollards never requested Maine "Dig-Safe" to mark underground utilities.

Employees reported no hot water in the building. The hot water was supplied by the propane boiler.

Propane company notified by the building maintenance supervisor that the propane tank was empty. The propane company delivered 391.9 gallons.

Propane tank was discovered empty with frost on the bottom half of the tank and the ground around the tank at approximately 0805 hours. The building exploded at approximately 0817 hours.

\section{Third Party Inspection Program}

The Third-Party Inspection Program in Maine began in July 2011 and primarily takes the place of the municipal building inspector for towns that are required to enforce the Maine Uniform Building and Energy Code but have elected not to conduct inspections. In these towns, the applicant is responsible for hiring a building inspector to review their plans prior to commencing construction and to then conduct the necessary building inspections after construction is completed. The scope of the third-party inspector does not include the inspection of heating, air conditioning, and ventilation (HVAC); plumbing; and electrical, except for some items that may have requirements within the Maine Uniform Building and Energy Code, such as insulating hot water supply lines within the plumbing system 


\section{Captain Killed and Six Firefighters Injured at a Propane Explosion in an Office Building-Maine}

[MUBEC 2015]. These components are the responsibility of state and local inspectors and/or licensed tradesmen. After completion of the project, the inspector provides a report to the town certifying that the project satisfies all relevant code requirements and requests the town issue a certificate of occupancy.

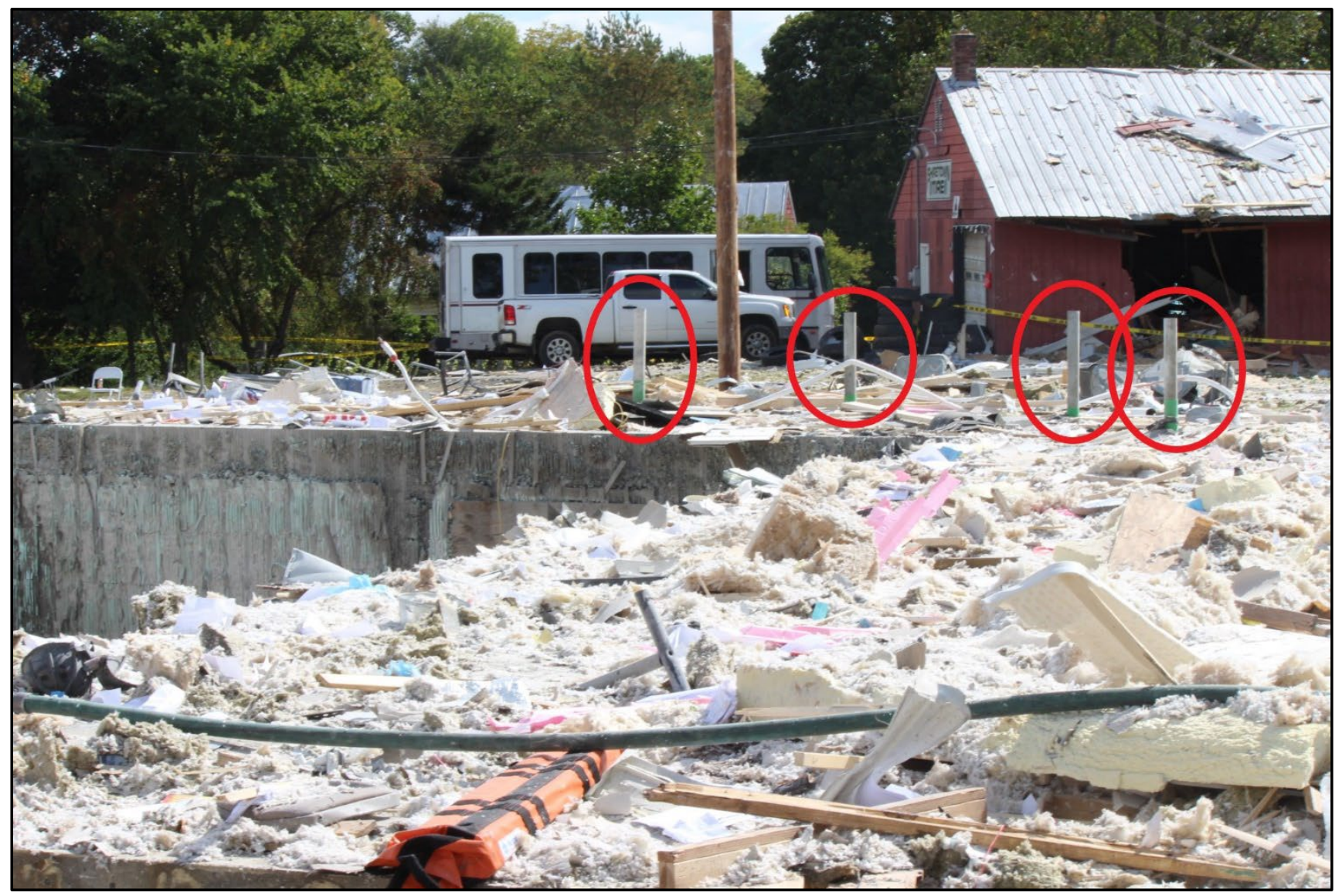

Photo 2. The bollards (red circles) that were placed to protect the air conditioning units in the parking lot on Side Bravo of the office building. When the bollards were driven into the ground, one of the bollards severed the propane supply line. (Photo courtesy of the Maine Office of the State Fire Marshal)

The Third-Party Inspection Program uses the International Codes Council (I-Codes), which are international codes developed by the International Code Council (ICC). The ICC is a family of fifteen coordinated, modern building safety codes that help ensure the engineering of safe, sustainable, affordable, and resilient structures.

The Third-Party Inspection Program consists of a third-party inspector reviewing and approving the following steps during a construction project:

- Construction plans and documents

- Footing forms with reinforcement installed prior to concrete placement

- Footings with concrete installed 


\section{Captain Killed and Six Firefighters Injured at a Propane Explosion in an Office Building-Maine}

- Foundation forms with reinforcement installed prior to concrete placement

- Foundation with concrete installed

- Basement prior to concrete (checking drainage and vapor barrier), which often occurs at the same time as footings with concrete installed

- Framing of structure prior to covering (this is typically done several times as construction progresses)

- Installation of exterior vapor barrier and wall and roof coverings

- Fire caulking and sealing

- Insulation prior to covering

- Installation of interior finishes

- Final inspection (includes finished building and all fire safety components such as fire alarm and sprinkler systems).

The building's maintenance supervisor contacted and hired a licensed third-party inspector for the renovation of this office building. The third-party inspector never received all the certified construction plans and never issued a notice to proceed for this project. A certificate of occupancy was never issued to this business by the town.

\section{Timeline}

The following timeline is a summary of events that occurred as the incident evolved. Not all incident events are included in this timeline. The times are approximate and were obtained by studying the dispatch records, audio recordings, witness statements, and other available information. This timeline also lists the changing fire behavior indicators and conditions reported, as well as fire department response and fireground operations. The timeline is not intended, nor should it be used, as a formal record of events.

\begin{tabular}{|c|c|c|}
\hline $\begin{array}{c}\text { Dispatch Communications \& Fire } \\
\text { Department Response }\end{array}$ & Time & $\begin{array}{l}\text { Fireground Communications \& } \\
\text { Fireground Operations }\end{array}$ \\
\hline \multicolumn{3}{|l|}{ September 16, 2019} \\
\hline $\begin{array}{l}\text { The maintenance supervisor from the } \\
\text { office building called the fire chief at } \\
\text { the fire station and advised there was a } \\
\text { possible propane leak in the building. }\end{array}$ & $\begin{array}{l}0806 \\
\text { Hours }\end{array}$ & \\
\hline
\end{tabular}




\section{Captain Killed and Six Firefighters Injured at a Propane Explosion in an Office Building-Maine}

\begin{tabular}{|c|c|c|}
\hline $\begin{array}{c}\text { Dispatch Communications \& Fire } \\
\text { Department Response }\end{array}$ & Time & $\begin{array}{l}\text { Fireground Communications \& } \\
\text { Fireground Operations }\end{array}$ \\
\hline $\begin{array}{l}\text { Car } 1 \text { (Fire Chief) called county } \\
\text { dispatch requesting the fire and rescue } \\
\text { department be dispatched to the office } \\
\text { building for a possible propane leak in } \\
\text { an office building. FD Incident } 2019 \text { - } \\
275 \text {. }\end{array}$ & $\begin{array}{l}0807 \\
\text { Hours }\end{array}$ & \\
\hline $\begin{array}{l}\text { County dispatch dispatched the fire } \\
\text { and rescue department to the office } \\
\text { building for a possible propane leak. }\end{array}$ & $\begin{array}{l}\text { 08:08:47 } \\
\text { Hours }\end{array}$ & \\
\hline $\begin{array}{l}\text { Car 1, Tower 3, and Engine } 2 \text { were } \\
\text { dispatched. }\end{array}$ & & \\
\hline Car 1 responded to the office building. & $\begin{array}{l}\text { 08:08:51 } \\
\text { Hours }\end{array}$ & \\
\hline Car 1 on-scene at the office building. & $\begin{array}{l}0810 \\
\text { Hours }\end{array}$ & $\begin{array}{l}\text { Car } 1 \text { met with the building } \\
\text { maintenance supervisor. }\end{array}$ \\
\hline $\begin{array}{l}\text { Tower } 3 \text { responded to the office } \\
\text { building. }\end{array}$ & $\begin{array}{l}\text { 08:11:38 } \\
\text { Hours }\end{array}$ & \\
\hline Tower 3 arrived on-scene. & $\begin{array}{l}0812 \\
\text { Hours }\end{array}$ & \\
\hline $\begin{array}{l}\text { Car } 1 \text { requested a technician from a } \\
\text { local propane company respond to the } \\
\text { office building. }\end{array}$ & $\begin{array}{l}0813 \\
\text { Hours }\end{array}$ & $\begin{array}{l}\text { Car } 1 \text {, the officer, and firefighter from } \\
\text { Tower } 3 \text { were investigating inside and } \\
\text { outside the structure to locate the } \\
\text { source of the propane leak. }\end{array}$ \\
\hline $\begin{array}{l}\text { Engine } 2 \text { responded to the office } \\
\text { building. }\end{array}$ & $\begin{array}{l}\text { 08:13:51 } \\
\text { Hours }\end{array}$ & \\
\hline Engine 2 arrived on-scene. & $\begin{array}{l}\text { 08:14:43 } \\
\text { Hours }\end{array}$ & $\begin{array}{l}\text { The officer (captain) and chauffeur of } \\
\text { Engine } 2 \text { joined the crew of Tower } 3 \\
\text { and Car } 1 \text { inside the building. }\end{array}$ \\
\hline
\end{tabular}




\section{Captain Killed and Six Firefighters Injured at a Propane Explosion in an Office Building-Maine}

\begin{tabular}{|c|c|c|}
\hline $\begin{array}{c}\text { Dispatch Communications \& Fire } \\
\text { Department Response }\end{array}$ & Time & $\begin{array}{l}\text { Fireground Communications \& } \\
\text { Fireground Operations }\end{array}$ \\
\hline & $\begin{array}{l}0816 \\
\text { Hours }\end{array}$ & $\begin{array}{l}\text { The chauffeur of Tower } 3 \text { and a deputy } \\
\text { chief (jumpseat of Engine 2) were } \\
\text { located on Side Bravo at the edge of } \\
\text { the parking lot. }\end{array}$ \\
\hline & $\begin{array}{l}0817 \\
\text { Hours }\end{array}$ & $\begin{array}{l}\text { An explosion occurred that destroyed } \\
\text { the office building. }\end{array}$ \\
\hline $\begin{array}{l}\text { A town police department sergeant } \\
\text { (PD3) radioed a Mayday on the police } \\
\text { department frequency to the county } \\
\text { dispatch. }\end{array}$ & $\begin{array}{l}0818 \\
\text { Hours }\end{array}$ & \\
\hline $\begin{array}{l}\text { PD3 arrived on-scene and informally } \\
\text { assumed Command. }\end{array}$ & & \\
\hline $\begin{array}{l}\text { Fire and rescue department's deputy } \\
\text { chief (Car 3) responded. }\end{array}$ & & \\
\hline $\begin{array}{l}\text { Fire and rescue department's Squad } 1 \\
\text { (PAR 3) responded to the building } \\
\text { explosion. }\end{array}$ & $\begin{array}{l}0820 \\
\text { Hours }\end{array}$ & $\begin{array}{l}\text { With the original firefighters } \\
\text { incapacitated, PD } 3 \text { informally assumed } \\
\text { command and ordered a } 13 / 4 \text {-inch } \\
\text { hoseline into operation to knock down } \\
\text { the active fire in the building debris. } \\
\text { Also, PD } 3 \text { assigned arriving resources } \\
\text { to locate and treat patients. }\end{array}$ \\
\hline $\begin{array}{l}\text { The county dispatch dispatched an } \\
\text { EMS Mass Casualty Incident response } \\
\text { of five medic units to the incident - } \\
\text { Medic } 33 \text {, Medic } 31 \text {, Medic } 41 \text {, Medic } \\
32 \text {, and Medic } 72 \text {. }\end{array}$ & $\begin{array}{l}0821 \\
\text { Hours }\end{array}$ & \\
\hline $\begin{array}{l}\text { Medic } 33 \text { responded from the county } \\
\text { fairgrounds. }\end{array}$ & & \\
\hline $\begin{array}{l}\text { Fire and rescue department's Engine } 1 \\
\text { (PAR 2) responded to the office } \\
\text { building. }\end{array}$ & & \\
\hline
\end{tabular}




\section{Captain Killed and Six Firefighters Injured at a Propane Explosion in an Office Building-Maine}

\begin{tabular}{|c|c|c|}
\hline $\begin{array}{c}\text { Dispatch Communications \& Fire } \\
\text { Department Response }\end{array}$ & Time & $\begin{array}{l}\text { Fireground Communications \& } \\
\text { Fireground Operations }\end{array}$ \\
\hline Squad 1 arrived on-scene. & $\begin{array}{l}0822 \\
\text { Hours }\end{array}$ & \\
\hline $\begin{array}{l}\text { Medic } 33 \text { arrived on-scene. } \\
\text { Engine } 1 \text { arrived on-scene and parked } \\
\text { behind Engine } 2 .\end{array}$ & $\begin{array}{l}0823 \\
\text { Hours }\end{array}$ & $\begin{array}{l}\text { Triage on the firefighters inside and } \\
\text { outside the building was started by } \\
\text { civilians. } \\
\text { Fire was showing from the building } \\
\text { debris created by the explosion on the } \\
\text { Side Alpha/Side Delta corner of the } \\
\text { building. }\end{array}$ \\
\hline \multirow[t]{2}{*}{$\begin{array}{l}\text { PD3 requested investigators from the } \\
\text { Maine Office of the State Fire Marshal } \\
\text { respond. }\end{array}$} & $\begin{array}{l}0824 \\
\text { Hours }\end{array}$ & $\begin{array}{l}\text { The EMS Director, who responded on } \\
\text { Medic 33, assumed Medical Group } \\
\text { Supervisor. } \\
\text { A paramedic on Medic } 33 \text { assumed } \\
\text { Triage, Treatment, and Transportation } \\
\text { Unit Leader, which was located at the } \\
\text { Side Alpha/Side Bravo corner of the } \\
\text { parking lot near the highway. }\end{array}$ \\
\hline & $\begin{array}{l}0827 \\
\text { Hours }\end{array}$ & $\begin{array}{l}\text { PD3 drove Engine 1, laying a 4-inch } \\
\text { supply line from a hydrant on the state } \\
\text { highway to Engine } 2 \text {. }\end{array}$ \\
\hline $\begin{array}{l}\text { Medic } 34 \text { and Medic } 51 \text { were } \\
\text { dispatched and responded to the } \\
\text { building explosion. }\end{array}$ & $\begin{array}{l}0828 \\
\text { Hours }\end{array}$ & \\
\hline $\begin{array}{l}\text { Car } 3 \text { (PAR 1) arrived on-scene. } \\
\text { Car } 3 \text { formally assumed Command. }\end{array}$ & $\begin{array}{l}0829 \\
\text { Hours }\end{array}$ & $\begin{array}{l}\text { PD3 met with the Car } 3 \text { and provided } \\
\text { an update. } \\
\text { The EMS Supervisor pronounced the } \\
\text { captain of Engine } 2 \text { deceased. }\end{array}$ \\
\hline
\end{tabular}




\section{Captain Killed and Six Firefighters Injured at a Propane Explosion in an Office Building-Maine}

\begin{tabular}{|c|c|c|}
\hline $\begin{array}{c}\text { Dispatch Communications \& Fire } \\
\text { Department Response }\end{array}$ & Time & $\begin{array}{l}\text { Fireground Communications \& } \\
\text { Fireground Operations }\end{array}$ \\
\hline Medic 31 arrived on-scene. & $\begin{array}{l}0830 \\
\text { Hours }\end{array}$ & $\begin{array}{l}\text { Civilians, EMS personnel, firefighters, } \\
\text { and law enforcement officers were } \\
\text { trying to locate and account for all } \\
\text { injured firefighters and building } \\
\text { occupants. } \\
\text { The injured firefighters and building } \\
\text { occupants were moved to the triage } \\
\text { area near the highway on the Side } \\
\text { Alpha/Side Bravo corner of the } \\
\text { property. }\end{array}$ \\
\hline $\begin{array}{l}\text { Medic } 31 \text { was enroute to the hospital } \\
\text { with the captain and firefighter from } \\
\text { Tower } 3 \text {. }\end{array}$ & $\begin{array}{l}0834 \\
\text { Hours }\end{array}$ & $\begin{array}{l}\text { Crews were still trying to locate and } \\
\text { account for the deputy chief that } \\
\text { responded on Engine } 2 .\end{array}$ \\
\hline Medic 34 arrived on-scene. & $\begin{array}{l}0840 \\
\text { Hours }\end{array}$ & \\
\hline $\begin{array}{l}\text { Medic } 51 \text { and Medic } 32 \text { arrived on- } \\
\text { scene. }\end{array}$ & $\begin{array}{l}0846 \\
\text { Hours }\end{array}$ & \\
\hline $\begin{array}{l}\text { Medic } 34 \text { was enroute to the hospital } \\
\text { with the fire chief. }\end{array}$ & $\begin{array}{l}0850 \\
\text { Hours }\end{array}$ & \\
\hline $\begin{array}{l}\text { Medic } 51 \text { was enroute to the hospital } \\
\text { with the maintenance supervisor. }\end{array}$ & & \\
\hline $\begin{array}{l}\text { Medic } 32 \text { was enroute to the hospital } \\
\text { with the chauffeur of Engine } 2 \text {. }\end{array}$ & $\begin{array}{l}0852 \\
\text { Hour }\end{array}$ & \\
\hline $\begin{array}{l}\text { Medic } 41 \text { was enroute to the hospital } \\
\text { with chauffeur of Tower } 3 \text {. }\end{array}$ & $\begin{array}{l}0855 \\
\text { Hours }\end{array}$ & \\
\hline $\begin{array}{l}\text { Medic } 31 \text { responded back and arrived } \\
\text { on-scene. }\end{array}$ & & \\
\hline $\begin{array}{l}\text { The first investigator from the Maine } \\
\text { Office of the State Fire Marshal } \\
\text { arrived on-scene. }\end{array}$ & & \\
\hline
\end{tabular}




\section{Captain Killed and Six Firefighters Injured at a Propane Explosion in an Office Building-Maine}

\begin{tabular}{|c|c|c|}
\hline $\begin{array}{c}\text { Dispatch Communications \& Fire } \\
\text { Department Response }\end{array}$ & Time & $\begin{array}{l}\text { Fireground Communications \& } \\
\text { Fireground Operations }\end{array}$ \\
\hline $\begin{array}{l}\text { Medic } 31 \text { was enroute to the hospital } \\
\text { with the deputy chief (Engine } 2 \text { ). }\end{array}$ & $\begin{array}{l}0858 \\
\text { Hours }\end{array}$ & \\
\hline \multirow[t]{3}{*}{$\begin{array}{l}\text { Command advised county dispatch } \\
\text { that the fire in the building was out. }\end{array}$} & $\begin{array}{l}1000 \\
\text { Hours }\end{array}$ & \\
\hline & $\begin{array}{l}1145 \\
\text { Hours }\end{array}$ & $\begin{array}{l}\text { Investigators from the Maine Office of } \\
\text { the State Fire Marshal and Office of } \\
\text { State Medical Examiner started the } \\
\text { recovery process of the captain of } \\
\text { Engine } 2 \text {. }\end{array}$ \\
\hline & $\begin{array}{l}1225 \\
\text { Hours }\end{array}$ & $\begin{array}{l}\text { The captain of Engine } 2 \text { was removed } \\
\text { from the building and transported to the } \\
\text { Office of State Medical Examiner. }\end{array}$ \\
\hline $\begin{array}{l}\text { Note: When fire investigators secured } \\
\text { each day of the investigation, law } \\
\text { enforcement remained on scene for } \\
\text { scene security. }\end{array}$ & & \\
\hline \multicolumn{3}{|l|}{ September 19, 2019} \\
\hline $\begin{array}{l}\text { Command was dissolved. All } \\
\text { resources were cleared from FD } \\
\text { Incident } 2019-275 \text {. }\end{array}$ & $\begin{array}{l}1350 \\
\text { Hours }\end{array}$ & \\
\hline
\end{tabular}

\section{Personal Protective Equipment}

The NIOSH investigators evaluated and inspected the personal protective equipment worn by the deceased captain of Engine 2 at the police department headquarters evidence room on October 24, 2019. The captain was wearing his second set of turnout gear that he kept at home. The captain's helmet could not be found. His turnout coat and turnout pants were intact but were not inspected due to body fluids. The turnout boots were in good condition.

The personal protective equipment (turnout gear) was not considered a contributing factor to the fatality in this incident. NIOSH investigators conducted no further evaluation or testing of the turnout gear. 


\section{Captain Killed and Six Firefighters Injured at a Propane Explosion in an Office Building-Maine}

\section{Weather}

At 0753 hours on September 16, 2019, the temperature was 55 degrees Fahrenheit $\left(55^{\circ} \mathrm{F}\right)$, the dew point was 47 degrees Fahrenheit $\left(47^{\circ} \mathrm{F}\right)$, the relative humidity was $74 \%$, and the winds were out of the WNW at 6 miles per hour. The conditions were fair. There was a slight trace of precipitation in the previous 24 hours [Weather Underground 2019].

\section{Investigation}

On September 16, 2019, at approximately 0750 hours, a maintenance employee for the company arrived at the office building. He started moving folding tables from the $1^{\text {st }}$ floor of the building to the basement, which was in the new addition of the building. After several trips to the basement, he started to feel lightheaded, which he mentioned to the building's maintenance supervisor. The maintenance employee wasn't sure what caused him to feel lightheaded. Both employees were in the basement at this time, which was approximately 0805 hours. The maintenance supervisor advised he was going to evacuate all employees from the building. The lights were on in the basement, but the maintenance supervisor turned the lights off when he left. There were no offices in the basement, only utilities in this new section of the building. There was one office in the basement of the old section of the building, but it had a separate entrance.

Upon exiting the building, the maintenance employee looked at the propane tank, which was located on the Side Bravo/Side Charlie corner of the property. The maintenance employee stated there was frost on the bottom of the tank and on the ground. At approximately 0806 hours, the maintenance supervisor called the fire chief (Car 1) requesting the fire and rescue department respond to the facility due to a possible propane leak in the building. Approximately 12 employees were evacuated from the building and told to locate to the end of the parking lot on Side Delta. At approximately 0807 hours, Car 1 called county dispatch requesting the fire and rescue department be dispatched to the office building for a possible propane leak. At 0808 hours, county dispatch alerted the town's fire and rescue department for a potential propane leak in an office building. The fire chief responded from fire headquarters at 0809 hours and arrived on-scene at 0811 hours. The fire chief parked in the parking lot near the highway entrance to the building. Tower 3 (PAR 3) was dispatched at 0811 hours and arrived at 0812 hours. Tower 3 pulled in the parking lot past the fire chief's vehicle facing Side Alpha of the structure. The maintenance employee met Car 1 in the parking lot on Side Alpha and walked him to Side Charlie to meet with the maintenance supervisor. When Tower 3 arrived, Car 1 advised the crew to bring the multi-gas detectors to Side Charlie of the structure. At 0813 hours, Car 1 called county dispatch requesting the response of a service technician from the local propane dealer to this incident.

The captain and firefighter from Tower 3 took the multi-gas detectors to Side Charlie to the propane tank. The deputy chief (jumpseat of Engine 2) met the chauffeur from Tower 3. They walked to Side Bravo near the end of the parking lot. The captain and chauffeur from Engine 2 went to Side Charlie to meet the fire chief and the crew from Tower 3. The firefighter from Tower 3 checked the atmosphere on Side Charlie with the multi-gas detector and nothing registered. The firefighter from Tower 3 noticed frost on the lower half of the propane tank and on the ground around the tank. The firefighter checked each bollard with the multi-gas detector, and nothing registered on the multi-gas detector. Car 1 then directed the crew from Tower 3 to enter the building (See Diagram 5). 
Captain Killed and Six Firefighters Injured at a Propane Explosion in an Office Building-Maine

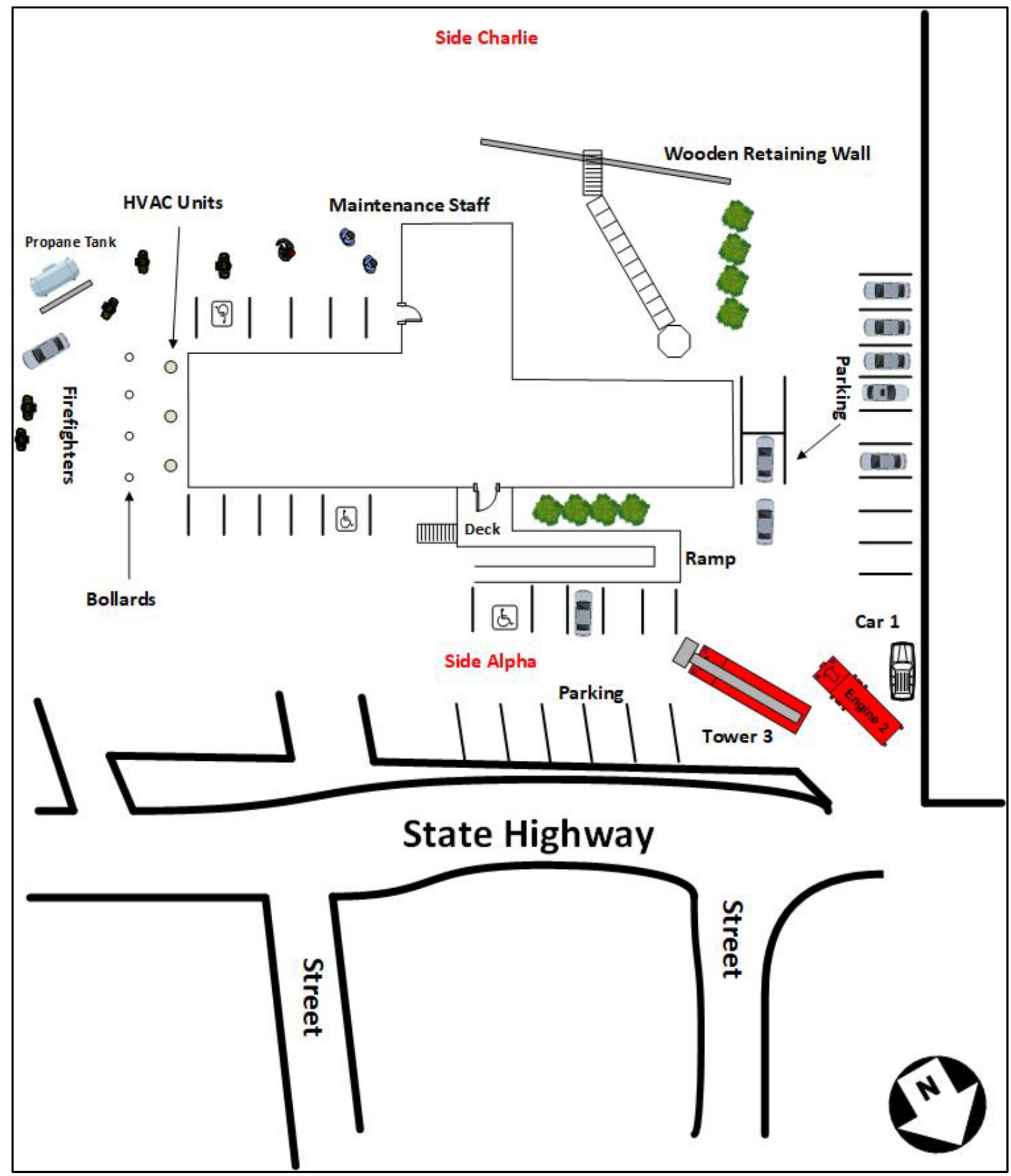

Diagram 5. The initial response of the fire and rescue department. Firefighters are monitoring the area around the propane tank. Engine 2, Tower 3, and Car 1 are on Side Charlie. The time was approximately 0815 hours. 


\section{Captain Killed and Six Firefighters Injured at a Propane Explosion in an Office Building-Maine}

Tower 3 surveyed the $1^{\text {st }}$ floor, and nothing registered on the multi-gas detector. The crew from Tower 3 then went to the basement. The firefighter on Tower 3 stated the multi-gas detector started alarming at $10 \%$ LEL at the top of the basement steps. As the firefighter started down the steps, the LEL started increasing. Once he reached the basement, the multi-gas detector read 100\% LEL and went into full alarm. The firefighter from Tower 3 mentioned this to the captain of Tower 3 . The captain of Tower 3 was in the basement and noticed the boiler on the wall. He was near the stairwell and was only in the basement approximately 30 seconds before the explosion occurred.

Prior to the explosion, the captain of Tower 3 was in the basement with the maintenance supervisor, the firefighter from Tower 3, and the chauffeur from Engine 2. Car 1 and the captain from Engine 2 were on the 1st floor of the office building on Side Charlie. The deputy chief (Car 2) (jumpseat of Engine 2) and the chauffer of Tower 3 were located on Side Bravo of the building near the end of the parking lot. The time was approximately 0816 hours.

At approximately 0817 hours, an explosion occurred which destroyed the $1^{\text {st }}$ floor and $2^{\text {nd }}$ floor of the new addition (See Photo 3).

The force of the explosion knocked down and seriously injured the captain, two firefighters and the maintenance supervisor in the basement. Car 1 and the captain from Engine 2, who were on the $1^{\text {st }}$ floor, were blown into the basement. The chauffeur of Tower 3 was walking towards Side Alpha of the building when the explosion occurred. He was blown into the grass on Side Bravo. The deputy chief (Car 2) who was standing on Side Bravo was knocked down. After the explosion, the deputy chief (Car 2) moved the chauffeur from Tower 3 towards the tire shop and started medical treatment on the chauffeur (See Photo 4). 


\section{Captain Killed and Six Firefighters Injured at a Propane Explosion in an Office Building-Maine}

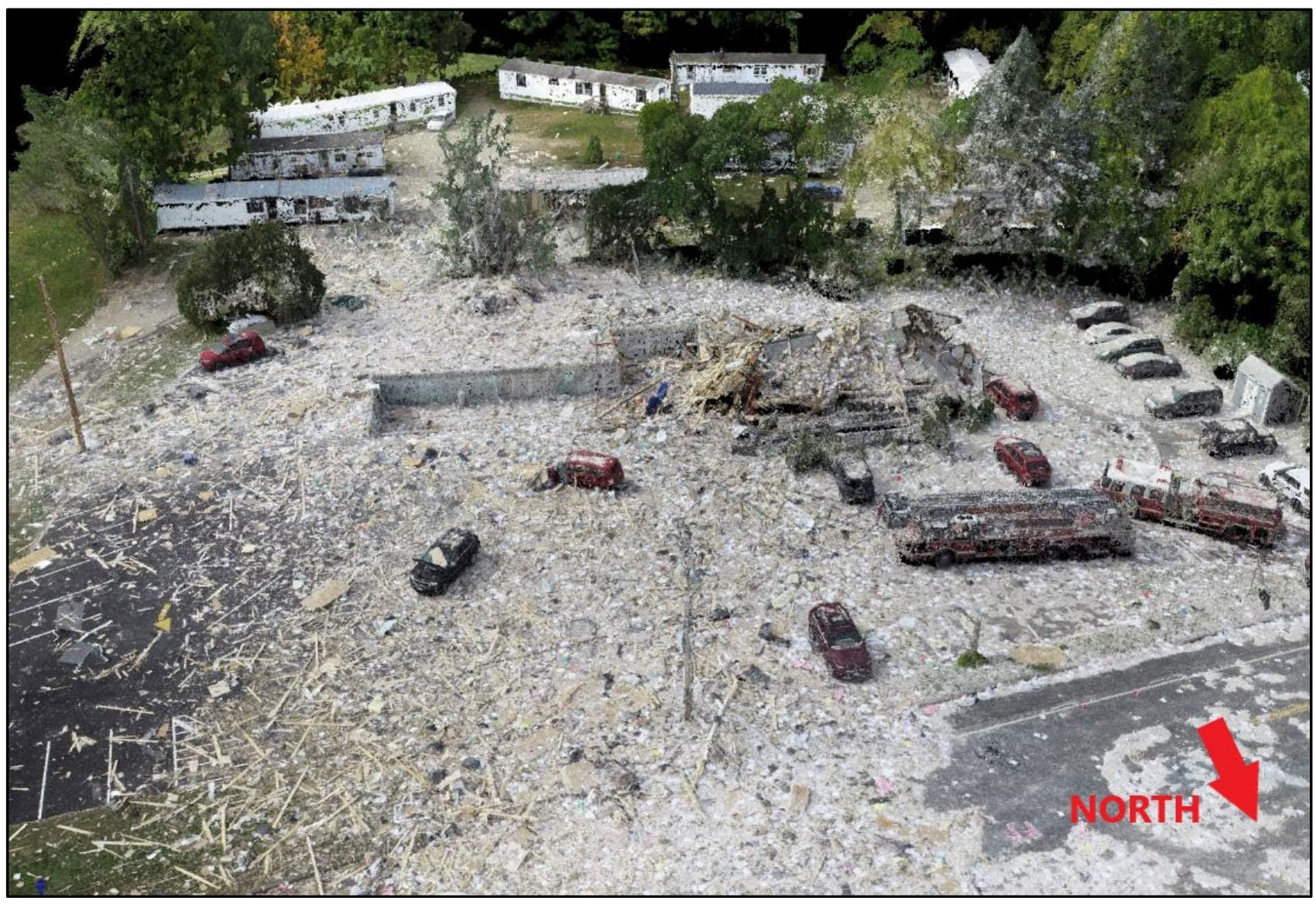

Photo 3. Drone footage of the office building and surrounding area after the explosion. A mobile home park was located to the south of the building property. (Photo courtesy of the Maine Office of the State Fire Marshal) 


\section{Captain Killed and Six Firefighters Injured at a Propane Explosion in an Office Building-Maine}

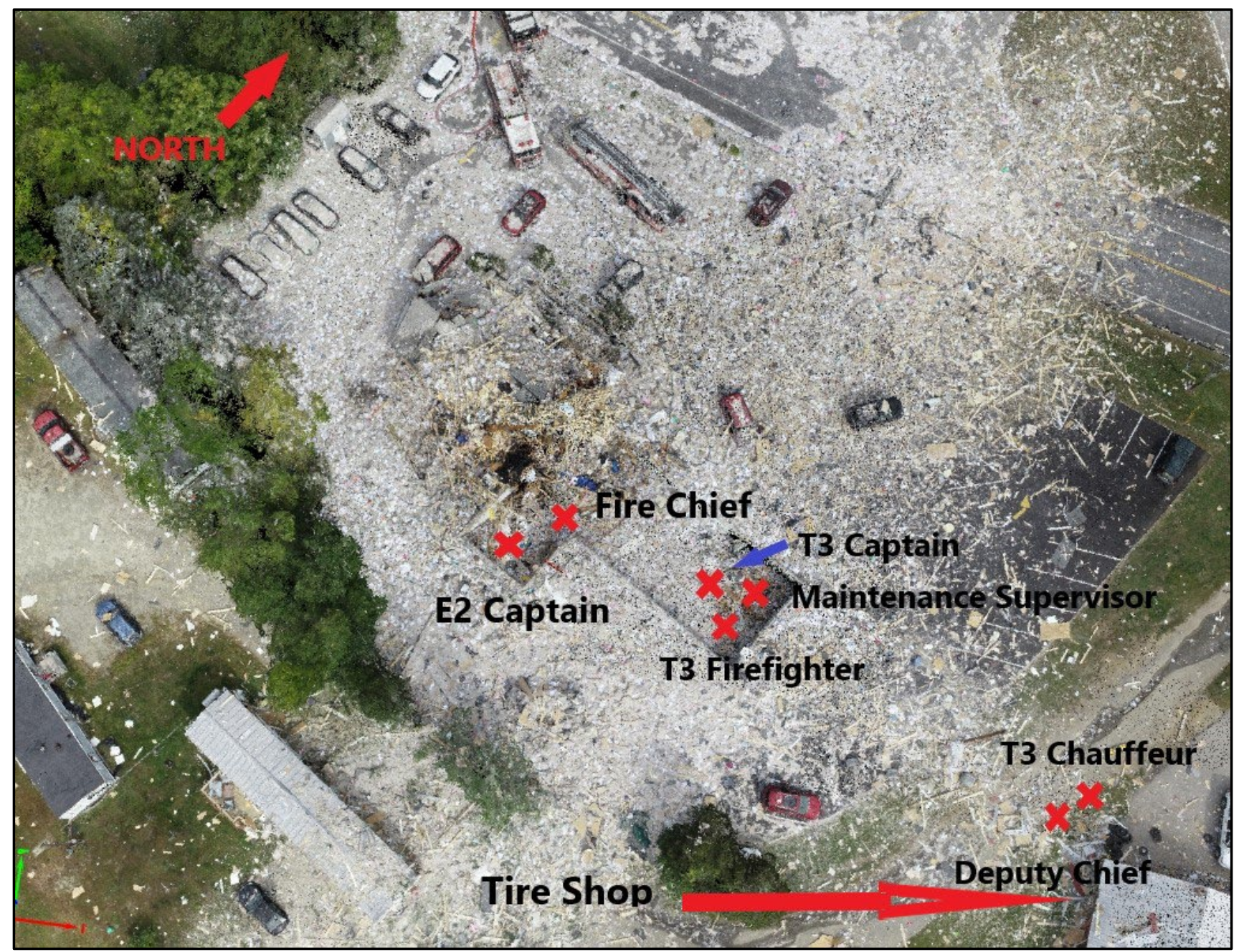

Photo 4. Location of the firefighters and maintenance supervisor are denoted by the red "Xs" after the explosion. (Photo courtesv of the Maine Office of the State Fire Marshal)

At approximately 0818 hours, a town police department sergeant (radio designation "PD3") called county dispatch to check on the status of the fire and rescue department due to a possible explosion. He left police department headquarters and started driving in the direction of the explosion. He turned onto the state highway and could see a building had exploded, though he wasn't sure which one. He arrived on-scene and advised the county dispatch that an explosion had occurred at an office building and provided the address. PD3 made a request for the power company and ambulances to respond. PD3 informally took command of the incident at this time. The time was approximately 0821 hours. Note: The actions of PD3 were confirmed by footage from his body camera. Also, at 0821 hours, County dispatch transmitted an EMS Mass Casualty Incident response of five medic units to the incident. Medic 33, Medic 31, Medic 41, Medic 32, and Medic 72 were dispatched. Medic 33 responded from the fairgrounds which was less than a mile away (See Table 1). Engine 1 responded at approximately 0821 hours with two firefighters. 


\section{Captain Killed and Six Firefighters Injured at a Propane Explosion in an Office Building-Maine}

When PD3 arrived on scene, he parked his vehicle behind Engine 2 on the state road. Bystanders were starting to access the property to assist with injured firefighters and civilians. PD3 went to Side Bravo of the building due to power lines down on Side Delta. As he approached the building, he identified the entire building had been blown off the foundation. He could see the captain of Tower 3 and the firefighter from Tower 3 moving around in the basement of the new addition of the building. Bystanders were climbing into the basement of the building on Side Charlie to assist the injured firefighters and the facility's maintenance supervisor.

There was active fire in the debris pile on top of the original office building. Due to the explosion, all fire and rescue department members that responded on the initial alarm were incapacitated. PD3 stretched a 13/4-inch hoseline from the bumper of Engine 2 . A bystander, who was a volunteer firefighter, pumped Engine 2. PD3 passed the hoseline to the captain of Tower 3, who was still in the basement. The firefighter from Tower 3 had climbed out of the basement. Squad 1 from the fire and rescue department arrived on-scene at approximately 0822 hours. PD3 assigned one firefighter to take the hoseline and try and knock down the fire. The two other firefighters were assigned to locate and treat the injured firefighters. Engine 1 arrived on the scene at approximately 0823 hours.

At 0824 hours, Medic 33 arrived on-scene. The agency's EMS director, who responded on Medic 33, assumed the role of medical group supervisor. The paramedic on Medic 33 assumed the role of triage, treatment, and transportation unit leader, which was located at the Side Alpha/Side Bravo corner of the building's parking lot near the state highway (See Photo 5). At this time, PD3 called county dispatch and requested the response of air ambulances and the state fire marshal's office. He organized and supervised bystanders to get medical supplies and backboards to move the injured firefighters and civilian. PD3 also checked on the status of all the office building employees. He assigned a patrol officer, who had arrived at the same time of Squad 1, to get the names of the employees. Also, PD3 assigned resources to check the status of the occupants in the trailer park located behind the office building.

PD3 realized that Engine 2 was nearly out of water and went to Engine 1 to lay a 4-inch supply line from a hydrant located approximately $400-500$ feet east of the office building on the state highway. A volunteer firefighter pulled the 4-inch supply line off Engine 1 and wrapped the hydrant. PD3 drove Engine 1 to the office building parking lot. He disconnected the supply line and hooked the supply line into the intake connection on Engine 2. The volunteer firefighter hooked the supply line to the hydrant and charged the supply line providing Engine 2 with water. The time was approximately 0827 hours. 


\section{Captain Killed and Six Firefighters Injured at a Propane Explosion in an Office Building-Maine}

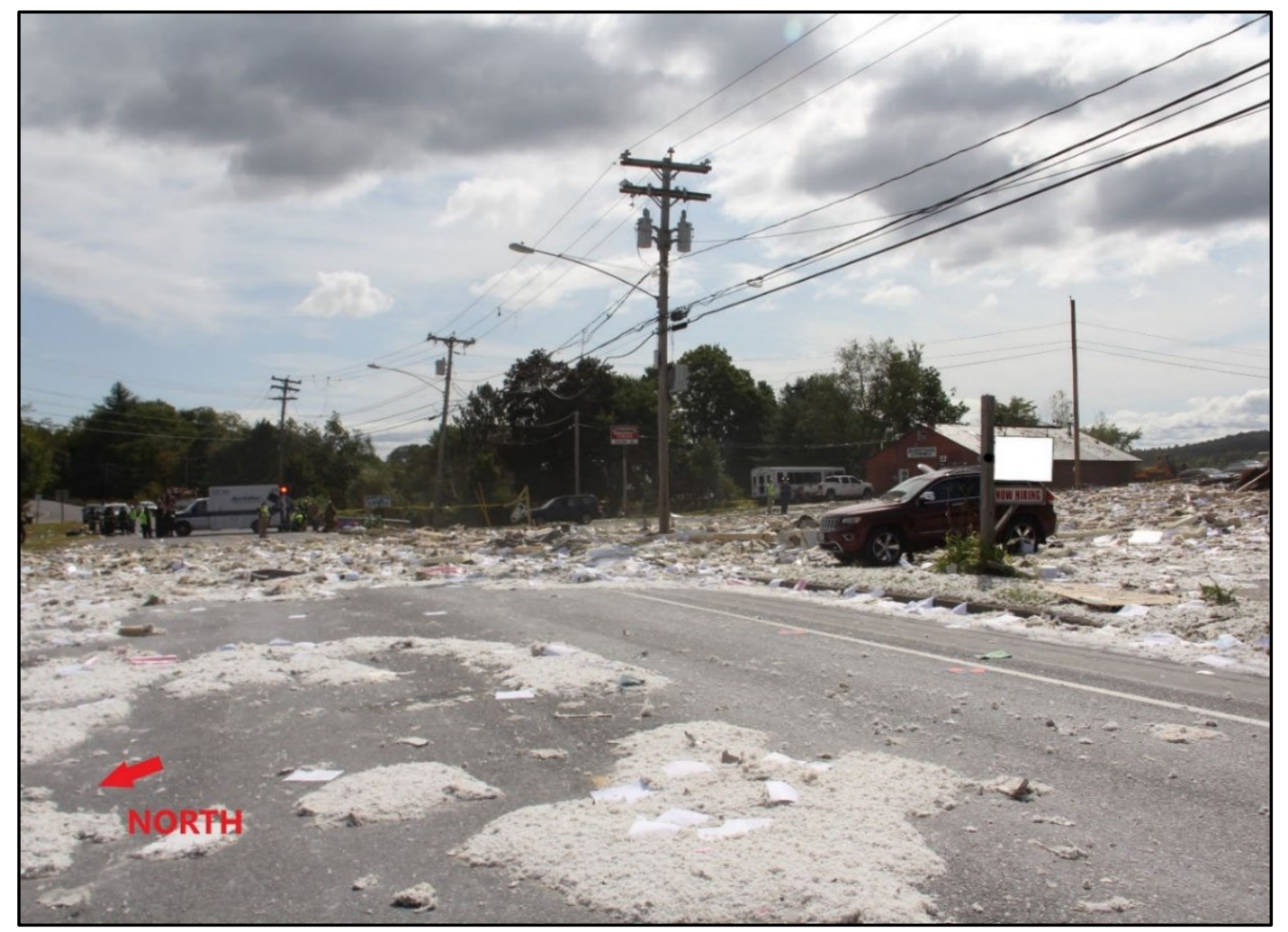

Photo 5. The ambulance is located at the triage, treatment, and transportation unit after the explosion. All patients were transported to the hospital from this location. (Photo courtesy of the Maine Office of the State Fire Marshal)

At 0828 hours, the county dispatch dispatched Medic 34, and Medic 51 to respond to the building explosion (See Table 1). Note: Except for Medic 33, all medic units responded from their assigned stations, which were in other jurisdictions.

\begin{tabular}{|c|c|c|c|c|c|c|c|}
\hline $\begin{array}{c}\text { Medic } \\
\text { Unit }\end{array}$ & Dispatch & Enroute & $\begin{array}{c}\text { On- } \\
\text { Scene }\end{array}$ & $\begin{array}{c}\text { Enroute to } \\
\text { Hospital }\end{array}$ & $\begin{array}{c}\text { At } \\
\text { Hospital }\end{array}$ & $\begin{array}{c}\text { Back at } \\
\text { Scene }\end{array}$ & $\begin{array}{c}\text { In- } \\
\text { Service }\end{array}$ \\
\hline Medic 33 & 0821 & 0821 & 0823 & N/A & N/A & N/A & 1230 \\
\hline Medic 31 & 0821 & 0821 & 0830 & 0834 & 0841 & 0855 & 1230 \\
\hline Medic 41 & 0821 & 0821 & 0850 & 0855 & 0905 & N/A & N/A \\
\hline Medic 34 & 0828 & 0828 & 0840 & 0850 & 0900 & N/A & N/A \\
\hline Medic 51 & 0828 & 0828 & 0846 & 0850 & 0900 & N/A & N/A \\
\hline Medic 32 & 0821 & 0821 & 0846 & 0852 & 0858 & 0900 & 1000 \\
\hline Medic 72 & 0821 & 0821 & 0910 & N/A & N/A & N/A & 1000 \\
\hline
\end{tabular}

Table 1. The table shows the times for dispatch, enroute, on-scene, enroute to the hospital, at the hospital, back at the scene, and in-service. 


\section{Captain Killed and Six Firefighters Injured at a Propane Explosion in an Office Building-Maine}

The fire and rescue department's deputy chief (Car 3), who is the county's emergency manager, responded from out of town and arrived on-scene at approximately 0829 hours. The deputy chief assumed Command which was in the parking lot on the Side Alpha/Side Bravo corner of the building near the state highway. The immediate priority of Command was to account for all the firefighters that responded to the incident and their condition, plus the employees of the office building. Car 3 assigned a fire chief from a neighboring department to be the accountability officer (resource status) to account for all first responders on-scene.

The EMS medical group supervisor (the EMS Director) went into the basement where the captain of Engine 2 was located. He pronounced the captain deceased at approximately 0829 hours. Command was trying to locate and account for the deputy chief that responded on Engine 2 . The deputy chief (Car 2) was accounted for at 0834 hours.

Injured firefighters and the civilian were moved to the triage, treatment, and transportation unit which had been established at the corner of the property near the state highway. Medic 31 arrived on-scene at 0830 hours and then transported the captain from Tower 3 and the firefighter from Tower 3 to the local hospital at 0834 hours. Medic 34 arrived on-scene at 0840 hours. Medic 51 and Medic 32 arrived onscene at 0846 hours. The fire chief was transported by Medic 51 and the maintenance supervisor was transported by Medic 34 at 0850 hours. At 0852 hours, Medic 32 was enroute to the hospital with the chauffeur of Engine 2. At 0854 hours, Medic 41 transported the chauffeur of Tower 3 . At 0855 hours, Medic 31 returned to the scene. Medic 31 transported the deputy chief (Car 2) from Engine 2 to the hospital at 0858 hours. This completed the patient care and transportation component of this incident. Command advised county dispatch of this benchmark. Also, Command started to demobilize fire and EMS resources that were on-scene. Also, Command advised the county dispatch to cancel all other responding resources. The scene was secured awaiting the arrival on investigators from the Maine Office of the State Fire Marshal. The first investigator from the Maine Office of the State Fire Marshal arrived at 0855 hours. Others continued to arrive throughout the morning.

The fire was completely extinguished and declared out by Command at approximately 1000 hours. The state medical examiner and investigator arrived on-scene at approximately 1115 hours. At 1145 hours, investigators started the recovery process for the captain from Engine 2. This process was completed by 1225 hours and the captain was transported to the Maine Office of the State Medical Examiner in Augusta, Maine.

At 1350 hours on September 19, 2019, Command was dissolved, and all resources were clear from the scene.

\section{Contributing Factors}

Occupational injuries and fatalities are often the result of one or more contributing factors or key events in a larger sequence of events that ultimately result in the injury or fatality. NIOSH investigators identified the following items as key contributing factors in this incident that ultimately led to the fatalities:

- Lack of locating and marking of underground utilities prior to digging or excavation 


\section{Captain Killed and Six Firefighters Injured at a Propane Explosion in an Office Building-Maine}

- Installation of vertical protective posts (Bollards) that severed the propane supply line

- Lack of pressure testing an empty tank by the propane company

- Odorant fade or scrubbing of ethyl mercaptan by soil and concrete

- Lack of scene size-up and risk assessment

- Lack of incident management

- Lack of understanding a multi-gas monitor's capability

- Improper gas sampling, monitoring, and detection

- Lack of hazardous materials training and recertification.

\section{Cause of Death}

According to the death certificate, the medical examiner listed the victim's cause of death as due to blunt force injuries to the head and torso associated with blast injuries. The manner of death was accidental.

\section{Recommendations}

Recommendation \#1: Fire departments responding to a hazardous materials incident should ensure that a scene size-up and initial risk assessment are performed. In addition, fire departments should establish isolation zones and ensure a continuous risk assessment is conducted throughout the incident.

Discussion: At this incident, fire and rescue members responded to the report of an odor of propane. The fire chief arrived on-scene followed by Tower 3 and Engine 2. Five of the seven firefighters went immediately to Side Charlie and operated in this area and near the propane tank. Eventually the five firefighters entered the building. At this time, the propane leak was not identified. Several firefighters noticed the frost on the lower part of the propane tank and ground but did not communicate this information to the fire chief. The firefighter from Tower 3 stated the multi-gas detector started alarming at $10 \%$ LEL at the top of the basement steps. The firefighter stated that the LEL continued to increase as he descended down the steps. Once he reached the basement, the multi-gas detector was reading $100 \%$ and went into full alarm. The firefighter stated at no time did he smell ethyl mercaptan.

Unlike a fast paced, offensive structural firefighting incident, a hazardous materials incident should start out in the defensive strategy.

The key point to remember is that a hazardous materials response begins with identification. Familiarity with hazardous materials recognition and identification processes is an essential skill for all responders. For incidents dealing with any hazardous material, including propane and natural gas, the size-up process starts with the dispatch center. For any known propane emergency response, the dispatch center should attempt to obtain all pertinent information from the person reporting a propane leak incident. This information should include (if known):

- Involved material(s) name, type, and/or class

- Amount of material involved and the size of tank

- Problem (leak, spill, fire, etc.) and its location 


\section{Captain Killed and Six Firefighters Injured at a Propane Explosion in an Office Building-Maine}

- Number of people injured or exposed [Fire and Rescue Departments of Northern Virginia 2014].

The dispatcher should remain on the phone with the caller to gain additional information after entering the call for dispatch. Any additional information should be relayed to responding units after dispatch. A representative from all agencies that may have a responsibility at the incident need to be contacted and asked to meet the fire department personnel at safe location at the scene. If the response call is generated by a responsible party with a knowledge of the hazardous situation, the responsible party should be instructed to meet the dispatched units at a safe location [Blue Card 2018].

First due companies must start the research process while enroute. This process involves using the Department of Transportation, Pipeline and Hazardous Materials Safety Administration, Emergency Response Guide (ERG) to identify:

- Material properties

- Safe staging distances

- Evacuation distances

- Isolation and protective zones distances (hot, warm, and cold zone determinations) [ERG 2016].

Hazardous materials incident sites are classified into hazard zones. The different hazard zones identify the competency levels required perform operations in a specific zone. These zones are:

- Hot zone: an immediately dangerous to life and health (IDLH) environment which is contaminated with products that require the full use PPE when operating in this zone.

- Warm zone: a defined area just outside of the hot zone that has the potential to become IDLH contaminated that requires a defined level of use of PPE when operating in this zone.

- Cold zone: a defined safe area outside of the warm zone that has little or no chance of becoming IDLH contaminated where no PPE is required. The cold zone is where the incident command, support personnel and uncommitted resources are all located.

The first arriving company should respond to the scene, upwind/uphill (whenever possible), in a defensive manner. All other companies should respond directly to a staging location designated by the first due unit or the dispatch center. This area should be upwind and a sufficient distance away from the incident to keep the scene clear and maintain good access to the incident site. If a representative from the propane company is not on-scene, the incident commander should ask the dispatch center for their estimated time of arrival [Fire and Rescue Departments of Northern Virginia 2014].

The initial radio report should be performed from the front seat of an engine company or the first arriving resource. Once the radio report has been given and the dispatch center acknowledges the report, the company officer of the first arriving engine or first arriving resource can be out of the apparatus and start to conduct a reconnaissance of the incident scene. The size-up report should include:

- $\quad$ Result of a 360-degree size-up (if performed)

- Information on the size, location, and identity of material(s) involved

- Confirmation of the wind direction 


\section{Captain Killed and Six Firefighters Injured at a Propane Explosion in an Office Building-Maine}

- Accountability location

- Any immediate safety concerns.

The wind direction can be retrieved from different areas, but it is very important the wind direction is confirmed during the initial size-up. Wind can be redirected by trees, structures, the terrain, or other barriers.

Other information should be identified through the size-up/recon process and be reported on the follow-up report or subsequent conditions, actions, and needs (CAN) reports. Major reporting items include:

- Involved material(s) identity

- Size and overall amount of the material

- Inside vs. outside

- Where are the materials stored: building, vehicle, tanker, train, airplane, in a field

- Hazards of the material to the public

- Explosion hazards

- How have the material(s) been dispersed after the trigging event

- Is the material continuing to be released [Blue Card 2018].

The basic level of any hazardous materials operations should meet the requirements of 29 CFR 1910.120, Hazard Waste Operations and Emergency Response (HAZWOPER) Operations Level and should follow this standard incident action plan (IAP):

- Operate in a DEFENSIVE manner

- Provide for the safety of all personnel and the public

- Evacuate exposed areas if necessary

- Identify and isolate the hot and warm zones

- Deny any entry

- Attempt to identify the products involved

- Upgrade the assignment based on the incident's hazard profile

- Contain the release from a safe distance, and keep it from spreading

- Protect exposures [OSHA 1990].

Atmospheres that may have potentially flammable or explosive vapors include but are not limited to: a reported natural gas or propane leak, a reported combustible liquid fuel spill, a suspected contaminated environment, and confined space which may also be oxygen deficient or enriched.

To ensure a proper risk evaluation is conducted, incident commanders should perform the following actions:

- Conduct an appropriate size-up and determine resource needs.

- Establish initial isolation zones - initial isolation and protective action distances per the Emergency Response Guide recommendations.

- If multiple victims are present or expected, determine the best location to establish a gross emergency decontamination corridor and ensure an adequate water supply. Companies laying supply lines should maintain situational awareness and not be forced into an untenable position. 


\section{Captain Killed and Six Firefighters Injured at a Propane Explosion in an Office Building-Maine}

- All personnel exiting the apparatus shall have personal protective equipment (PPE) in place including self-contained breathing apparatus (SCBA); immediate transition to "on air" may be necessary. The officer and driver shall don PPE and SCBA as soon as possible after arrival.

- At least one 13/4-inch handline should be placed on the ground, charged, and manned for emergency decontamination, chemical contaminant triage, and standoff protection.

- Consider the use of positive pressure ventilation (PPV) to assist keeping the product in the hot zone [Fire and Rescue Departments of Northern Virginia 2014].

Once the initial size-up and risk assessment has been completed, the isolation zones are established, the strategy and incident action plan are defined and in place, the risk assessment becomes a continuous process.

\section{Electricity}

A critical element of the emergency response to a propane or natural gas leak inside a structure is to ensure that electricity is never turned on or off in a structure. This includes any other type of flammable gas leak or any type of flammable liquid leak inside a structure.

If a leak is suspected/confirmed, the proper procedure is to evacuate all fire department members and secure the building. Incident commanders should request the response of the local power or utility company to secure or shut-off the power outside the hazard zone.

\section{Recommendation \#2: Fire departments should ensure incident commanders initiate a defensive strategy and communicate the incident action plan (tactics) during initial operations of a hazardous materials incident. The strategy and IAP are revised based upon the tactical objectives taken to mitigate the hazard.}

Discussion: Unlike a fast paced, offensive structural firefighting incident, a hazmat incident should start out in the defensive strategy. Protective actions are those steps taken to preserve the health and safety of emergency responders and the public during an incident involving the release of hazardous materials. The specific IAP should identify the method of hazard control and the resources necessary to accomplish this goal.

Overall operational strategies for a hazardous materials incident can be divided into the following categories:

- Offensive operations:

- Responders take direction action on the material, container, or equipment involved. This is a hazmat technician level operation, and a Site Safety Control Plan (ICS 208 HM) must be completed (See Appendix One).

- Defensive operations

- Responders seek to confine the incident in a given area without directly contacting the hazardous material involved.

- Nonintervention operations:

- Responders take no direct actions on the problem or situation. The main strategy for this incident would be to protect life and property by evacuation [IFSTA 2017]. 


\section{Captain Killed and Six Firefighters Injured at a Propane Explosion in an Office Building-Maine}

These separate strategies create a simple, understandable plan that describes how close the responders will get to the incident's hazards. The overall strategic decision is based on the incident's critical factors weighed against the risk management plan (e.g., risk a lot, risk a little, or risk nothing).

The defined strategy describes the overall approach to incident operations and drives the IAP established by an incident commander at each incident. The IAP provides the tactical assignments required to achieve the offensive/defensive objective. The order of occurrence is key-the strategic goals are developed first followed by the tactical objectives that can be assigned to responding companies. At each incident, the incident commander should start with a standard placement-oriented operational plan that develops a strong, dependable foundation for command and control of the incident. This is the purpose of the IAP [Brunacini 2002; Brunacini, AV and Brunacini, N 2004; Blue Card 2018].

NFPA 1561 defines an IAP as a verbal plan, tactical worksheet, written plan, or combinations thereof that reflects the overall incident strategy, tactics, risk management, and firefighter safety that are developed by an incident commander. NFPA 1561, Standard on Emergency Services Incident Management System and Command Safety [NFPA 2020b] requires the following regarding an IAP:

- 5.3.16.1. The incident commander shall be responsible for developing and/or approving an incident action plan (IAP).

- 5.3.16.2. This IAP shall be communicated to all staged and assigned members at an incident.

- 5.3.16.3. For Type IV and Type V incidents, the incident commander shall communicate the IAP verbally to all on-scene resources.

- 5.3.24 The incident commander shall be responsible for reviewing, evaluating, and revising the IAP and overall strategy of the incident.

\section{All known hazmat incidents will start in the defensive strategy.}

The initial defensive tactical priorities include:

- Define the hazard zone

- Isolate the hazard zone

- Search and evacuate exposures

- Protect exposures. [Blue Card 2018]

The IC should follow the standard IAP for a hazmat incident:

- Provide for the safety of all personnel and the public

- Evacuate exposed areas if necessary

- Identify and isolate the hot and warm zones

- Deny entry

- Attempt to identify the products involved

- Upgrade the alarm assignment based on the incident's hazard profile

- Contain the release from a safe distance, and keep it from spreading

- Protect exposures

The IC can delegate responsibility to a geographic divisional or functional group supervisor. The specific supervisor is responsible for carrying out the tactics within their assignment. When a 


\section{Captain Killed and Six Firefighters Injured at a Propane Explosion in an Office Building-Maine}

supervisor completes or makes progress, they shall inform the incident commander with conditions, actions, and needs (CAN) report. For example, the incident commander assigns an officer as hazmat group supervisor. The incident commander or hazmat group supervisor then assigns a hazmat entry leader to facilitate overall entry operations of assigned personnel within the exclusion or the hot zone. This entry leader gives updates through the hazmat group supervisor to Command on conditions, actions, and needs. Note: A hazardous materials decontamination leader or site access control leader can also perform these duties. When the command officer arrives on-scene, an update from the initial incident commander can occur (face-to-face or by radio). The command officer will then assume command at a stationary location. By following this process, the initial incident commander, and the subsequent incident commander will be in a stronger position to manage an emergency event during an incident [FIRESCOPE 2017]. In addition to using a tactical worksheet, the hazmat group supervisor, and the hazmat assistant safety officer should develop and complete an ICS 208 Hazardous Materials (HM) Site Safety and Control Plan ICS Form 208 HM, Site Safety and Control Plan (fema.gov) (See Appendix One).

When a command officer (e.g., battalion chief, district chief, deputy chief, or fire chief) arrives onscene, he/she should automatically assume a standard stationary, exterior, and remote command position. The command officer will immediately assume Command and begin functioning as the incident commander. Command officers generally establish and continue command and control functions inside their vehicles or at the rear of the vehicle, which has a command board and/or a tactical worksheet. To effectively command an incident, the incident commander should be in the most advantageous position possible. The best position is a fixed, visible, and accessible location. This can be accomplished by utilizing the incident commander's staff vehicle, a designated command vehicle, or fire apparatus. An acceptable alternative is utilizing the rear area of a sport utility vehicle or pick-up truck type vehicle. This method will provide the incident commander with an area that is quiet and free of distractions. It is vital for the incident commander to be able to hear all radio transmissions, especially from those operating in the hazard zone. The best way to accomplish this is using a radio communication headset. [NFPA 2020b].

With any plan, the first order of business is to move upwind and uphill. Evacuating the immediate and adjacent areas, establishing isolation zones through access control, and using the Emergency Response Guide throughout the initial response are invaluable actions regardless of the level of threat [ERG 2016].

After the product(s) of the release have been identified and the scope of the incident has been established, it is critical that Command make a resource determination based on the following:

- Can the current level of dispatched resources adequately control the incident's problems?

- Is another agency required to control the incident's problems (gas company, clean-up company, etc.)?

- Does a hazmat unit (technician level or above) need to be consulted to control the incident's problems?

- Are additional technician level hazmat resources are needed to control the incident's problems?

- Is an entire hazmat team needed to control the incident's problems [Blue Card 2018]? 


\section{Captain Killed and Six Firefighters Injured at a Propane Explosion in an Office Building-Maine}

Continuously performing size-up, evaluation, and revision, ensures that firefighters can operate safely, complete the tactical priorities, and go home unharmed after the event. This standard front-end approach ensures incident operations remain under control and assures incident operations occur within a structured plan. When the incident commander performs the standard command functions from the very beginning of the incident, it provides a basis for any revisions required to match the strategy and incident action plan to the current incident conditions. The ongoing evaluation of the incident's critical factors is the basis for managing the current strategy and IAP and keeping it current (positions always match conditions). Hazmat incidents provide the incident commander with the discretionary time needed to make critical decisions.

The key to an appropriate hazmat response is to subscribe to a particular set of tactical responses, standardized in their approach and straightforward in their application.

\section{Recommendation \#3: Fire departments should ensure firefighters are trained to understand the scrubbing or odorant fade of ethyl mercaptan from propane and natural gas. This training includes the use of multi-gas detectors to determine if a potential explosive atmosphere is present.}

Discussion: Prior to this incident, the propane supply line was severed on September 10, 2019, by a company that installed four bollards on Side Bravo of the office building parking lot. The bollards were 10 feet in length and one of the bollards the propane supply line when driven into the ground. Approximately 391 gallons leaked into the ground. The propane tank was filled again on September 13, and approximately another 300 gallons leaked into the ground. During this time, no employees smelled ethyl mercaptan.

Ethyl mercaptan is a clear liquid that is added to natural gas and propane to give it a distinct odor. The odor is described as smelling like a rotten egg or rotten cabbage. This liquid is added prior to transportation as a safety precaution to help detect a gas leak because natural gas and propane are odorless. Anosmia (inability to smell), hyposomnia (reduced sense of smell), and nasal inflammation can interfere with the ability to smell ethyl mercaptan [Roberson, E. 2001; NIOSH 2021].

The odor of ethyl mercaptan fades or is scrubbed due to oxidation, adsorption, or absorption. Leaking natural gas or propane from underground lines loses the odor of ethyl mercaptan as it passes through soils and concrete. Materials such as drywall, plywood, and new piping for natural gas or propane will also adsorb the odor until the material becomes saturated. See Safety Advisory: Odor Fade in Nature Gas and Propane, DHHS (NIOSH) Publication Number 2021-106 | NIOSH | CDC. Odor fade is generally more common in new, large-diameter steel pipes and storage tanks; however, odor fade can also occur in smaller- diameter gas lines made of polyethylene. For new natural gas or propane installations, many gas installation companies perform pipe pickling or pipeline conditioning to saturate the new gas installations prior to use. Likewise, new storage tanks and new components of natural gas or propane installations should be conditioned prior to use [CPSC 1987].

On the morning of September 16, 2019, a maintenance worker was moving tables to the basement of the office building. He complained of dizziness and being light-headed. The maintenance supervisor called the fire and rescue department at 0806 hours. When the fire and rescue department arrived on- 


\section{Captain Killed and Six Firefighters Injured at a Propane Explosion in an Office Building-Maine}

scene and firefighters started their investigation, no one smelled ethyl mercaptan. The facility maintenance work and several firefighters noticed frost on the bottom portion of the tank and the ground underneath the propane tank. The building exploded at approximately 0817 hours.

During the investigation conducted by the Maine Office of the State Fire Marshal, investigators dug up the propane supply line two days later and found a high concentration of ethyl mercaptan in the soil. The soil, concrete, and building materials absorbed the propane creating odorant fade. Propane has an expansion ratio of 270:1. The vapor density of propane is 1.56 , making it heavier than air. Propane will seek low areas and accumulate until it dissipates or finds an ignition source. Propane has a LEL of 2.3 and an upper explosion limit (UEL) of 9.5, and one gallon of liquid weighs 4.23 pounds. Propane has an ignition temperature between $920^{\circ} \mathrm{F}$ and $1,120^{\circ} \mathrm{F}$ [FRDNV 2014, Airgas 2018] (See Appendix Two).

Propane in its natural form is colorless and odorless and ethyl mercaptan is added to propane for leak detection. Department of Transportation requires any combustible/flammable gas in a distribution line to be odorized or have a natural odorant. It states that a person with a normal sense of smell should be able to detect a concentration in air of $20 \%$ of the lower explosive limit. The mercaptan is added at a rate of one pound per 10,000 gallons of liquid propane. This equates to a one part per billion. The odorization of propane is addressed by a myriad of Federal and State laws and regulations, as well as, by accepted industry standards and practices. When offered and transported in commerce, the Hazardous Materials Regulations specifies that all propane in cargo and portable tanks be effectively odorized using either 1.0 pound of ethyl mercaptan, 1.0 pound of thiophane, or 1.4 pounds of amyl mercaptan per 10,000 gallons of propane, in the event of an unintended release or leak to indicate the presence of gas. The Hazardous Materials Regulations do not, however, require propane to be odorized if odorization would be harmful in the use or further processing of the propane, or if odorization will serve no useful purpose as a warning agent in such use or further processing. Essentially, this exception applies to propane being transported to industrial end-users [Federal Register 2013].

Training on sampling, monitoring, and detection is a critical component of this process. Firefighters trained to the Operations Level of 29 CFFR 1910.120, HAZWOPER, can conduct atmospheric monitoring with a multi-gas detector designed to monitor oxygen levels, presence of carbon monoxide, hydrogen sulfide, and LEL of flammable gases. Annual continuing education training provides opportunities for firefighters and fire officers to maintain their competencies for sampling, monitoring, and detection at a hazardous materials incident. The training should include discussion regarding the use of turnout gear and SCBA during the sampling, monitoring, and detection function.

\section{Recommendation \#4: Fire departments should ensure that firefighters wear proper PPE including $S C B A$ when entering an IDLH environment involving propane and natural gas.}

Discussion: NFPA 1500, Standard on Fire Department Occupational Safety, Health, and Wellness Program states in Paragraph 7.1.1.1, "A risk assessment for the need and, if necessary, selection of protective ensembles, ensemble elements, and protective equipment shall be conducted in accordance with 29 CFR 1910.132, Personal Protective Equipment." In Paragraph 7.1.1.2, "The selection of applicable protective ensembles, ensemble elements, and other protective equipment shall be based on 


\section{Captain Killed and Six Firefighters Injured at a Propane Explosion in an Office Building-Maine}

a selection program containing a risk assessment in compliance with 29 CFR 1910.132, Personal Protective Equipment and all applicable NFPA standards." In Paragraph 7.1.2, "Protective ensembles, ensemble elements, and other protective equipment shall be used whenever the member is exposed or potentially exposed to the hazards for which it is provided." Also, in Paragraph 7.1.3 of NFPA 1500, states, "The fire department shall require all members to wear or use all protective ensembles, ensemble elements, and other protective equipment specific to the operation in which members are engaged" [NFPA 2021].

With the development of a defensive strategy and the incident action plan for an incident with a report on an odor of propane, the process starts at the hazmat operations level. All members should be in a minimum of full structural protective clothing including SCBA. Personnel working in a suspected ignitable atmosphere should be backed up by a staffed protective hand line, which should be at a minimum of $1 \frac{3}{4}$-inch hoseline. The number of exposed personnel will be kept to an absolute minimum [FRDNV 2014; NFD 2007].

\section{Recommendation \#5: Fire departments should have a SOP/SOG (standard operating procedure/standard operating guideline) for conducting sampling, detection, and monitoring at propane and natural gas emergencies.}

Discussion: For all propane and natural gas emergencies, fire departments should develop and implement a SOP/SOG for this process that is compliant with OSHA requirements. There should be at least two 4-gas meters (oxygen levels, presence of carbon monoxide, hydrogen sulfide, and LEL of flammable gases - O2, CO, H2S, and LEL) placed in operation by the engine company or truck company firefighters. Firefighters should obtain enough gas concentration readings for Command to evaluate the hazard and take appropriate action. These readings are used to define a proper isolation perimeter and the isolation zones (hot, warm, and cold) [FRDNV 2014]. The standard response action for isolation zones is defined by OSHA 1910.120 - HAZWOPER.

Monitoring is conducted in a methodical process with firefighters operating in full PPE, including SCBA. Also, a covering hoseline should be deployed to protect the firefighters conducting the monitoring. The first meter readings should be taken on the exterior of the building. These readings will determine the course of action. [VBFD 2019b, VBFD 2019c] (See Appendix Three).

Multi-gas meters measure a percentage of the LEL. Readings should be interpreted as follows:

- Atmospheres where the quantity of flammable/explosive gas is less than $10 \%$ of the LEL, personnel may, with caution, continue to mitigate the hazard.

- Atmospheres where the quantity of flammable/explosive gas is between $10 \%$ and $25 \%$ of the LEL, continuous monitoring and the full ensemble of personal protective equipment is required. Personnel may continue with caution to operate seeking the source or mitigating the hazard.

- Atmospheres where the quantity of flammable/explosive gas is greater than $25 \%$ of the LEL, personnel shall immediately withdraw from the area to the cold zone and consult the expert advice of the HAZMAT team. In addition to a withdrawal, the tactical considerations should 


\section{Captain Killed and Six Firefighters Injured at a Propane Explosion in an Office Building-Maine}

include ventilation or the application of Class B foam to fuel spills for vapor suppression [VBFD 2019a].

Any incident that involves a potential hazardous atmosphere is the responsibility of the fire department. The first arriving resource should establish command and work within the scope of their training, initially taking the actions to determine the scope of the situation requiring an emergency response. A key component of this process is to identify the need for additional resources early in the incident.

After the product(s) of the release have been identified and the scope of the incident has been established, it is critical that Command make a resource determination based on the following:

- Can the current level of dispatched resources adequately control the incident's problems?

- Is another agency required to control the incident's problems (gas company, clean-up company, etc.)?

- Does a hazmat unit (tech level or above) need to be consulted to control the incident's problems?

- Are additional technician level hazmat resources needed to control the incident's problems?

- Is an entire hazmat team needed to control the incident's problems [Blue Card 2018]?

If the decision is made to put firefighters on the inside of the building, this causes a revision to the strategy and IAP. Also, this should require a change from the hazmat operations level to the hazmat technician level. Command needs to communicate this to all firefighters and other first responders onscene [Blue Card 2018].

Recommendation \#6: Fire departments should ensure that firefighters are properly trained and certified to understand the capabilities of the department's multi-gas detectors, especially catalytic LEL combustible gas senor performance.

Discussion: Understanding how combustible sensors detect gas is critical to correctly interpreting readings and avoiding misuse of instruments that include a LEL combustible gas sensor.

Different gases and vapors have different LEL concentrations. Below the LEL, the ratio of combustible gas molecules to oxygen is too low for combustion to occur. In other words, the mixture is "too lean" to burn. Most (but not all) combustible gases and vapors also have an upper limit of concentration beyond which ignition will not occur. The UEL is the maximum concentration of combustible gas or vapor in air that will support combustion. Above the UEL, the ratio of gas to oxygen is too high for the fire reaction to propagate. In other words, the mixture is "too rich" to burn. The difference in concentration between the LEL and UEL is commonly referred to as the flammability range. Combustible gas concentrations within the flammability range will burn or explode provided that the other conditions required in the fire tetrahedron (adequate oxygen, adequate fuel, a source of ignition, and sufficient molecular energy to sustain the fire chain reaction) are met [AP 1018 2013]. 


\section{Captain Killed and Six Firefighters Injured at a Propane Explosion in an Office Building-Maine}

Whenever readings exceed 10\% LEL an explosion and fire hazard is possible. This is the least conservative (or highest acceptable) alarm set point for instruments used for monitoring combustible gases and vapors.

Catalytic-bead sensors require at least eight to ten percent oxygen by volume to detect accurately. A combustible sensor in a $100 \%$ gas or vapor environment will likely produce a reading of zero percent LEL. This is the reason that testing protocols for evaluating confined spaces specify measuring oxygen first and then combustible gases and vapors. For this reason, confined space instruments that contain catalytic-bead sensors should also include a sensor for measuring oxygen. If the instrument being used does not include an oxygen sensor, the firefighter should be especially cautious when interpreting results. A rapid up-scale reading followed by a declining or erratic reading may indicate that the environment contains insufficient oxygen for the sensor to read accurately. It may also indicate a gas concentration beyond the upper scale limit for the sensor, the presence of a contaminant which has caused a sudden inhibition or loss of sensitivity in the sensor, or other conditions which prevent the sensor or instrument from obtaining proper readings [AP 1018 2013].

A combustible gas sensor may be calibrated to any number of different gases or vapors. Where possible, the user should calibrate the instrument to achieve the level of sensitivity required for the substances to be measured (Note: See Recommendation 7). When interpreting the reading on a combustible gas indicator, the readings represent the percentage of LEL.

The important thing to remember is that the LEL is stated as a percentage of concentration of a gas in the atmosphere while the meter reading displayed is a percentage of the specified LEL concentration. Because methane has an LEL of 5 percent concentration in air, a reading of " 10 " indicates that the concentration is only 10 percent (or $1 / 10$ th) of the 5 percent concentration in air that would be needed to reach the LEL. Likewise, a reading of " 5 " indicates that the concentration is only 5 percent (or $1 / 20$ th) of the concentration needed to reach the 5 percent LEL.

Regardless of the LEL value, a reading of 10 percent or more of that value is cause for concern, as stated in OSHA Standard 29 CFR 1910.146, Permit-Required Confined Spaces, which considers 10 percent or more of any LEL to be a hazardous atmosphere [OSHA 1993].

As with the readings discussed earlier for methane, for this particular gas, a reading of 5 percent LEL is $1 / 20$ th of the concentration in air that would be needed to reach the LEL $(1 / 20$ th of 20 percent LEL is equal to 1 percent concentration). Likewise, a reading of 25 percent LEL is equal to $1 / 4$ th of the LEL concentration of 20 percent, or a 5 percent concentration of the gas in the atmosphere [See Chart 1] [De Lisi 2010]. 


\section{Captain Killed and Six Firefighters Injured at a Propane Explosion in an Office Building-Maine}

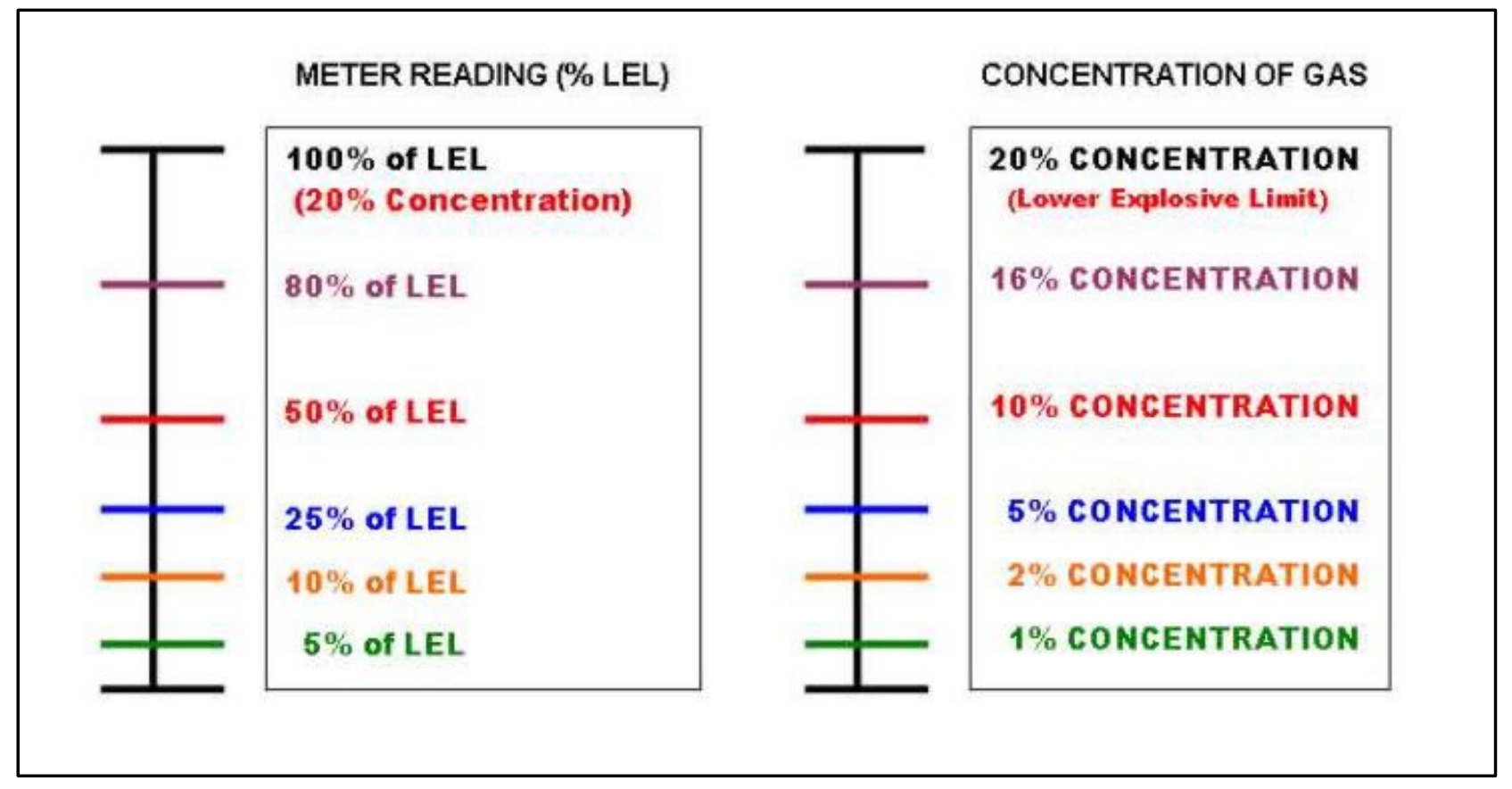

Chart 1. A chart based on a gas with a LEL of 20 percent and is read left to right.

Another concern with using a combustible gas indicator is that readings provided by the monitor are accurate only when attempting to measure the same gas used during calibration procedures. Since the sensitivity of combustible gas sensors varies with exposure to different types of atmospheres, any attempt to measure the concentration of gases other than that used during calibration will result in a reading that is likely greater or less than the actual concentration. Remedying this situation will require the use of a correction factor or relative response curve specific to the gas or vapor measured to obtain more accurate results [De Lisi 2010]. To better understand this, consider an analogy to time zones where a clock set to Eastern Standard Time in New York is accurate only in that time zone. To use that same clock in California, you would have to subtract three hours from the time displayed.

Some atmospheric monitors can perform these adjustments internally based on the appropriate relative response or correction factor. To ensure proper adjustment, it may be necessary to compare the displayed reading on some instruments to a chart or graph provided by the manufacturer, and then manually calculate the actual reading [De Lisi 2010]. For example, if a combustible gas indicator of an atmospheric monitor is calibrated with methane, readings when the instrument is used to detect methane will be "correct." However, if this same instrument is used to detect the presence of propane gas, it is necessary to use a correction factor.

If the correction factor for propane is " 1.5 ," all readings obtained with the atmospheric monitor when measuring propane must then be multiplied by 1.5 . Therefore, a reading of 1 percent LEL is actually $1.5 \%$ of the LEL, whereas a reading of 6 percent LEL is actually $9 \%$ of the LEL, determined by multiplying 6 percent $x$ 1.5. Likewise, when using an atmospheric monitor calibrated to methane to 


\section{Captain Killed and Six Firefighters Injured at a Propane Explosion in an Office Building-Maine}

measure the concentration of gasoline vapors, calculations using a correction factor will be necessary to adjust the readings accordingly [De Lisi 2010].

\section{Recommendation \#7: Fire departments should ensure that multi-gas detectors are properly maintained per the manufacturer's recommendations.}

Discussion: The calibration process is important to maintaining and operating a multi-gas detector. Fire department members should have a thorough understanding of the selection, care, and maintenance of multi-gas detectors. Most importantly, firefighters and other first responders should follow the manufacturer's use and maintenance guidelines to ensure the multi-gas detector will operate as intended. Using the multi-gas detector and understanding the sensor technology using LEL is an important component of air sampling and air monitoring. The oxygen level is very significant to the detection of the LEL [ISEA 2010].

Calibration is a two-step procedure. In the first step the instrument is exposed to contaminant free "fresh" air (that is, air which contains $20.9 \%$ oxygen and no combustible gas), turned on, and allowed to warm-up fully. The combustible sensor should read zero. If necessary, the combustible sensor is adjusted to read zero. Instrument manuals and other support materials usually refer to this step as the "fresh air zero." The second step is to expose the sensor to a known concentration of calibration gas, and (if necessary) adjust the readings to match the concentration. This is called making a "span adjustment." A "span adjustment" sets the sensitivity of the sensor to a specific gas. Always follow the manufacturer's instructions when calibrating or adjusting the instrument [AP1018 2021].

Bump testing and calibration testing are essential for fire departments that operate direct-reading portable multi-gas detectors to check oxygen levels and monitor for toxic or combustible gases. A bump test determines whether a direct-reading portable multi-gas detector can detect the presence of a possibly hazardous gas. The bump test is simple and should only take about one minute. The test should be performed daily prior to use of each installed sensor. A full calibration should be performed at least monthly to ensure direct-reading portable multi-gas detector equipment is accurate.

Direct-reading portable multi-gas detectors fall under the guidance of the International Safety Equipment Association [ISEA]. In 2010, the ISEA released a statement on how to improve consistency in the use, testing, and proper maintenance of direct-reading portable multi-gas detectors. The statement discussed the differences between a bump test (calibration check) and full calibration test plus how and when to conduct each test [ISEA 2010].

The ISEA definitions are:

- Bump Test (Function Check) - A qualitative function check where a challenge gas is passed over the sensor(s) at a concentration and exposure time sufficient to activate all alarm indicators to present at least their lower alarm setting. The purpose of this check is to confirm that gas can get to the sensor(s) and that all the alarms are functional. This is typically dependent on the response time of the sensor(s) or a minimum level of response achieved, such as $80 \%$ of gas concentration applied. Note this check is not intended to provide a measure of calibration accuracy. 


\section{Captain Killed and Six Firefighters Injured at a Propane Explosion in an Office Building-Maine}

- Calibration Check - A quantitative test utilizing a known traceable concentration of test gas to demonstrate that the sensor(s) and alarms respond to the gas within manufacturer's acceptable limits. This is typically $\pm 10-20 \%$ of the test gas concentration applied unless otherwise specified by the manufacturer, internal company policy, or a regulatory agency.

- Full Calibration - The adjustment of the sensor(s) response to match the desired value compared to a known traceable concentration of test gas. This should be done in accordance with the manufacturer's instructions [ISEA 2010].

According to manufacturer's instructions, users should perform a bump test and calibration check every day before anyone uses the direct-reading portable multi-gas. The direct-reading portable multigas detector's manufacturer's guidelines - plus internal fire department procedures and OSHA regulatory requirements - determine exactly how and how often to fully calibrate direct-reading portable multi-gas detectors. Full calibration is also necessary if a bump test or calibration check fails. You can perform a full calibration twice, but after two "fails," the device must be pulled from use. Full calibrations should also take place after the following types of exposures:

- Different operator or working environment

- Extreme environmental, storage, and operating conditions

- Highly concentrated target gases and vapors

- Solvent vapors and corrosive gases

- Poisons and inhibitors [OSHA 2013].

When testing a device, use the following guidelines:

- Perform the calibration in fresh air

- Choose a test environment with conditions that match your workplace

- Use a recommended gas mixture, which should meet the National Institute of Standards and Technology

- Check the gas's expiration date

- Always refer to your product manual for specifics [OSHA 2014].

The atmosphere in which an instrument is used can have an effect on catalytic-bead sensors. Poisoning or degraded performance can occur when combustible sensors are exposed to certain substances. Commonly encountered substances that degrade LEL sensor performance include silicones, lead containing compounds (especially tetraethyl lead), sulfur containing compounds, substances containing phosphorus and halogenated hydrocarbons. Combustible sensors can also be affected by exposure to high concentrations of ignitable mixtures.

Age and usage can also affect the sensitivity of combustible sensors. Chronic exposure to low levels of poisons or inhibitors acts cumulatively. This usually means that the sensitivity must be increased when calibration occurs. In the extreme, the sensor may require replacement. This again demonstrates that regular calibration is essential to the safe use of combustible sensors.

For many combustible sensors, if sensitivity is lost due to poisoning, it tends to be lost first with regards to methane. This means that a partially poisoned sensor might still respond accurately to other combustible gases while showing a significantly reduced response to methane. This is a particularly 


\section{Captain Killed and Six Firefighters Injured at a Propane Explosion in an Office Building-Maine}

important concern for instruments used to monitor atmospheres associated with confined spaces, where methane is by far the most encountered combustible gas [AP1018 2013].

Employers should keep calibration records for the life of each instrument. This record enables operators to quickly identify a direct-reading portable gas monitor that has a history of excessive maintenance/repair, or is prone to erratic readings, and to track drift of the sensors to determine when they need replacement [OSHA 2013]. Even without an incident, testing and maintenance data can track other valuable information, and new technology makes recordkeeping easier and more valuable than ever. Digital tracking and remote monitoring are just some newer technologies that automatically track and allow the user to manage the department's bump tests and calibrations. Some direct-reading portable multi-gas detectors can even be paired with GPS devices so that Command always knows where firefighters are located. If firefighters have been exposed or if a man-down alarm indicates that a firefighter experienced a health emergency, Command knows exactly where to send help and what kind of help to send.

Recommendation \#8: Fire departments that respond to propane and natural gas emergencies should comply with the requirements of 29 CFR Part 1910.120, Hazardous Waste Operations and Emergency Response.

Discussion: Hazardous materials training and certification is completed through the Maine Emergency Management Agency, State Emergency Response Commission (SERC). The SERC supports training of first responders and emergency managers across the state. Training is coordinated regionally through the 16-county based local emergency planning committee. The SERC offers the following hazardous materials training, which complies with 29 CFR 1910.120, Hazardous Waste Operations and Emergency Response:

- First Responder Awareness Level

- Hazardous Materials Operations Level

- Hazardous Materials Technician Level

- Hazardous Materials Specialist

The necessary components of 29 CFR 1910.120, Hazardous Waste Operations and Emergency Response that need to be addressed include:

- Occupational Safety and Health Program. Each hazardous waste site mitigation and clean-up effort will require a site-specific occupational safety and health program headed by the site coordinator or the employer's representative. The purpose of the program will be the protection of employees at the site and will be an extension of the employer's overall safety and health program work. It will provide the overall means for planning and implementing the needed safety and health training and job orientation of employees who will be working at the site. The program will provide the means for identifying and controlling worksite hazards and for monitoring program effectiveness. The program will need to cover the responsibilities and authority of the site coordinator for the safety and health of employees at the site, and the relationships with contractors or support services as to what each employer's safety and health responsibilities are for their employees on the site [OSHA 1990]. 


\section{Captain Killed and Six Firefighters Injured at a Propane Explosion in an Office Building-Maine}

- Training. The training programs for employees to fulfill the requirements of paragraph (e) of this standard (included below) should address: the safety and health hazards employees should expect to find on hazardous waste clean-up sites; what control measures or techniques are effective for those hazards; what monitoring procedures are effective in characterizing exposure levels; what makes an effective employer's safety and health program; what a site safety and health plan should include; hands on training with personal protective equipment and clothing they may be expected to use; the contents of the OSHA standard relevant to the employee's duties and function; and employee's responsibilities under OSHA and other regulations. Supervisors will need training in their responsibilities under the safety and health program and its subject areas such as the spill containment program, the personal protective equipment program, the medical surveillance program, the emergency response plan, and other areas. ○ $1910.120(\mathrm{e})(3)$

Initial training. $1910.120(\mathrm{e})(3)(\mathrm{i})$

General site workers (such as equipment operators, general laborers, and supervisory personnel) engaged in hazardous substance removal or other activities which expose or potentially expose workers to hazardous substances and health hazards shall receive a minimum of 40 hours of instruction off the site, and a minimum of three days actual field experience under the direct supervision of a trained experienced supervisor.

- $1910.120(\mathrm{e})(3)(\mathrm{iii})$

Workers regularly on site who work in areas which have been monitored and fully characterized indicating that exposures are under permissible exposure limits and published exposure limits where respirators are not necessary, and the characterization indicates that there are no health hazards or the possibility of an emergency developing, shall receive a minimum of 24 hours of instruction off the site, and the minimum of one day actual field experience under the direct supervision of a trained, experienced supervisor.

- $1910.120(\mathrm{e})(3)(\mathrm{iv})$

Workers with 24 hours of training who are covered by paragraphs (e)(3)(ii) and (e)(3)(iii) of this section, and who become general site workers or who are required to wear respirators, shall have the additional 16 hours and two days of training necessary to total the training specified in paragraph (e)(3)(i).

- $1910.120(\mathrm{e})(7)$

Emergency response. Employees who are engaged in responding to hazardous emergency situations at hazardous waste clean-up sites that may expose them to hazardous substances shall be trained in how to respond to such expected emergencies.

○ $1910.120(\mathrm{e})(8)$

Refresher training. Employees specified in paragraph (e)(1) of this section, and managers and supervisors specified in paragraph (e)(4) of this section, shall receive eight hours of refresher training annually on the items specified in paragraph (e)(2) and/or (e)(4) of this section, any critique of incidents that have occurred in the past year that can serve as training examples of related work, and other relevant topics.

- 1910.120(e)(9)

Equivalent training. 


\title{
Captain Killed and Six Firefighters Injured at a Propane Explosion in an Office Building-Maine
}
Employers who can show by documentation or certification that an employee's work experience and/or training has resulted in training equivalent to that training required in paragraphs (e)(1) through (e)(4) of this section shall not be required to provide the initial training requirements of those paragraphs to such employees and shall provide a copy of the certification or documentation to the employee upon request. However, certified employees or employees with equivalent training new to a site shall receive appropriate, site specific training before site entry and have appropriate supervised field experience at the new site. Equivalent training includes any academic training or the training that existing employees might have already received from actual hazardous waste site experience [OSHA 1990].

\begin{abstract}
Note: National Fire Protection Association standards NFPA 472, Standard for Competence of Responders to Hazardous Materials/Weapons of Mass Destruction Incidents and NFPA 1072, Standard for Hazardous Materials/Weapons of Mass Destruction Emergency Response Personnel Professional Qualifications are excellent resource documents to aid fire departments and other emergency response organizations in developing their training program materials. NFPA 472 provides guidance on the skills and knowledge needed for first responder awareness level, first responder operations level, HAZMAT technicians, and HAZMAT specialist. It also offers guidance for the officer in charge of a hazardous material incident. NFPA 1072 identifies the job performance requirements for personnel at the scene of a hazardous materials/weapons of mass destruction incident, including the following levels: awareness, operations, operations specific, hazardous materials technician, and incident commander [NFPA 2018b, NFPA 2017b].
\end{abstract}

- Decontamination. Decontamination procedures should be tailored to the specific hazards of the site and will vary in complexity and number of steps, depending on the level of hazard and the employee's exposure to the hazard. Decontamination procedures and PPE decontamination methods will vary depending upon the specific substance, since one procedure or method will not work for all substances. Evaluation of decontamination methods and procedures should be performed, as necessary, to assure that employees are not exposed to hazards by reusing PPE. References in Appendix D may be used for guidance in establishing an effective decontamination program. In addition, the United States Coast Guard's Manual, Policy Guidance for Response to Hazardous Chemical Releases, United States Department of Transportation, Washington, DC (COMDTINST M16465.30) is a good reference for establishing an effective decontamination program [OSHA 1990].

- Emergency Response Plans. States, along with designated districts within the states, will be developing or have developed emergency response plans. These state and district plans should be utilized in the emergency response plans called for in the standard. Each employer should assure that its emergency response plan is compatible with the local plan. The major reference being used to aid in developing the state and local district plans is the Hazardous Materials Emergency Planning Guide, NRT - 1. The current Emergency Response Guidebook from the U.S. Department of Transportation, CMA's CHEMTREC and the Fire Service Emergency Management Handbook may also be used as resources. 


\section{Captain Killed and Six Firefighters Injured at a Propane Explosion in an Office Building-Maine}

Employers involved with treatment, storage, and disposal facilities for hazardous waste, which have the required contingency plan called for by their permit, would not need to duplicate the same planning elements. Those items of the emergency response plan may be substituted into the emergency response plan required in 1910.120 or otherwise kept together for employer and employee use [OSHA 1990].

- Monitoring. Frequency and types of air monitoring, personnel monitoring, and environmental sampling techniques and instrumentation to be used, including methods of maintenance and calibration of monitoring and sampling equipment to be used. Note: See Recommendation \#6 and Recommendation \#7.

Monitoring the air with appropriate direct reading test equipment for (i.e., combustible gas meters, detector tubes) for IDLH and other conditions that may cause death or serious harm (combustible or explosive atmospheres, oxygen deficiency, toxic substances.) Visually observing for signs of actual or potential IDLH or other dangerous conditions [OSHA 1990].

- Personal Protective Equipment Programs. The purpose of personal protective clothing and equipment (PPE) is to shield or isolate individuals from the chemical, physical, and biologic hazards that may be encountered at a hazardous substance site.

As discussed in Appendix B of 29 CFR 1910.120, no single combination of protective equipment and clothing can protect against all hazards. Thus, PPE should be used in conjunction with other protective methods and its effectiveness evaluated periodically. The use of PPE can itself create significant worker hazards, such as heat stress, physical and psychological stress, and impaired vision, mobility, and communication. For any given situation, equipment and clothing should be selected that provide an adequate level of protection. However, over-protection, as well as under-protection, can be hazardous and should be avoided where possible. Two basic objectives of any PPE program should be to protect the wearer from safety and health hazards, and to prevent injury to the wearer from incorrect use and/or malfunction of the PPE. To accomplish these goals, a comprehensive PPE program should include hazard identification, medical monitoring, environmental surveillance, selection, use, maintenance, and decontamination of PPE and its associated training.

The written PPE program should include policy statements, procedures, and guidelines. Copies should be made available to all employees, and a reference copy should be made available at the worksite. Technical data on equipment, maintenance manuals, relevant regulations, and other essential information should also be collected and maintained [OSHA 1990].

- Incident Command System (ICS). Paragraph 1910.120(q)(3)(ii) requires the implementation of an incident command system. The ICS is an organized approach to effectively control and manage operations at an emergency incident. ICS is implemented for emergency response to all incidents, both large and small, that involve hazardous materials.

The Incident Command System (ICS) is a management system designed to enable effective and efficient domestic incident management by integrating a combination of facilities, equipment, 


\section{Captain Killed and Six Firefighters Injured at a Propane Explosion in an Office Building-Maine}

personnel, procedures, and communications operating within a common organizational structure. ICS is normally structured to facilitate activities in five major functional areas: command, operations, planning, logistics, finance, and administration. It is a fundamental form of management, with the purpose of enabling incident managers to identify the key concerns associated with the incident - often under urgent conditions - without sacrificing attention to any component of the command system. Officers who may be expected to be in charge at an incident should be fully knowledgeable of their department's incident command system. They should know where and how to obtain additional assistance and be familiar with the local district's emergency response plan and the state emergency response plan [OSHA 1990].

Note: NFPA 1561, Standard on Emergency Services Incident Management System and Command Safety serves as an excellent resource on how to effectively command and control and emergency incident including a hazardous materials incident.

- Site Safety and Control Plans. The safety and security of response personnel and others operating at an emergency response incident site should be of primary concern to the incident commander. The use of a site safety and control plan could greatly assist those in charge of assuring the safety and health of employees on the site.

A comprehensive site safety and control plan [using the ICS Form 208 HM] ICS Form 208 HM, Site Safety and Control Plan (fema.gov) should include the following: summary analysis of hazards on the site and a risk analysis of those hazards; site map or sketch; site work zones (clean zone, transition or decontamination zone, work or hot zone); use of the buddy system; site communications; command post or command center; standard operating procedures and safe work practices; medical assistance and triage area; hazard monitoring plan (air contaminate monitoring, etc.); decontamination procedures and area; and other relevant areas. This plan should be a part of the employer's emergency response plan or an extension of it to the specific site [OSHA 1990].

- Medical surveillance programs. Workers handling hazardous substances may be exposed to toxic chemicals, safety hazards, biologic hazards, and radiation. Therefore, a medical surveillance program is essential to assess and monitor workers' health and fitness for employment in hazardous waste operations and during the course of work; to provide emergency and other treatment as needed; and to keep accurate records for future reference. The medical surveillance program shall be instituted by the employer for the following employees:

- All employees who are or may be exposed to hazardous substances or health hazards at or above the established permissible exposure limit, above the published exposure levels for these substances, without regard to the use of respirators, for 30 days or more a year.

- All employees who wear a respirator for 30 days or more a year or as required by 29 CFR 1910.134.

- All employees who are injured, become ill or develop signs or symptoms due to possible overexposure involving hazardous substances or health hazards from an emergency response or hazardous waste operation and members of HAZMAT teams. 


\section{Captain Killed and Six Firefighters Injured at a Propane Explosion in an Office Building-Maine}

- Medical examinations and consultations shall be made available by the employer to each employee prior to assignment and at least once every twelve months for each employee covered unless the attending physician believes a longer interval (not greater than biennially) is appropriate [OSHA 1990].

Note: This should include a health maintenance program which meets the requirements of NFPA 1582, Standard on Comprehensive Occupational Medical Program for Fire Departments.

- Recordkeeping. Training providers should maintain records listing the dates courses were presented, the names of the individual course attendees, the names of those students successfully completing each course, and the number of training certificates issued to each successful student. These records should be maintained for a minimum of five years after the date an individual participated in a training program offered by the training provider. These records should be available and provided upon the student's request or as mandated by law [OSHA 1990].

\section{Recommendation \#9: Fire departments should use a personnel accountability system requiring a check-in and check-out procedure with a designated accountability officer or the incident commander.}

Discussion: Note: Although there is no evidence that the following recommendation would have prevented this fatality, it is being provided as a reminder of a critical firefighter safety component to be to be utilized during incident operations. At this incident, arriving first responders were tasked with locate and accounting the initial responding firefighters and office employees. This process took approximately 30 minutes to complete. There was an influx of first responders and citizens that were not accounted for initially until the deputy chief arrived on-scene and established a designated accountability officer.

A personnel accountability system is a system that readily identifies both the location and function of all members operating at an incident scene [NFPA 2021]. The philosophy of the personnel accountability system starts with the same principles of an incident management system-company unity and unity of command. Unity can be fulfilled initially and maintained throughout the incident by documenting the situation status and resource status on a tactical worksheet.

An integral part of the accountability system is to make sure that the firefighters assigned and operating in the hazard zone are accounted for, starting with the initial operations through the entire incident. Also, a process should be in place to periodically make sure that all members operating in the hazard zone are accounted for by this system.

NFPA 1561, Standard on Emergency Services Incident Management System and Command Safety, states in Paragraph 8.12.4, "The incident commander and members who are assigned a supervisory responsibility that involves three or more companies or crews under their command shall have an additional member(s) (e.g., staff aide) assigned to facilitate the tracking and accountability of the assigned companies or crews" [NFPA 2020b]. 


\section{Captain Killed and Six Firefighters Injured at a Propane Explosion in an Office Building-Maine}

A functional personnel accountability system requires the following:

- Development and implementation of a departmental standard operating procedure/standard operating guideline

- Necessary components and hardware, such as an accountability board, individual name tags, and company name tags

- Training for all members on the operation of the system

- Strict enforcement during emergency incidents.

A functional personnel accountability system should be able to identify:

- all members operating in the hazard zone (who)

- the location of all members in the hazard zone (where)

- the conditions in the hazard zone (conditions)

- the actions being taken in the hazard zone (actions)

- the paths of access and egress in and out of the hazard zone (exits)

- and assign rapid intervention crew(s) (RIC).

There are many different methods and tools for resource accountability. Some examples are:

- Tactical worksheets

- Command boards

- Apparatus riding lists

- Company responding boards

- Electronic bar-coding systems

- Accountability tags or keys (e.g., PASSPORT System) [NFPA 2020b].

Resource accountability should be assigned to personnel who are responsible for maintaining the location and status of all assigned resources at an incident. As the incident escalates, resource status would be placed under the Planning Section. This function is separate from the role of the incident commander who is responsible for the overall command and control of the incident. Due to the importance of responder safety, resource status should be assigned to a dedicated member as the size and complexity of the incident dictates. Several positions could function in this role including an incident command technician, staff assistant, chief officer, or other designated member. As the incident escalates and tactical-level management components (e.g., divisions or groups) are assigned, the resource status officer (accountability officer) works with the division or group supervisors to maintain an on-going tracking and accountability of members [FIRESCOPE 2015]. A properly initiated and enforced personnel accountability system enhances firefighter safety and survival.

An important aspect of a personnel accountability system is the personnel accountability report, an onscene roll call in which each supervisor reports the status of their crew when requested by the incident commander [NFPA 2020b]. The personal accountability report should be conducted every 15-20 minutes or when benchmarks are met.

For the personnel accountability system to properly function, the process should include a SOP/SOG that defines each function's responsibility and the necessary hardware required to ensure this process is 


\section{Captain Killed and Six Firefighters Injured at a Propane Explosion in an Office Building-Maine}

successful on the fireground. Also, a training component, including both classroom and practical, should be conducted to ensure this process functions properly during emergency incidents.

\section{Recommendation \#10: Fire departments should develop and implement a SOP/SOG on the use and deployment of rapid intervention crews.}

Discussion: Note: Although there is no evidence that the following recommendation would have prevented this fatality, it is being provided as a reminder of a critical firefighter safety component to be to be utilized during incident operations. In order to ensure compliance with 29 CFR 1910.134 Respiratory Protection [OSHA 1998], fire departments must maintain a rapid intervention crew (RIC) or company when members are operating in an IDLH or potentially IDLH atmosphere [NFPA 2018]. In some organizations, they can be known as a rapid intervention team or firefighter assist and search team (FAST).

The RIC function should be incorporated into the department's incident management system and the personnel accountability system [NFPA 2020a]. The needs of critical fireground operations and staffing should be continuously evaluated regarding firefighter safety. Resource assignments should always be made with the goal of having the RIC function in place. When the incident commander needs additional resources, the consideration of deploying the RIC for an operational assignment without additional resources on-scene to function as the RIC should be carefully assessed [NFPA 2020a].

The following restrictions regarding the use of RIC/FAST should be considered by the incident commander during fireground operations:

- The RIC should not be used for firefighting operations

- The RIC is dedicated to assist and, if necessary, rescue members who become lost, trapped, distressed, or involved in other serious life-threatening situations

- The RIC should not be used to provide relief for operating companies until the fire/incident has been declared "under control" by Command

- If assigned by a superior officer to other than RIC duties, the RIC unit officer should remind such officer of RIC designation [Toledo Fire \& Rescue Department 2012; TSFRS 2014].

When incident commanders order the RIC to work, the incident commander should immediately assign another on-scene company to stand by as the RIC. At a minimum, the incident commander should request an additional alarm and designate a company or companies to function as RIC. The remainder of the companies should report to staging. If no units are available, the incident commander should assign at least two members to act as a rapid intervention team while awaiting a special-called RIC to arrive. An engine company may be designated as the RIC pending arrival of an additional ladder company or rescue company. This ensures compliance with OSHA's "2 In/2 Out” rule under 29 CFR 1910.134, Respiratory Protection [OSHA 1998].

Many fire departments have a defined response plan for the dispatch of an additional company (engine, truck, squad, rescue, and/or command officer) to respond to an incident and stand by as the RIC. Based upon the complexity, magnitude, configuration of the structure or geographical layout of the incident, 


\section{Captain Killed and Six Firefighters Injured at a Propane Explosion in an Office Building-Maine}

the incident commander may deploy additional RIC/Firefighter Assist and Search Team (FAST) by location or function [NFPA 2020a].

Upon arrival or upon appointment, the RIC officer should confer with the incident commander. The RIC officer should establish an area to stage the rapid intervention team and the necessary RIC equipment. The RIC equipment should include:

- Tool staging tarp

- Rescue SCBA (RIC Pack)

- Forcible entry tools such as a Halligan bar or other pry tool

- Stokes basket

- 150-foot rope for search and rescue

- Wire cutters

- Rebar cutter

- Saws

- Thermal imager

- Emergency strobe lights

- Life-saving rope/life belt

- Elevator keys for buildings with elevators [FDNY 2011; LAFD 2001; TSFRS 2014].

It is important to stage all necessary RIC equipment in an expedient manner. The RIC officer, accompanied by one member of the RIC/FAST, should perform an incident scene survey while the remaining RIC members assemble the RIC equipment. If the size of the structure does not allow for a 360-degree survey of the building, this fact should be relayed to the incident commander as soon as possible. This should be a benchmark for Command to designate another RIC/FAST to effectively cover all sides of the building.

During this survey, the RIC officer and members should look for ways in and out of the structure, including window configuration, fire escapes, and construction features. The RIC officer should note the feasibility for placement of ground ladders for rescue or escape purposes. The RIC officer should be responsible for setting up and securing a suitable secondary egress for interior crews. This may include laddering multiple sides of the structure. Once the RIC has determined the need for an egress ladder, the window glass should be removed. This should only be done after conferring with Command that the removal of the window will not affect firefighting operations. Once approved by Command, the egress ladder should be placed at the window. The location of the egress ladder(s) should be announced over the radio by the RIC officer [Toledo Fire \& Rescue Department 2012]. After the above tasks are completed, the RIC officer should inform Command that a 360-degree survey is complete and the RIC is ready to intervene, if necessary. Once the incident scene survey has been completed and the RIC equipment is in place, the entire RIC should be in an area immediately accessible to the building for rapid deployment plus maintaining radio contact with Command. The RIC officer should brief all members of the RIC as to the results of his/her incident scene survey. The RIC should operate as one unit. Additional crews may be added to or in support of the team as necessary. When more than one company is added as part of the rapid intervention team, a rescue group should be formed with a rescue group supervisor [Toledo Fire \& Rescue Department 2012]. Another consideration for Command is to request the response of an advanced life support (ALS) 


\section{Captain Killed and Six Firefighters Injured at a Propane Explosion in an Office Building-Maine}

engine company or truck company as a component of the RIC Group. The members of the advance life support company are trained to operate in an IDLH atmosphere and can function as part of the RIC, plus they can provide advanced life support to affected firefighters [FDNY 2011].

The RIC officer and RIC members will coordinate with Command to formulate rescue plan contingencies and continue to monitor the radio and fireground conditions. RIC protection is not a passive assignment. This is a process of ongoing information gathering and diligent scene monitoring until the unit is released by the incident commander. The RIC function is a critical component for firefighter safety.

To ensure that firefighters and fire officers are properly trained to conduct RIC operations, they should meet the requirements of NFPA 1407, Standard for Training Fire Service Rapid Intervention Crews [NFPA 2020a]. NFPA 1407 provides rapid intervention techniques and maneuvers pus necessitates a vast knowledge of tools and equipment and their applications. A well-trained and well-equipped RIC with just the basics in equipment is a safety net at structural fires, but the crew must be knowledgeable in technical rescue skills as well. The training programs should cover risk assessment, deployment, and activation of RICs, radio communications procedures, the integration of firefighter Maydays and their rescues into departmental incident management system, and full and operable personnel accountability system. [NFPA 2020a].

Recommendation \#11: Fire departments should ensure that their radio communication system can provide adequate coverage based on the demands of an incident and complies with NFPA 1561, Standard on Emergency Services Incident Management System and Command Safety and NFPA 1221, Standard for the Installation, Maintenance, and Use of Emergency Services Communications Systems.

Discussion: Note: Although there is no evidence that the following recommendation would have prevented this fatality, it is being provided as a reminder of effective radio communication operations. At this incident, the county dispatch dispatched on the VHF frequency. The county is divided into County Fire North and County Fire South dispatch frequencies. The state fire channel is used for a tactical channel for working incidents. The state fire channel is a non-repeater channel and is not recorded.

NFPA 1221, Standard for the Installation, Maintenance, and Use of Emergency Services Communications Systems, supports the National Incident Management System (NIMS) requirements for interoperability; reliability, scalability, and portability; and resilience and redundancy among communications systems. The standard establishes a benchmark for communication equipment installation, maintenance, and testing/use, which are critical to ensure that communications remain in place for emergency management/response personnel and to mitigate the chance of disruptions during an incident. NFPA 1221 supports the components of an interoperability plan by requiring that emergency services organizations develop policies and SOPs/SOGs for use of communications equipment. The standard ensures that communications equipment is properly functioning. Practicing preventive maintenance, as called for in the standard, helps emergency management/response organizations avoid high replacement costs for communications equipment [NFPA 2019]. 


\section{Captain Killed and Six Firefighters Injured at a Propane Explosion in an Office Building-Maine}

Effective fireground radio communication is an important tool to ensure proper command and control of an incident plus firefighter safety and health. The radio system must be dependable, consistent, and functional to ensure that effective communications are maintained, especially during emergency incidents. Fire departments should have a Communications SOP/SOG that outlines the communication procedures for fireground operations. Fire departments should ensure that the department's communications division and communication center and/dispatch center are part of this process. Another important aspect of this process is an effective education and training program for all members of the department.

Radio frequency usually refers to the radio frequency of the assigned channel. A radio channel is defined as the width of the channel depending on the type of transmissions and the tolerance for the frequency of emission. A radio channel is normally allocated for radio transmission in a specified type of service or by a specified transmitter. Fire departments should ensure that an adequate number of radio channels are available. Multiple radio channels are necessary at large-scale or complex incidents, such as a commercial structure fire, mass-casualty incident, hazardous materials incident, or special operations incident [FIRESCOPE 2017; NFPA 2020b].

NFPA 1561 Standard on Emergency Services Incident Management System and Command Safety, Paragraph 6.1.2, requires, "The communications system shall have the capacity to provide one dispatch radio channel and a separate tactical radio channel for initial use at the incident." Paragraph 6.1.3 states, "When a division or group has been implemented, the communications system shall have the capacity to provide a dispatch radio channel, a command radio channel, and a tactical radio channel." Fire departments should preplan for not only large-scale or complex incidents, but also for the ability to handle daily operations. SOPs/SOGs, radio equipment (e.g., mobile radios, portable radios), other hardware (e.g., mobile data terminals, laptop computers, CAD system), and dispatch and communications protocols should be in place to ensure that these additional channels are available when needed [NFPA 2020b].

Every firefighter and company officer should take responsibility to ensure radios are properly used. Firefighters must have their portable radio and have the portable radio turned on and on the correct channel. A company officer must ensure that all members of the crew comply with these requirements. Portable radios should be designed and positioned to allow a firefighter to monitor and transmit a clear message [IAFF 2010;].

A fire department should provide the necessary number of radio channels relating to complex or largescale incidents needing multiple tactical channels. NFPA 1561 Standard on Emergency Services Incident Management System and Command Safety states in Paragraph 6.1.4, "The communications system shall provide reserve capacity for complex or multiple incidents." This would require fire departments to preplan radio channel usage for all incident levels based upon the needs of an emergency incident including large-scale or complex incidents [NFPA 2020b].

When a fire department responds to an incident, incident commanders should forecast for the incident to determine if there is potential for it being a complex or long-term operation that may require additional resources, including demands on the communications system. As incidents increase in size, 


\section{Captain Killed and Six Firefighters Injured at a Propane Explosion in an Office Building-Maine}

the communication system must keep up with the demands of the incident. The incident commander must be able to communicate with company officers and division/group supervisors [FIRESCOPE 2015]. Before communications become an issue, the incident commander must consider options for alleviating excessive radio traffic. Several options are:

- Assign non-fireground resources (e.g., Staging, Rehab) to a separate tactical channel or talkgroup channel

- Designate a command channel, which is a radio channel designated by the fire department to provide for communications between the incident commander and the division/group supervisors or branch directors during an emergency incident

- For incidents involving large geographical areas, designate a tactical channel or talk-group for each division [NFPA 2020b].

NFPA 1561, Paragraph 6.2.2 states, "Clear text/plain language shall be used for radio communications." The intent of the use of clear text/plain language for radio communications is to reduce confusion at incidents, particularly where different agencies work together [NFPA 2020b].

Recommendation \#12: States should ensure anyone (including homeowners) using power tools or other digging equipment that will penetrate the ground call "811 or 811 Dig Safe" three business days (72 hours) prior to digging to identify if any buried utilities are present and mark their location(s).

Discussion: Prior to this incident, four bollards were installed at the office building on September 10, 2019, on Side Bravo in the parking lot to protect the heat pumps next to the building. The contractor that installed the bollards did not contact "811 Dig Safe" prior to digging the holes for the bollards.

811 is the national call-before-you-dig phone number. Anyone who plans to dig should call 811 or go to their state 811 center's website at least three business days before digging to request that the approximate location of buried utilities be marked with paint or flags to avoid unintentionally digging into an underground utility line [CGA 2021]. Hitting a buried line while digging can disrupt utility service, cost money to repair, and cause serious injury or death.

"811 DigSafe" operates in the states of Maine, Vermont, Rhode Island, New Hampshire, and the Commonwealth of Massachusetts. The Public Utilities Commission is the agency that oversees the "811 DigSafe" program in Maine. Utility locators will show the approximate horizontal location in advance of any type of digging or excavation by locating and marking underground facilities. This information helps anyone digging or excavating around underground facilities stay safe. Maine state code clearly provides for marking for all underground utilities. Communications with "811 DigSafe" is necessary to provide the mapping of underground utilities to prevent accidents from occurring [811 Dig safe 2020].

"811 DigSafe" offers an Excavator Manual, A Guide to Safe Excavation Practices in Massachusetts, Maine, New Hampshire, Rhode Island, and Vermont. [DigSafe 2020] The purpose of this document is to provide anyone who is going to conduct any type of excavation with a basic understanding of the 


\section{Captain Killed and Six Firefighters Injured at a Propane Explosion in an Office Building-Maine}

responsibilities of each state concerning safe excavation practices and the protection of underground facilities.

Recommendation \#13: Local and state enforcement agencies should ensure that a leak test of the piping system is conducted in accordance with the requirements of NFPA 54, National Fuel Gas Code, and NFPA 58, Liquefied Petroleum Gas Code, whenever propane service is initiated or restored.

Discussion: At this incident, when the propane tank was refilled and returned to service, a leak test of the piping system was never performed, which was required by NFPA 54, National Fuel Gas Code and NFPA 58, Liquefied Petroleum Gas Code.

NFPA 54, National Fuel Gas Code, covers the appliances and piping downstream of the second-stage regulator, while NFPA 58, Liquefied Petroleum Gas Code, covers the propane tank and piping up to the second-stage regulator. Both codes require that the piping system shall be checked for leakage immediately after the gas is turned on into a new system or into a system that has been initially restored after an interruption of service. [NFPA 2018a; NFPA 2017a].

When there is propane in a tank, there is constant pressure in the system. When the amount of fuel goes down, so does the pressure. Loss of pressure can cause leaks because of the expansion and retraction of the piping compound in the propane system. Whenever there is an interruption in service, such as running out of propane, a leak test will reveal any leaks in the piping. A leak test reveals any leaks that may have formed during the shutdown period.

Leak testing should be performed by a certified technician.

NFPA 54, Annex C, and NFPA 58, Annex L, suggest methods for checking for leaks [NFPA 2018a, NFPA 2017a].

NFPA 54, Annex D, provides guidelines for emergency procedures where an investigation discloses a concentration of gas inside a building [NFPA 2018a].

\section{References}

Airgas [2018]. Safety Data Sheet: Propane. Radnor, PA: Airgas Inc.

AP 1018 [2013]. AP 1018: Understanding catalytic LEL combustible gas sensor performance. GfG Instrumentation, Ann Arbor, MI.

Blue Card [2018]. Blue card command sops. Phoenix, AZ: BShifter.

Brunacini AV [2002]. Fire command. Quincy, MA: National Fire Protection Association.

Brunacini AV, Brunacini N [2004]. Command safety. Phoenix, AZ: Across the Street Publications. 


\section{Captain Killed and Six Firefighters Injured at a Propane Explosion in an Office Building-Maine}

CGA [2021]. Call 811. Common Ground Alliance.

CPSC [1992]. United States Consumer Product Safety Commission, Characterization of LP Gas Odorant Fade - Part 1 (CPSC C-86-1281). Washington, DC: Consumer Product Safety Commission.

CPSC [1992]. United States Consumer Product Safety Commission, Characterization of LP Gas Odorant Fade - Part 2 (CPSC C-86-1281). Washington, DC: Consumer Product Safety Commission.

De Lisi S [2010]. Hazmat Survival Tips: Interpreting Readings from Atmospheric Monitors. Fire Engineering, August 26, 2010.

Dig Safe [2020]. Dig Safe. Wilmington, MA: Dig Safe System, Inc.

Federal Register [2013]. Safety Alert: Risks Associated with Liquid Petroleum (LP) Gas Odor Fade, Pipeline and Hazardous Materials Safety Administration (PHMSA), Department of Transportation, July 12, 2013, Washington, DC.

FDNY [2011]. Fire Department of New York Firefighter Assist and Search Team - FAST Unit, Chapter 2, Managing Members in Distress, New York, NY: Fire Department of New York.

FRDNV [2014]. Utility Emergencies. 2nd ed. Fairfax County, VA: Fire and Rescue Departments of Northern Virginia.

FIRESCOPE [2015]. Incident command system for structure fire operations, ICS 500. Riverside, CA; FIRESCOPE.

FIRESCOPE [2017]. Field Operations Guide (FOG), ICS 420-1. Riverside, CA; FIRESCOPE.

IAFF [2010]. IAFF Fire Ground Survival Training Program. Washington, DC: International Association of Firefighters.

IFSTA [2017]. Hazardous Materials Technician, Oklahoma State University, $2^{\text {nd }}$ edition. International Fire Service Training Association.

ISEA [2010]. ISEA Statement on Validation of Operation for Direct Reading Portable Gas Monitors. Arlington, VA: International Safety Equipment Association.

LAFD [2001]. Rapid intervention company, fireground safety, and incident accountability. Los Angeles, CA: Los Angeles Fire Department.

MUBEC [2015]. Maine Uniform Building and Energy Code. Augusta, ME: Office of the State Fire Marshal. 


\section{Captain Killed and Six Firefighters Injured at a Propane Explosion in an Office Building-Maine}

[NFPA 2017a] NFPA 58, Liquefied petroleum gas code, Quincy, MA: National Fire Protection Association.

NFPA [2017b]. NFPA 1072, Standard for hazardous materials/weapons of mass destruction emergency response personnel professional qualifications. Quincy, MA: National Fire Protection Association.

NFPA [2018a]. NFPA 54, National fuel gas code. Quincy, MA: National Fire Protection Association.

NFPA [2018b]. NFPA 472, Standard for competence of responders to hazardous materials/weapons of mass destruction incidents. Quincy, MA: National Fire Protection Association.

NFPA [2019]. NFPA 1221, Standard for the installation, maintenance, and use of emergency services communications systems. Quincy, MA: National Fire Protection Association.

NFPA [2020a]. NFPA 1407, Standard for training fire service rapid intervention crews. Quincy, MA: National Fire Protection Association.

NFPA [2020b]. NFPA 1561, Standard on emergency services incident management system and command safety. Quincy, MA: National Fire Protection Association.

NFPA [2021]. NFPA 1500, Standard on fire department occupational safety, health, and wellness program. Quincy, MA: National Fire Protection Association.

NFD [2007]. Norwich, VT Fire Department Standard Operating Procedures. Norwich, VT: Norwich, VT Fire Department.

NIOSH [2021]. NIOSH Safety Advisory, Odor Fade in Natural Gas and Propane, Morgantown, WV: U.S. Department of Health and Human Services, Centers for Disease Control and Prevention, National Institute for Occupational Safety and Health, Publication No. 2021-106.

OSHA [1990]. Occupational Safety and Health Administration, 1910.120, Hazardous waste operations and emergency response. Washington, DC: United States Department of Labor.

OSHA [1993]. Occupational Safety and Health Administration, 1910.146, Permit-required confined spaces. Washington, DC: United States Department of Labor.

OSHA [2013]. Occupational Safety and Health, Safety and Health Bulletin, Calibrating and Testing Direct-Reading Portable Gas Monitors. Washington DC: United States Department of Labor.

PHMSA [2016]. Emergency Response Guidebook. Washington, DC:_Department of Transportation, Pipeline and Hazardous Materials Administration. 


\section{Captain Killed and Six Firefighters Injured at a Propane Explosion in an Office Building-Maine}

Roberson E [2001]. Principles of Odorization in Proceedings, American School of Gas Measurement Technology, Pages 136 - 138. Baytown, TX: Natural Gas Odorizing, Inc.

The Weather Underground [2019]. The Weather Underground.

Toledo Fire \& Rescue Department [2012]. Rapid intervention team (RIT) standard operating procedure C82. Toledo, OH: Toledo Fire \& Rescue Department.

TSFRS [2014]. Rapid intervention team, interim procedure 2014-003. Township of Spring, PA: Township of Spring Fire \& Rescue.

VBFD [2019a]. Virginia Beach Fire Department, SOP HM5.22.0, Monitoring of Atmospheric Conditions. April 2019. Virginia Beach, VA: Virginia Beach Fire Department.

VBFD [2019b]. Virginia Beach Fire Department, SOP HM5.22.1, Appendix A - Atmospheric Monitoring of Investigation Checklist. April 2019. Virginia Beach, VA: Virginia Beach Fire Department.

VBFD [2019c]. Virginia Beach Fire Department, SOP HM5.23.0, Initial Response to Unknowns, Virginia Beach VA; Virginia Beach Fire Department.

\section{Investigator Information}

This incident was investigated by Murrey E. Loflin, Investigator; Stephen T. Miles, Safety and Occupational Health Specialist; and Jeffery Funke, Lead Occupational Health Manager with the NIOSH Fire Fighter Fatality Investigation and Prevention Program, Surveillance and Field Investigations Branch, Division of Safety Research located in Morgantown, WV. An expert technical review was provided by Master Fire Fighter Mark Hundley, Hazardous Materials Specialist with the Virginia Beach Fire Department and Captain Kevin Okonski, Hazardous Material Technician with the Houston Fire Department. A technical review was also provided by the National Fire Protection Association, Public Fire Protection Division.

\section{Disclaimer}

Mention of any company or product does not constitute endorsement by the National Institute for Occupational Safety and Health, Centers for Disease Control and Prevention. In addition, citations to websites external to NIOSH do not constitute NIOSH endorsement of the sponsoring organizations or their programs or products. Furthermore, NIOSH is not responsible for the content of these websites. All web addresses referenced in this document were accessible as of the publication date. 


\section{Captain Killed and Six Firefighters Injured at a Propane Explosion in an Office Building-Maine}

\section{Appendix One \\ Site Safety and Control Plan \\ ICS 208 HM}

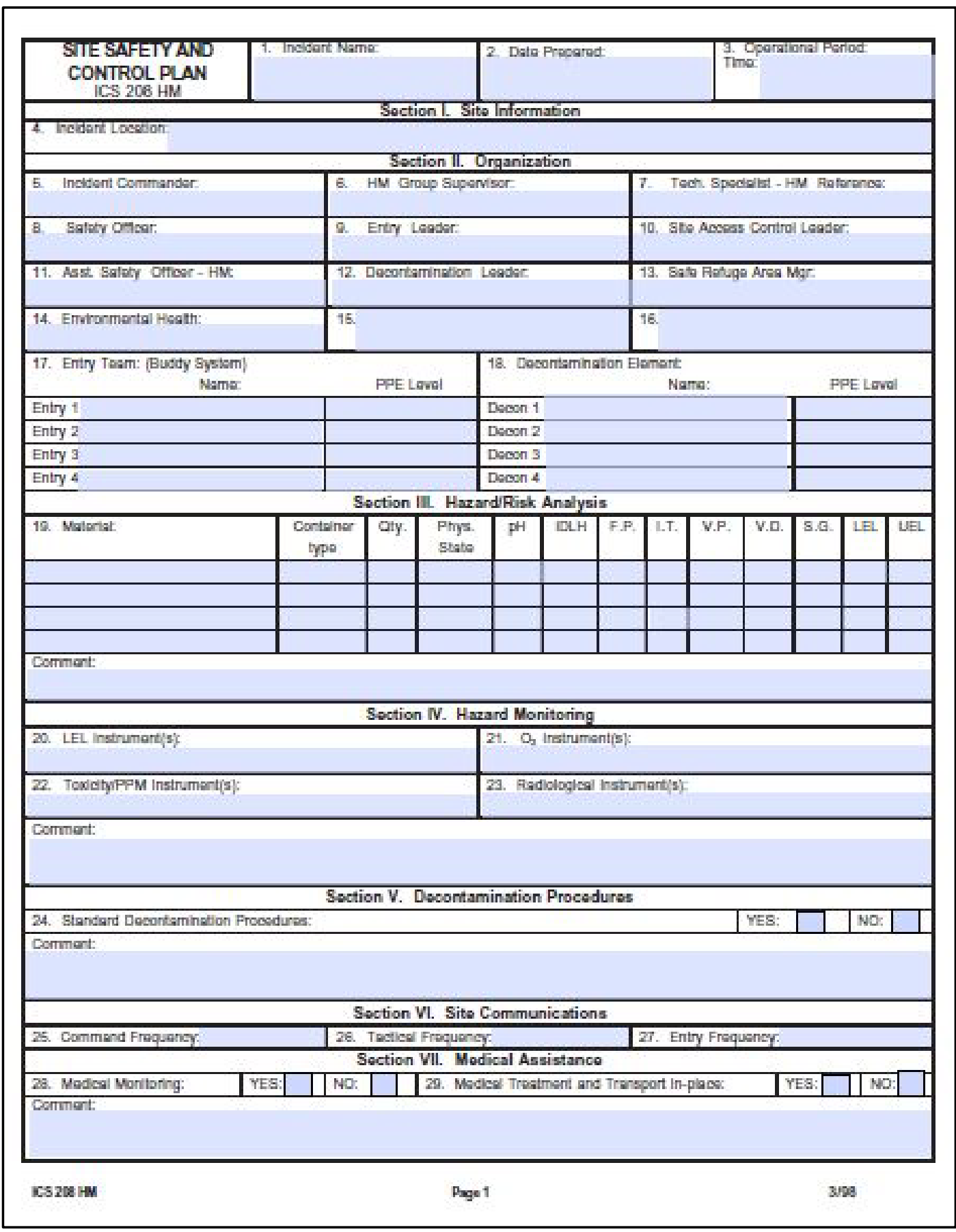


Captain Killed and Six Firefighters Injured at a Propane Explosion in an Office Building-Maine

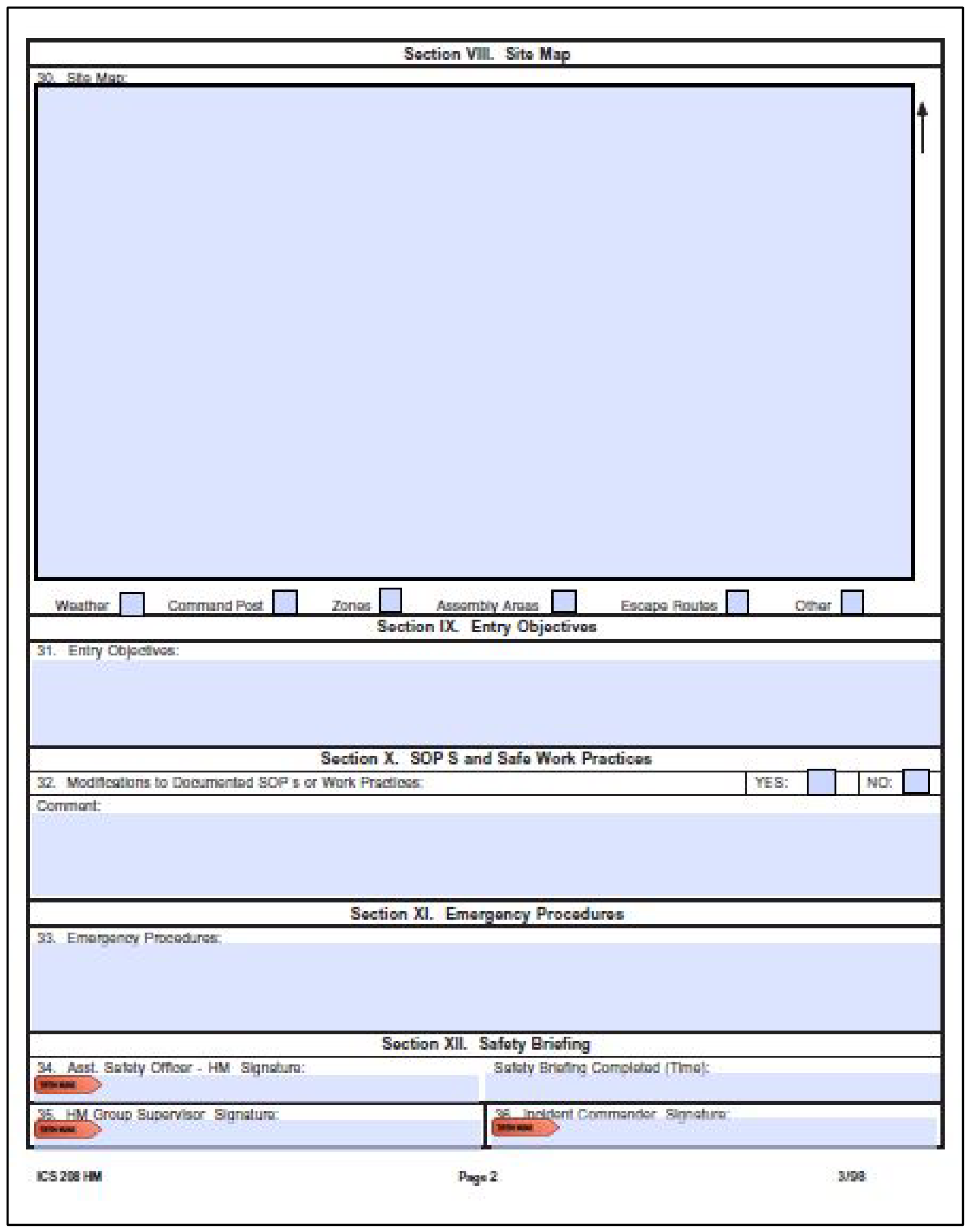




\section{Captain Killed and Six Firefighters Injured at a Propane Explosion in an Office Building-Maine}

\begin{tabular}{|c|c|c|}
\hline \multicolumn{3}{|c|}{$\begin{array}{l}\text { INSTRUCTIONS FOR COMPLETING THE SITE SAFETY AND CONTROL PLAN } \\
\text { ICS } 208 \mathrm{HM}\end{array}$} \\
\hline Tiem Number & Thern Tinte & Instructions \\
\hline 1. & Incident Namo/Number & Print name and/or incident number. \\
\hline 2. & Date and Time & Enter date and time propared. \\
\hline 3. & Operational Period & Enter the time interval for which the form applies. \\
\hline 4. & Incident Location & Enter the address and or map coordinates of the incident. \\
\hline $5-16$. & Organization & $\begin{array}{l}\text { Enter names of all individuals assigned to ICS positions. (Entrios } 58 \\
8 \text { mandatory). Use Boxes } 15 \text { and } 16 \text { for other functions: i.e. Medical } \\
\text { Monitoring. }\end{array}$ \\
\hline $17-18$. & $\begin{array}{l}\text { Entry ToamDecon } \\
\text { Elomont }\end{array}$ & $\begin{array}{l}\text { Enter names and lovel of PPE of Entry \&. Decon porsonnel. (Entries } 1 \\
-4 \text { mandatory buddy system and back-up.) }\end{array}$ \\
\hline 19. & Material & $\begin{array}{l}\text { Enter names and pertinent information of all known chemical } \\
\text { products. Enter UNK if material is not known. Include any which } \\
\text { apply to chemical propertios. (Definitions: ph = Potential for Hydrogen } \\
\text { (Coorrosivity), IDLH = Immediately Dangerous to Lifo and Health, } \\
\text { F.P. = Flash'Point, I.T. = Ignition Tomperature, V.P. = Vapor Prossure, } \\
\text { V.D. = Vapor Density, S.G. = Specific Gravity, LEL = Lower Explosive } \\
\text { Limit, UEL = Upper Explosive Limit) }\end{array}$ \\
\hline $20-23$ & Hazard Monitoring & List the instruments which will be used to monitor for chemical. \\
\hline 24. & $\begin{array}{l}\text { Decontamination } \\
\text { Procedures }\end{array}$ & $\begin{array}{l}\text { Check NO if modifications are made to standard docontamination } \\
\text { procedures and make appropriate Comments including type of } \\
\text { solutions. }\end{array}$ \\
\hline $25-27$ & Site Communications & Enter the radio frequency(ies) which apply. \\
\hline $28-29$. & Modical Assistanco & Enter comments if NO is checkod. \\
\hline 30. & Sito Map & $\begin{array}{l}\text { Sketch or attach a site map which defines all locations and layouts of } \\
\text { operational zones. (Check boxes are mandatory to be identified.) }\end{array}$ \\
\hline 31. & Entry Objectives & $\begin{array}{l}\text { List all objectives to be performed by the Entry Team in the } \\
\text { Exclusion Zone and any parameters which will alter or stop entry } \\
\text { operations. }\end{array}$ \\
\hline $32-33$ & $\begin{array}{l}\text { SOP s, Safo Work } \\
\text { Practices, and } \\
\text { Emergency } \\
\text { Procedures }\end{array}$ & $\begin{array}{l}\text { List in Comments if any modifications to SOP s and any omorgency } \\
\text { procodures which will bo affected if an emergency occurs while } \\
\text { personnel are within the Exclusion Zone. }\end{array}$ \\
\hline $34-36$ & Safoty Briefing & $\begin{array}{l}\text { Have the appropriate individual ploce their signature in the box once } \\
\text { the Site Safety and Control Plan is roviewed. } \\
\text { Note the time in box } 34 \text { when the safoty briefing has been completed. }\end{array}$ \\
\hline ICs2De HM & & Page 3 \\
\hline
\end{tabular}




\title{
Captain Killed and Six Firefighters Injured at a Propane Explosion in an Office Building-Maine
}

\author{
Appendix Two \\ Example Safety Data Sheet - Propane
}

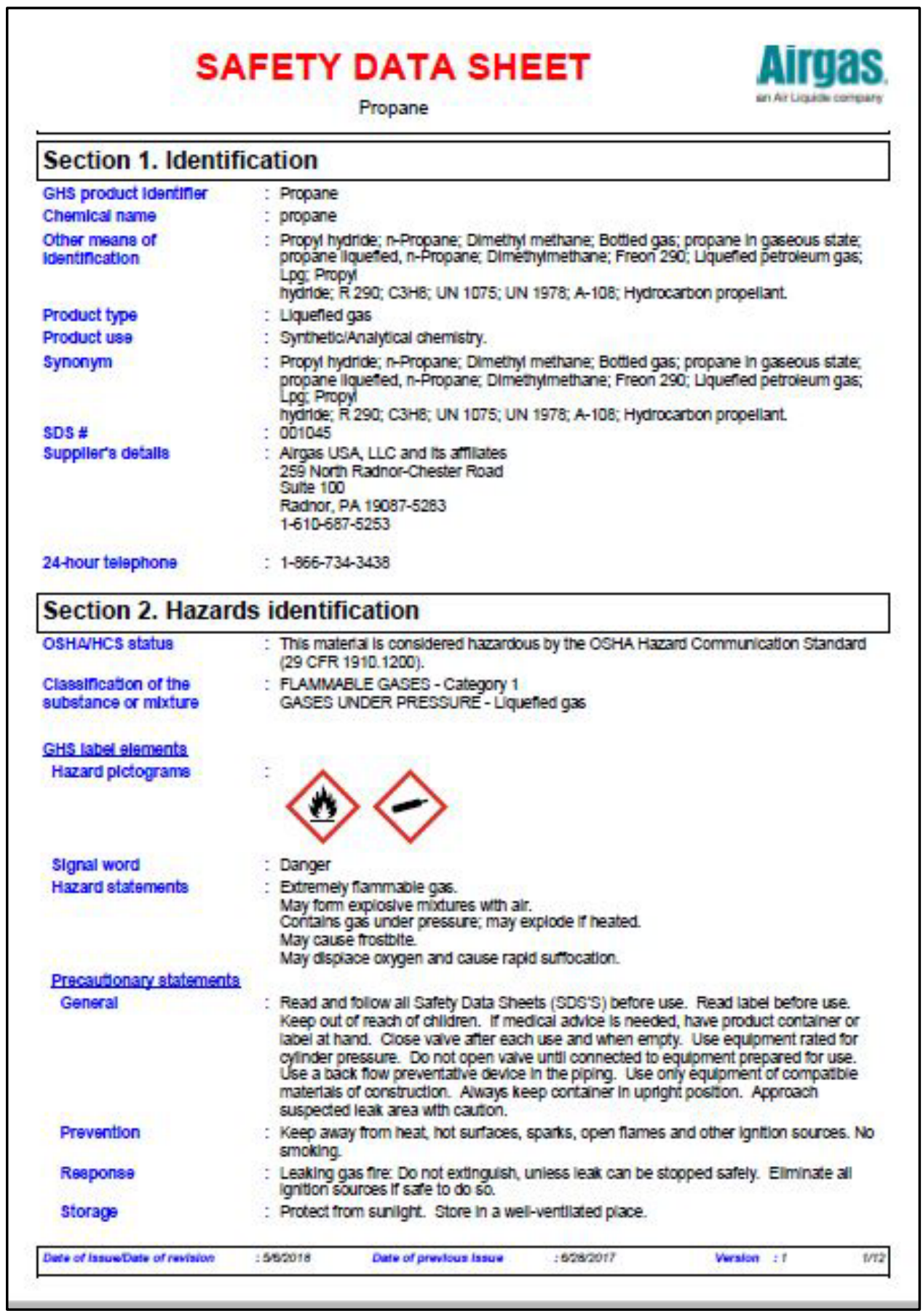




\section{Captain Killed and Six Firefighters Injured at a Propane Explosion in an Office Building-Maine}

\begin{tabular}{|c|c|c|}
\hline \multicolumn{3}{|l|}{ Properes } \\
\hline \multicolumn{3}{|c|}{ Section 2. Hazards identification } \\
\hline Dlsposal & \multicolumn{2}{|l|}{ Not applicabie. } \\
\hline $\begin{array}{l}\text { Hazzards not otherwise } \\
\text { classined }\end{array}$ & \multicolumn{2}{|l|}{ : Liquid can cause bums simliar to frostite. } \\
\hline \multicolumn{3}{|c|}{ Section 3. Composition/information on ingredients } \\
\hline Substance/mixture & \multicolumn{2}{|l|}{ : Substance } \\
\hline Chemical name & \multicolumn{2}{|c|}{ : propane } \\
\hline $\begin{array}{l}\text { Other means of } \\
\text { Identincation }\end{array}$ & \multicolumn{2}{|c|}{$\begin{array}{l}\text { : Propyl hydride; n-Propane; Dimethyl methane; Botted gas; propane in gaseous state; } \\
\text { propane liqueted, n-Propane; Dimethymethane; Freon 290; Uquefed petroleum gas; } \\
\text { pg; Progyl } \\
\text { hydide; R290; C3H8; UN 1075; UN 1978; A-108; Hydrocarton propellant. }\end{array}$} \\
\hline Product $\operatorname{cod} \theta$ & \multicolumn{2}{|c|}{$: 001045$} \\
\hline \multicolumn{3}{|c|}{ CAS numberiother identiners } \\
\hline CAS number & \multicolumn{2}{|l|}{$: 74-98-6$} \\
\hline Ingredlent name & $\%$ & CAS number \\
\hline Propane & 100 & $74-98-6$ \\
\hline
\end{tabular}

Any concentration shown as a range is to protect confidentality or is due to batch variation.

There are no addituonal ingredlents present which, within the current knowledge of the suppller and in the concentrations appllcable, are classified as hazardous to health or the environment and hence require reporting In this section.

Occupational exposure Ilmits, If avallable, are llated in Section 8.

\section{Section 4. First aid measures}

\section{Description of neceesary first ald measures}

Eyø contact

Immedlately flush eyes wth plenty of water, occasionaly lifing the upper and lower eyellds. Check for and remove any contact lenses. Contnue to ninse for at least 10 minutes. Get medica atiention if intlation occurs.

Inhalation

: Remove victim to ftesh air and keep at rest in a position comfortable for breathing. If not breashing, if breathing is infegular or if respiratory amest occurs, provide attificial respiration or oxygen by tralned personnel. It may be dangerous to the person providing ald to give moutf-to-mouth resusciation. Get medcal attention if adverse healh effects persist or are severe. If unconsclous, place in recovery position and get medical attenton immediately. Maintain an open alway. Loosen tight clothing such as a colar. te, belt or waistband.

Skin contact $\quad$ : Wash contaminated skin wth soap and water. Remove contaminated clothing and shoes. To avoid the risk of static discharges and gas igniton, soak contaminated dotting thoroughly with water before removing it. Get medlcal attention if symptoms occur. In case of contact with Iquid, warm towen tissues slowly with lukewarm water and get medical atiention. Do not rib affected area. Wash clothing before reuse. Clean shoes thoroughly before reuse.

Ingestion : Remove vctim to fresh air and keep at rest in a position comfortable for breathing. Get medical attention if adverse healh effects persist or are severe. Ingestion of Ilquid can cause burns similar to frostihe. If frostote occurs, get medical attenton. Never give anyening by mouth to an unconscious person. If unconsclous, place in recovery position and get medical attention Immedlately. Maintain an open airway. Loosen tgint coothing such 3 a collar, te, belt or waisthand. As this product rapldy becomes a gas when released, refer to the inhalation section.

Most impertant symptomsisftects, acute and delayed

Potentlal acute health effecto

Eye contact

Inhalation

Llquild can cause bums simlar to frostbite.

Skin contact

No known slgnificant effects or critical hazards.

Dermal contact wth rapidy evaporating liquid could result in freezing of the tissues or Fostite.

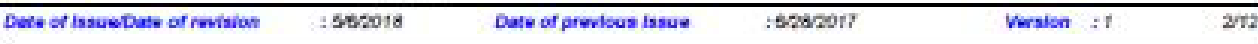




\section{Captain Killed and Six Firefighters Injured at a Propane Explosion in an Office Building-Maine}

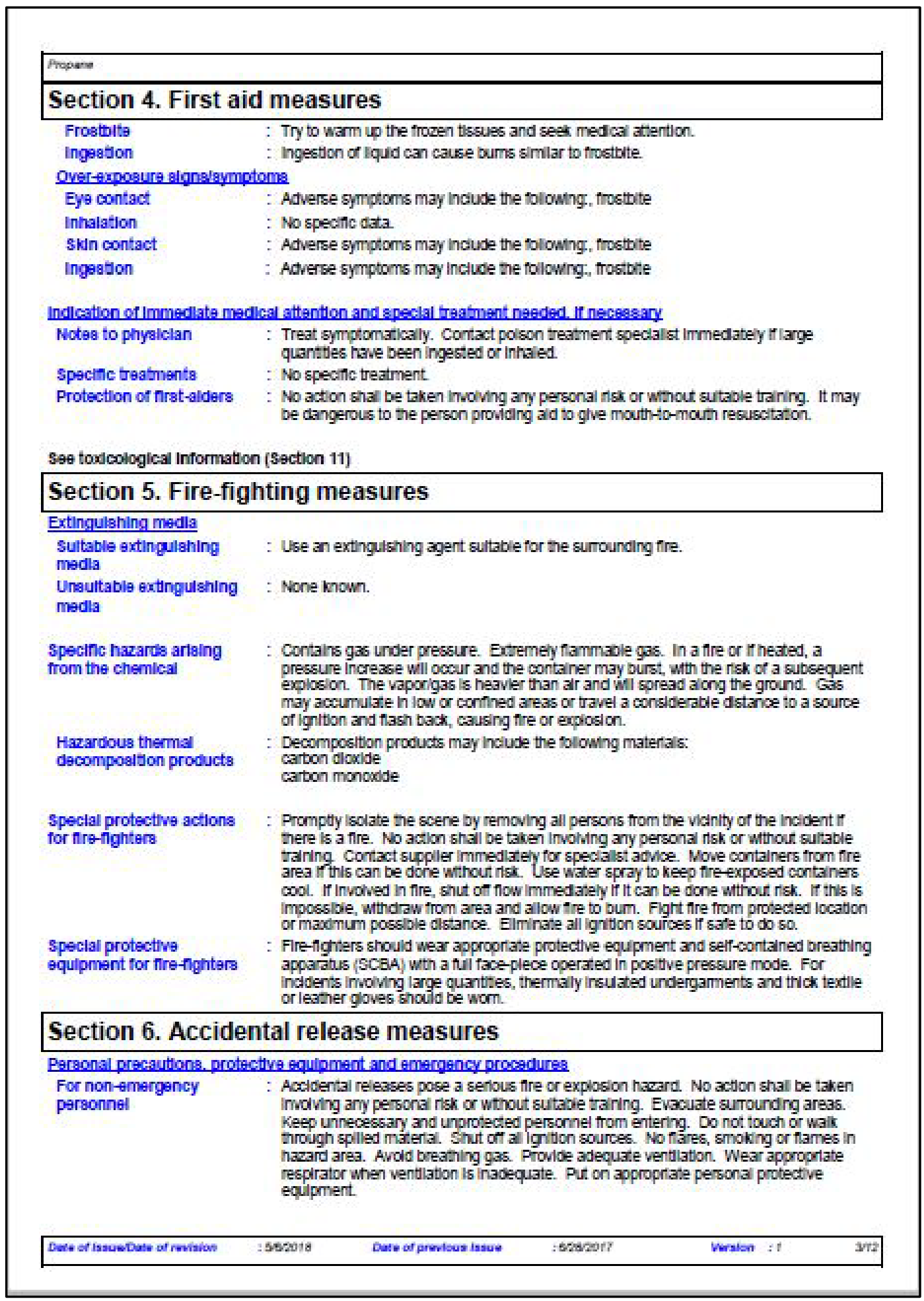




\section{Captain Killed and Six Firefighters Injured at a Propane Explosion in an Office Building-Maine}

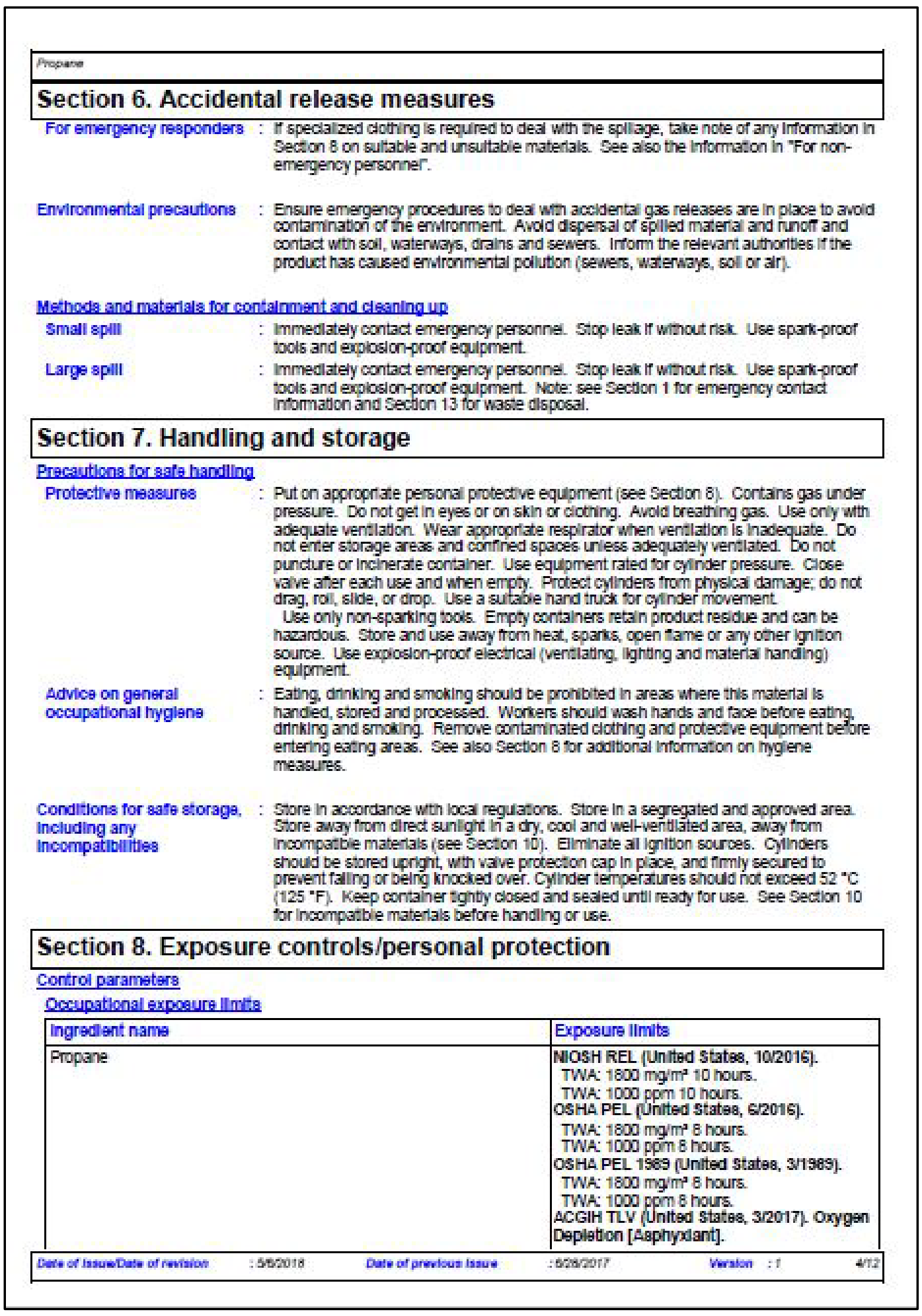




\section{Captain Killed and Six Firefighters Injured at a Propane Explosion in an Office Building-Maine}

\begin{tabular}{|c|c|}
\hline \multicolumn{2}{|l|}{ Fropese } \\
\hline \multicolumn{2}{|c|}{ Section 8. Exposure controls/personal protection } \\
\hline & \\
\hline $\begin{array}{l}\text { Approprlate engineering } \\
\text { controls }\end{array}$ & $\begin{array}{l}\text { : Use only with adequate vertiation. Use process enclosures, local exhaust ventilation or } \\
\text { other engineering controls to keep worker exposure to airborne contaminants below any } \\
\text { recommended or statutory linits. The engineering controis also need to keep gas, } \\
\text { vapor or dust concentrations below any lower explosive imits. Use explosion-proof } \\
\text { ventiation equipment. }\end{array}$ \\
\hline $\begin{array}{l}\text { Enwironmental exposure } \\
\text { controls }\end{array}$ & $\begin{array}{l}\text { : Emissions trom ventiation or work process equipment shoud be checked to ensure } \\
\text { they comply with the requirements of envronmental protection leg'slation. In some } \\
\text { cases, fume scruboers, fiters or engineering modications to the process equipment } \\
\text { will be necessary to reduce emissions to acceptable levels. }\end{array}$ \\
\hline
\end{tabular}

Indlvidual protection measuree

Hyglene measures

Wash hands, forearms and face thoroughly atter handing chemical products, before eating, smoking and using the lavatory and at the end of the working period. Appropriate techriques should be used to remove potentially contianinated clothing. Wash contaminated clothing before reusing. Ensure that eyewash statons and satety showers are close to the workstation location.

Eyerface protection

Safely eyewear complying wth an approved standard should be used when a risk assessment indcates this is necessary to avold exposure to liquid splashes, mists, gases or dusts. If contact is possible, the followng protecton should be wom, unless the assessment indcates a higher degree of protection: safety glasses with sideshelds.

skin protection

Hand protection

Chemical-resistant, impervious gloves complying wth an approved standard should be wom at all times when handing chemical products if a risk assessment Indicates this is necessary. If contact whth the liquid is possible, insulated gloves sultable for iow temperatures should be worn. Considering the parameters specifled by the glove manuracturer, check during use that the gloves are stll retaining their protective propertes. It should be noted that the tme to breakshrough for any glove material may be different for different glove manufacturers. In the case of mbxtures, consisting of several substances, the protection time of the gloves cannot be accurately estimated.

Body protection : Personal protective equipment for the body should be selected based on the task being performed and the risks involved and should be approved by a specialist before handing this product. When there is a risk of Igrition ffom static electricty, wear antlstatic protective clothing. For the greatest protection from static dlscharges, clothing should incude ant-static overals, boots and gioves.

Other akin protection : Appropriate footsear and any additona skin protection measures should be selected based on the task being performed and the risks invoived and should be approved by a specialst before handing this product.

Respiratory protection : Based on the hazard and potertlal for exposure, select a resoirator that meets the appropriate standard or certification. Respliatiors must be used according to a respiratory protecton program to ensure proper fitting, training, and other important aspects of use.

Thermal hazards

If there is a risk of contact with the lquid, all protectlve equipment wom should be sutable for use wth extremely low temperature materials.

\section{Section 9. Physical and chemical properties}

\section{Appesarance}

Physical atate

Color

Odor

Odor threehold

pH

Melting point

Bolling point
Gas. [Compressed gas.]

Coloriess.

Odorless. BUT MAY HAVE SKUNK ODOR ADDED.

Not avalable

Not avalable

$-187.6^{\circ} \mathrm{C}\left(-305.7^{\circ} \mathrm{F}\right)$

$-161.46^{\circ} \mathrm{C}\left(-258.7^{\circ} \mathrm{F}\right)$

Dete of lasuedate of reviatove

1552018

Date of previous issue

$: 62282007$

Vuraton :1 


\section{Captain Killed and Six Firefighters Injured at a Propane Explosion in an Office Building-Maine}

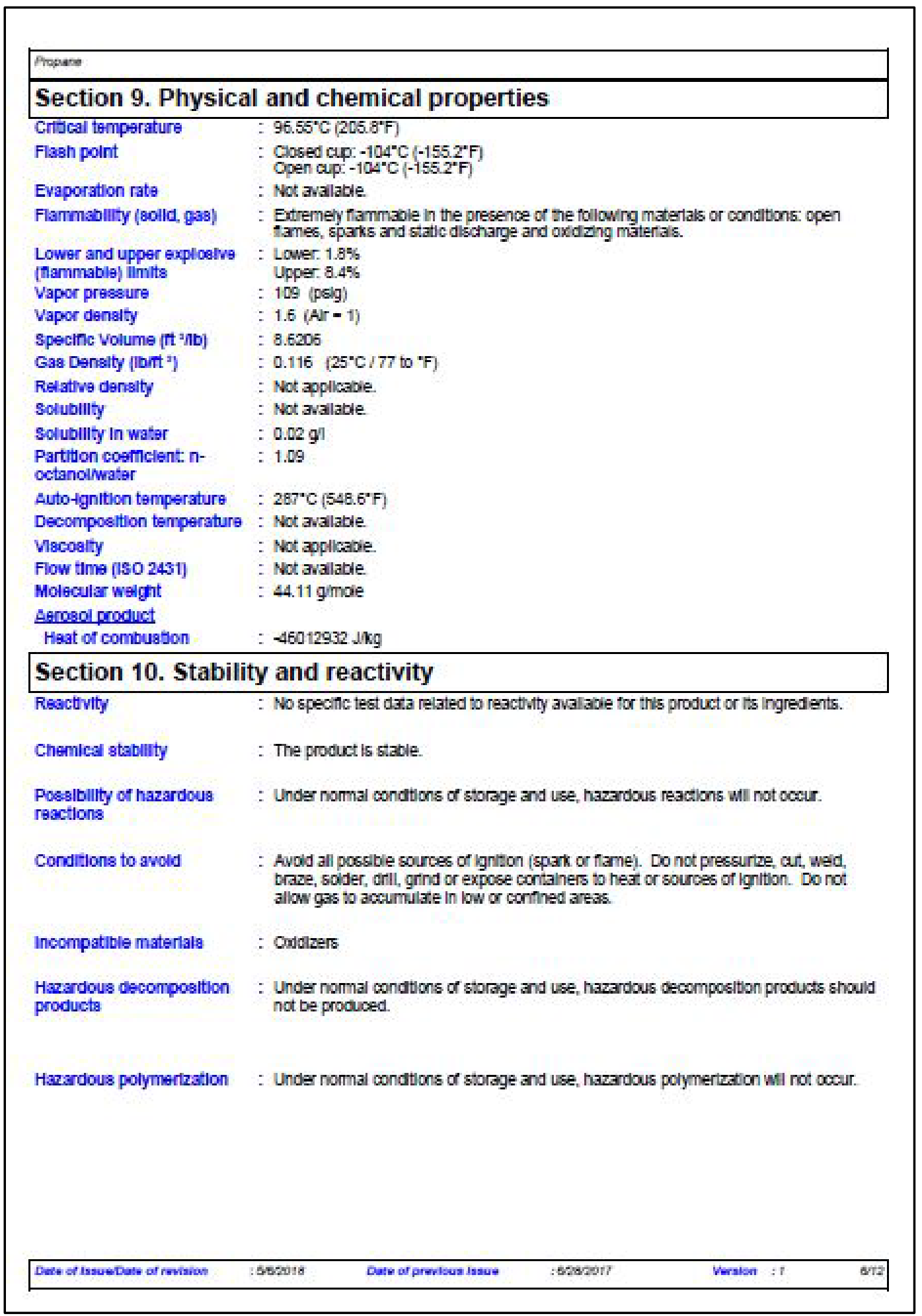




\section{Captain Killed and Six Firefighters Injured at a Propane Explosion in an Office Building-Maine}

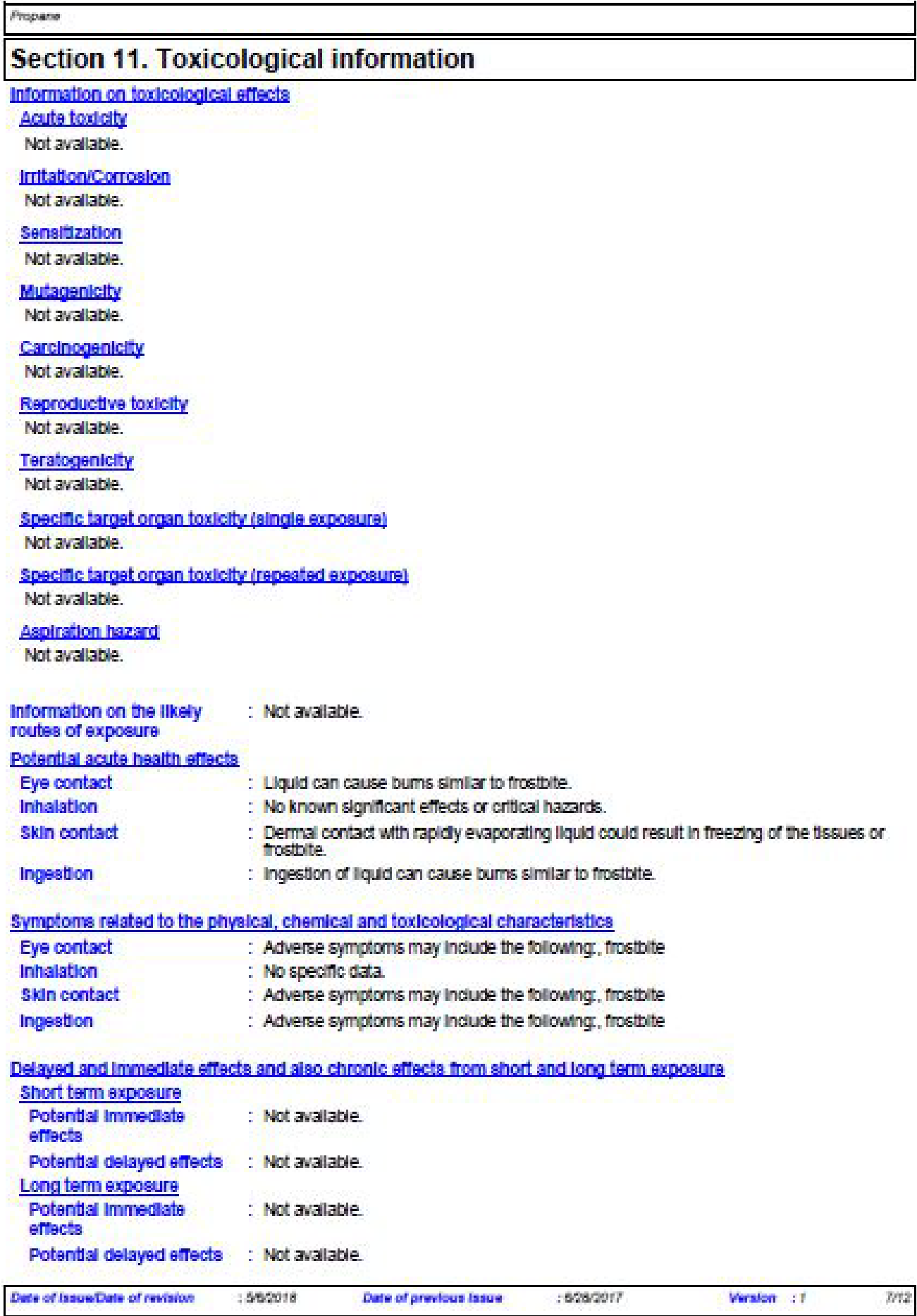

Delayed and inmedlate effects and alse chronlc effects from short and leng term exposure Short term exposure Potentlal immedlate eflects

Potentlal delayed efrects : Not avalable. Long term exposure 


\section{Captain Killed and Six Firefighters Injured at a Propane Explosion in an Office Building-Maine}

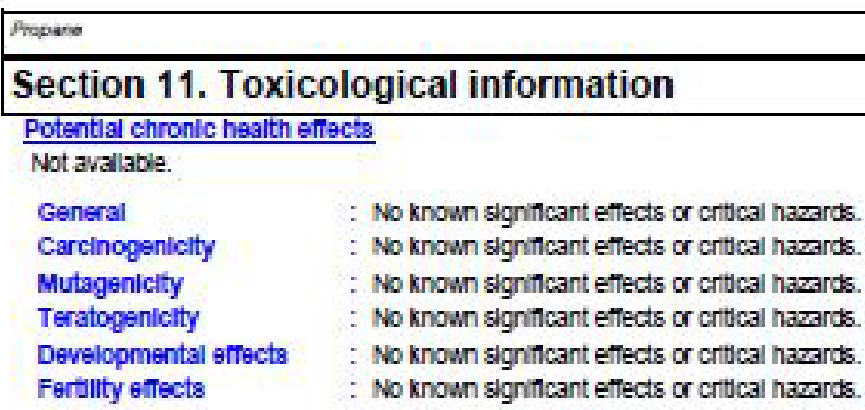

Numerical messures of toxicity

Acute toxicity estimates

Not avaliable.

\section{Section 12. Ecological information}

Noxiclity

Persistence and degradabillity

Not avalabie.

Bloaccumulathe potentyal

\begin{tabular}{|l|l|l|l|}
\hline Product/ngredlent name & LogP & BCF & Potential \\
\hline Propane & 1.09 & - & IOW \\
\hline
\end{tabular}

\section{Mobillty in 8 oll}

Sollwater partition : Not avalable.

coefnclent ( $\left.\mathrm{K}_{\mathrm{se}}\right)$

Other adverse effects

: No known significant effects or critlcal hazards.

Section 13. Disposal considerations

Disposal methods

The generaton of waste should be avolded or minimized wherever posslble. Disposal of this product, solutions and any by-products should at all times comply with the requirements of environmental profection and waste disposal legisiation and any regonal local authority requirements. Dispose of surpius and non-recyclable products va a licensed waste dsposal contractor. Waste should not be dsposed of untreated to the sewer unless fully complant wth the requirements of all authoritles with jurisdiction. Empty Alrgas-owned pressure vessels should be returned to Argas. Waste packaging should be recycled. Incineration or landtill should only be considered when recyding is not feasible. This material and its container must be dlsposed of in a safe way. Empty containers or iners may retain some product residues. Do not puncture or incinerate container.

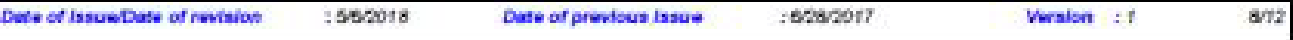




\section{Captain Killed and Six Firefighters Injured at a Propane Explosion in an Office Building-Maine}

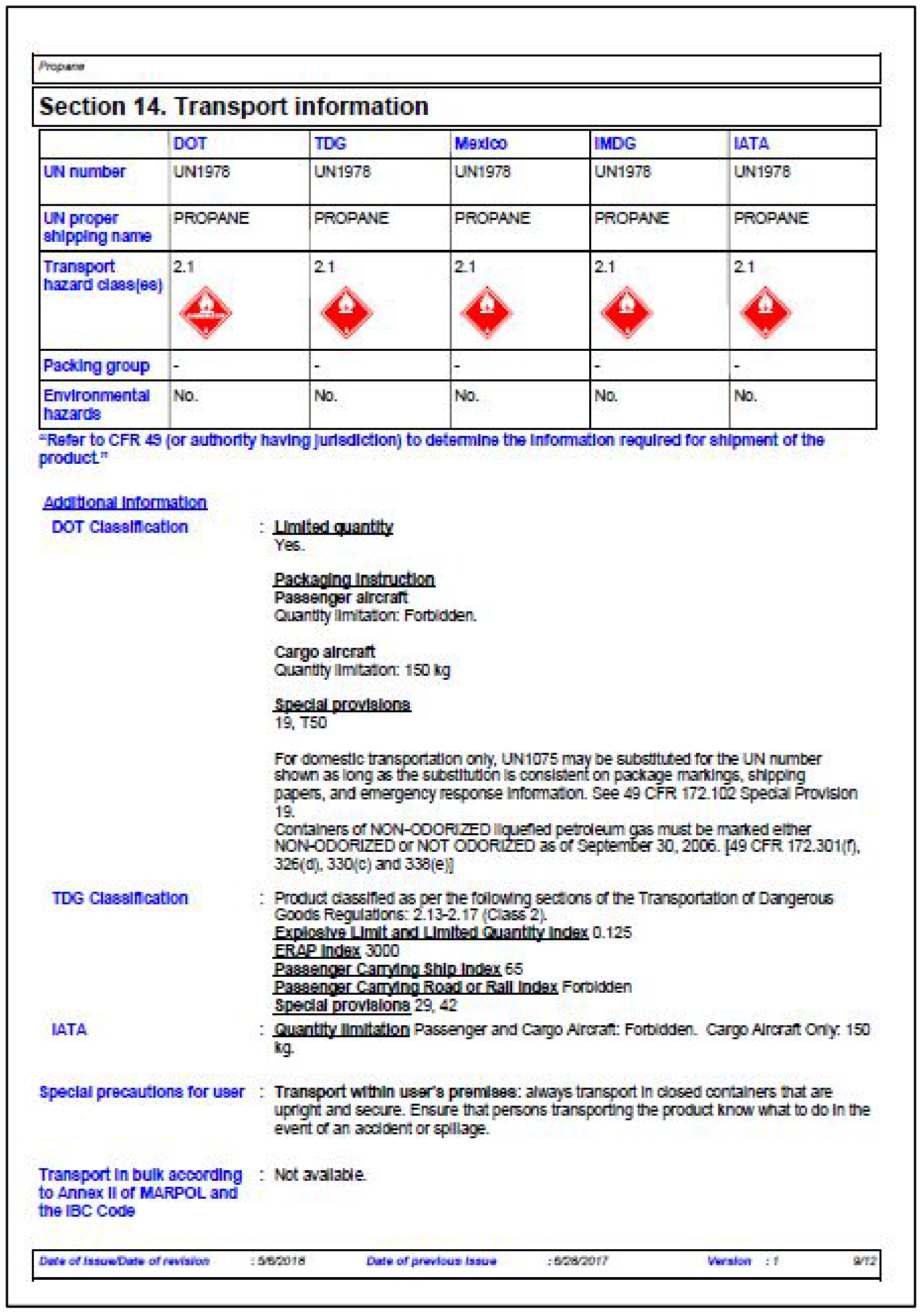




\section{Captain Killed and Six Firefighters Injured at a Propane Explosion in an Office Building-Maine}

\begin{tabular}{|c|c|}
\hline \multicolumn{2}{|l|}{ Propueso } \\
\hline \multicolumn{2}{|c|}{ Section 15. Regulatory information } \\
\hline U.S. Federal regulations & $\begin{array}{l}\text { : TSCA \&(a) CDR Exempt/Partial exemption: Not determined } \\
\text { Clean Alr Act (CAA) } 112 \text { regulated nammable substances: propane }\end{array}$ \\
\hline $\begin{array}{l}\text { Clean Alr Act Section } 112 \\
\text { (b) Hazardous Alr } \\
\text { Pollutants (HAPs) }\end{array}$ & : Not listed \\
\hline $\begin{array}{l}\text { Claan Alr Act Section } 602 \\
\text { Clase I Subatancas }\end{array}$ & : Not listed \\
\hline $\begin{array}{l}\text { Clean Alr Act Section } 602 \\
\text { Class II Subatances }\end{array}$ & : Not listed \\
\hline $\begin{array}{l}\text { DEA List I Chemicals } \\
\text { (Precursor Chemicals) }\end{array}$ & : Not llsted \\
\hline $\begin{array}{l}\text { DEA List II Chemicals } \\
\text { (Essentlal Chemicals) }\end{array}$ & : Not listed \\
\hline \multirow{2}{*}{\multicolumn{2}{|c|}{$\begin{array}{l}\text { SARA } 302 / 304 \\
\text { Composition/information on ingredlents }\end{array}$}} \\
\hline & on ingredlents \\
\hline \multicolumn{2}{|c|}{ No products were found. } \\
\hline SARA 304 RQ & : Not applicable. \\
\hline \multicolumn{2}{|l|}{ SARA311/312 } \\
\hline Classinication & : Refer to Section 2: Hazards Identification of this SDS for classitcation of substance. \\
\hline \multicolumn{2}{|l|}{ State requlations } \\
\hline Massachusetts & : This material is lsted. \\
\hline New York & : This material is not ilsted. \\
\hline New Jersey & : This materia is Isted. \\
\hline Pennsylvania & : This materia is Isted. \\
\hline \multicolumn{2}{|c|}{ Intemational regulations } \\
\hline \multirow{2}{*}{\multicolumn{2}{|c|}{$\begin{array}{l}\text { Chemical Weapen Convention List Schedules L. II \& Ill Chemicals } \\
\text { Not listed. }\end{array}$}} \\
\hline & \\
\hline \multicolumn{2}{|c|}{ Mentreal Protocol (Annexes A.B.C.E) } \\
\hline \multicolumn{2}{|c|}{ Not llsted. } \\
\hline \multicolumn{2}{|c|}{ Stockholm Convention on Pergistent Organic Pollutants } \\
\hline \multicolumn{2}{|c|}{ Not listed. } \\
\hline \multicolumn{2}{|c|}{ Rosterdam Conwention on Prior informed consent (PIC) } \\
\hline \multicolumn{2}{|c|}{ Not listed. } \\
\hline \multirow{2}{*}{\multicolumn{2}{|c|}{$\begin{array}{l}\text { UNECE Aarhus Protocol on POPs and Heary Matals } \\
\text { Not listed. }\end{array}$}} \\
\hline & \\
\hline \multicolumn{2}{|l|}{ Inventery llst } \\
\hline Australla & : This material is llsted or exempted \\
\hline Canada & : This material Is llsted or exempted. \\
\hline China & : This material is Ilsted or exempted. \\
\hline Europe & : This material is listed or exempted. \\
\hline Japan & $\begin{array}{l}\text { : Japan Inventory (ENCS). This material is Isted or exempted. } \\
\text { Japan Inventory (ISHL): This material is listed or exempted. }\end{array}$ \\
\hline Malaysla & : This material is listed or exempted. \\
\hline New Zealand & : This material is llsted or exempted. \\
\hline Phillppines & : This material is listed or exempted. \\
\hline Republle of Korea & : This material Is ilsted or exempted. \\
\hline Deres of issuedate of rewiaion & Date of previlous issue \\
\hline
\end{tabular}




\section{Captain Killed and Six Firefighters Injured at a Propane Explosion in an Office Building-Maine}

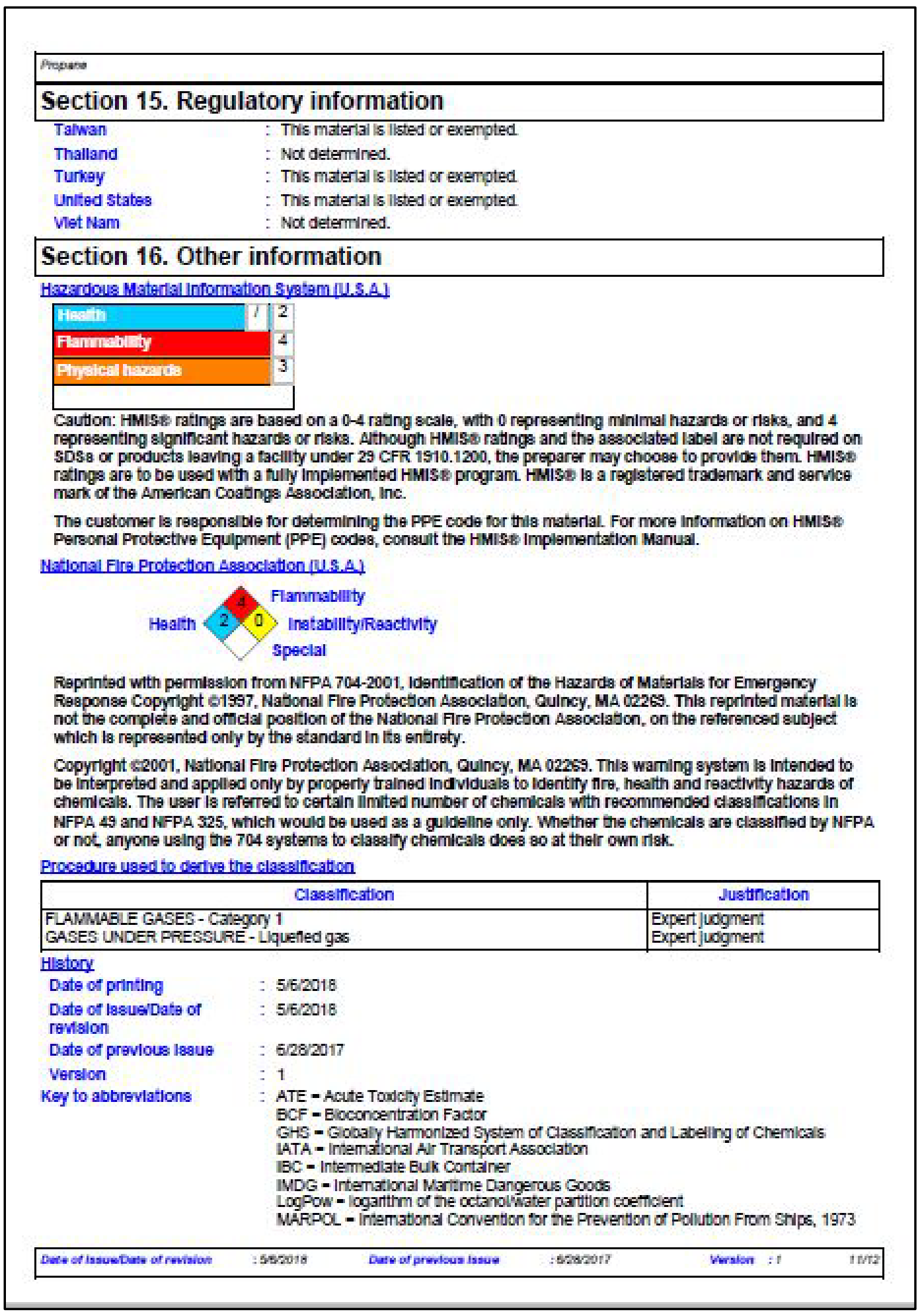




\section{Captain Killed and Six Firefighters Injured at a Propane Explosion in an Office Building-Maine}

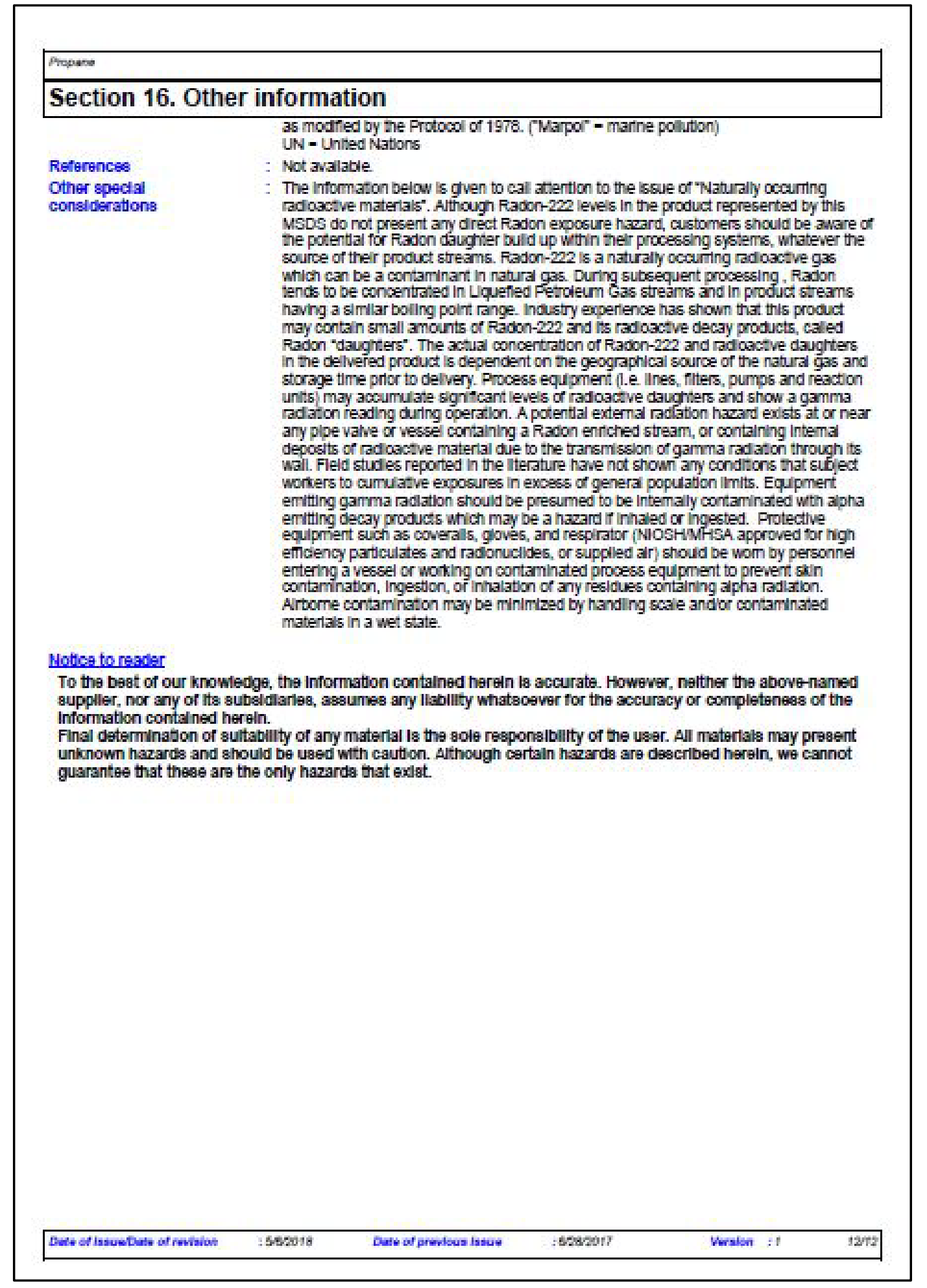




\title{
Captain Killed and Six Firefighters Injured at a Propane Explosion in an Office Building-Maine
}

\author{
Appendix Three \\ Atmospheric Monitoring Investigation Checklist
}

Virginia Beach Fire Department Standard Operating Policy

SOP HM 5.22.01 - Low Priority - Four Year Review Monitoring of Atmospheric Canditions Appendix A

\section{ATMOSPHERIC MONITORING INVESTIGATION CHECKLIST}

This checklist is designed as a guide for Fire Department personnel conducting a preliminary investigation for the source of a hazardous atmosphere. It is NOT a qualified inspection of the structure and its appliances. It will NOT be given to the occupant/owner.

DATE:

INCIDENT \#:

ADDRESS:

CALIBRATION

Prior to making entry the meter shall be fresh air calibrated and bump tested as needed.

INVESTIGATION (Use of PPE and SCBA is required in accordance with action levels.)

- Co Incidents

- PPM of CO outside the door

- PPM inside the front door

- Does occupant have a CO detector? Yes ___ No

- If the presence of $\mathrm{CO}$ is detected, can it be isolated to an appliance in the structure? Yes No

- Never leave without CO levels below acceptable limits

- Flammable Incidents

- Position all apparatus in a safe area

- Percent of LEL outside the structure

- Percent of LEL inside the front door

- Does occupant have natural gas, propane, or any other fuel servicing the structure? Yes _ No

- Is the presence of a flammable atmosphere contained to this unit/occupancy/structure? Yes No

- If presence of a flammable gas is detected, can it be isolated to the structure entered? Yes No 